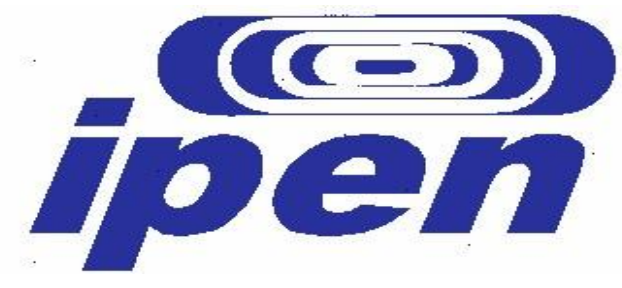

INSTITUTO DE PESQUISAS ENERGÉTICAS E NUCLEARES

Autarquia associada à Universidade de São Paulo

TRATAMENTO DA MUCOSITE ORAL RADIO E QUIMIOINDUZIDA: COMPARAÇÃO ENTRE PROTOCOLO MEDICAMENTOSO CONVENCIONAL E TRATAMENTOS COM LASERS EM BAIXA INTENSIDADE

ANELISE RIBEIRO PEIXOTO ALENCAR

Dissertação apresentada como parte dos requisitos para obtenção do Grau de Mestre em Ciências na área de Tecnologia Nuclear Materiais.

Orientadora:

Dra . Martha Simões Ribeiro 


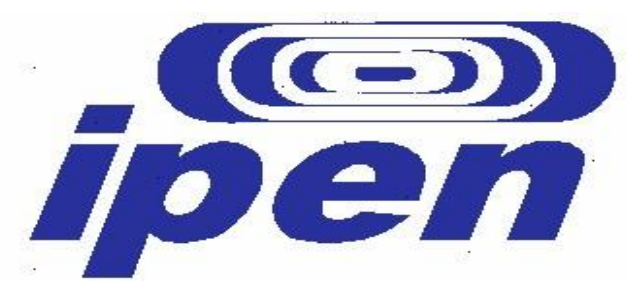

INSTITUTO DE PESQUISAS ENERGÉTICAS E NUCLEARES Autarquia associada à Universidade de São Paulo

TRATAMENTO DA MUCOSITE ORAL RADIO E QUIMIOINDUZIDA: COMPARAÇÃO ENTRE PROTOCOLO MEDICAMENTOSO CONVENCIONAL E TRATAMENTOS COM LASERS EM BAIXA INTENSIDADE

ANELISE RIBEIRO PEIXOTO ALENCAR

Dissertação apresentada como parte dos requisitos para obtenção do Grau de Mestre em Ciências na área de Tecnologia Nuclear Materiais

Orientadora:

Dra . Martha Simões Ribeiro 
Dedico este trabalho a todos que contribuíram para a realização do mesmo, em especial aos funcionários do Serviço de Oncologia do Hospital Regional de Araguaína e aos pacientes portadores de câncer de cabeça e pescoço que, apesar de estarem vivendo um momento de tantas incertezas, aceitaram participar deste estudo clínico, a todos meus mais sinceros agradecimentos. 


\section{AGRADECIMENTOS}

A Deus, por todas as bênçãos que tem me concedido ao longo de todos estes anos e pela saúde e força para superar os obstáculos.

A minha orientadora, Prof ${ }^{a}$. Dra ${ }^{\mathrm{a}}$. Martha Simões Ribeiro, pela doçura, disponibilidade e desprendimento, compartilhando seu conhecimento e tornando mais fácil e agradável a realização deste trabalho.

Ao Prof. Hebert Batista sem o qual a realização deste trabalho seria impossível.

"Se pude enxergar mais longe é porque me apoiei nos ombros de

gigantes."

(Isaac Newton)

Ao meu mestre Prof. José Ferreira de Menezes Filho que me apresentou ao diagnóstico e me encantou com seu conhecimento, dedicação e amor à Odontologia.

Aos meus filhos Bruno e Guilherme pela paciência e amor. Obrigada, peço desculpas pela falta de tempo e de paciência. Amo vocês.

Ao meu marido Iramilson, pelo carinho e amor que sempre dedicou a mim e a nossa família. Eu te amo!

Seus olhos meu clarão

Me guiam dentro da escuridão

Seus pés me abrem o caminho

Eu sigo e nunca me sinto só

(Arnaldo Antunes)

A minha mãe Célia Maria, pelo amor, carinho e dedicação incondicional a todos de nossa família.

A minha irmã Isabela e ao meu pai Raimundo, pelo incentivo e carinho sempre tão presentes.

Aos meus sogros Iranísio e Maria José, pelo carinho, apoio e incentivo.

A Silmar, Ruth, Tânia e Socorro, sempre disponíveis e atenciosas para comigo e principalmente para com os pacientes.

Aos amigos André Machado Senna e Rosa Maria Machado de Sena pelo apoio, incentivo e ajuda imensurável, sem os quais a realização deste projeto seria praticamente impossível.

Ao Instituto de Pesquisas Energéticas e Nucleares - IPEN pela oportunidade e apoio sem os quais não seria possível a realização deste projeto. 
Este trabalho recebeu apoio financeiro da Secretaria Estadual de Ciência e Tecnologia do Tocantins e do Conselho Nacional de Desenvolvimento Científico e Tecnológico - CNPq - Brasil, através do Edital SECT n. 02/2009 - Pesquisa para o SUS: Gestão Compartilhada em Saúde (PPSUS 2008/2009). 
"Quando eu tropeçar, dá-me valor.

Quando me cansar, renova minhas forças.

Quando fraquejar porque sou humano, inspira-me por mais tempo.

Se todos se tornarem muito exigentes e os dias forem demasiadamente curtos para minhas obrigações, ajuda-me a recordar que escolhi servir e a fazê-lo com generosidade." 


\title{
TRATAMENTO DA MUCOSITE ORAL RADIO E QUIMIOINDUZIDA: COMPARAÇÃO ENTRE PROTOCOLO MEDICAMENTOSO CONVENCIONAL E TRATAMENTOS COM LASERS EM BAIXA INTENSIDADE
}

\author{
Anelise Ribeiro Peixoto Alencar
}

\begin{abstract}
RESUMO
Neste estudo clínico verificaram-se os efeitos do laser em baixa intensidade na prevenção e tratamento da mucosite oral radio e/ou radioquimioinduzida. Foram selecionados 31 pacientes portadores de câncer em cabeça e pescoço a serem submetidos à radioterapia ou a radioterapia em associação a quimioterapia, os quais foram distribuídos aleatoriamente em três grupos: grupo 1 - (controle) tratamento medicamentoso; grupo 2 tratamento medicamentoso e laserterapia diária, a partir do início da ulceração referente à mucosite grau 2 e grupo 3 - tratamento medicamentoso e laserterapia diária a ser iniciada imediatamente antes do início da radioterapia. Os parâmetros de irradiação foram: comprimento de onda de $660 \mathrm{~nm}$, potência de $100 \mathrm{~mW}$, modo de operação contínuo, aplicação pontual, energia de $2 \mathrm{~J}$ por ponto em 30 pontos pré-determinados, sendo o tempo utilizado de 20 s por ponto. O grupo controle recebeu tratamento medicamentoso que consistia no uso de um conjunto de medidas preventivas e terapêuticas para abordagem dos efeitos adversos agudos radioinduzidos. Os resultados foram avaliados, quanto à ocorrência, graus e escore de dor associados à mucosite oral, perda de massa corpórea, uso de sonda nasogástrica, necessidade de internação e interrupção do tratamento oncológico decorrentes da mucosite oral. Os resultados indicam que o protocolo de aplicação do laser em sua forma preventiva é o mais efetivo na prevenção e tratamento da mucosite oral e que seu uso diário contribuiu para o alívio da sintomatologia dolorosa colaborando para melhora da qualidade de vida do paciente oncológico.
\end{abstract}




\title{
RADIO AND CHEMIOINDUCED ORAL MUCOSITIS TREATMENT: COMPARISON BETWEEN CONVENTIONAL DRUG PROTOCOL AND TREATMENTS WITH LOW INTENSITY LASERS
}

\author{
Anelise Ribeiro Peixoto Alencar
}

\begin{abstract}
In this clinical study verified the effects of low intensity laser in the prevention and treatment of oral mucositis radio and/or chemical induced. Thirty one patients with head and neck cancer were selected before being submitted to cancer exclusive radiotherapy or radio and associated chemotherapy. The patients were distributed into three randomly groups as follows: group 1- (control) conventional medicine treatment; group 2 - conventional medicine treatment and daily lasertherapy as soon as grade two oral mucositis appeared; group 3 - conventional medicine treatment and daily lasertherapy to be initiated immediately before radiotherapy sessions. The irradiation parameters were: wavelength of $660 \mathrm{~nm}$, potency of $100 \mathrm{~mW}$, continuous mode, punctual application, $2 \mathrm{~J}$ energy on thirty pre-determined 30 points, with 20 s of exposure per point. The control group received medical treatment which consisted in using a set of preventive and therapeutic approach for acute radiation-induced adverse effects. Results were evaluated observing occurrence and grade of oral mucositis, score of pain, loss of body mass, use of nasogastric sound line, internment and interruption of oncologic treatment due to oral mucositis. The results showed that the preventive protocol as used was the most effective in prevention and treatment of oral mucositis and that its daily application contributed in relieving the painful symptomatology so collaborating to maintain and/or bettering the life quality of oncologic patients.
\end{abstract}




\section{SUMÁRIO}

\section{Página}

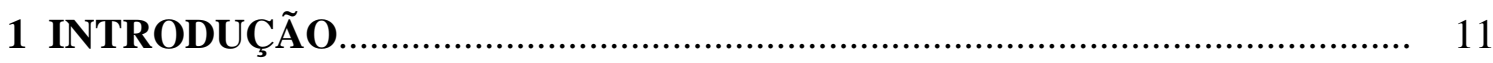

2 OBJETIVOS

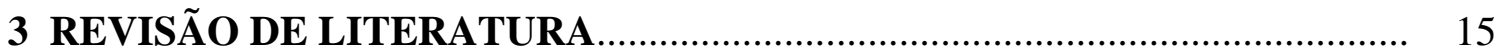

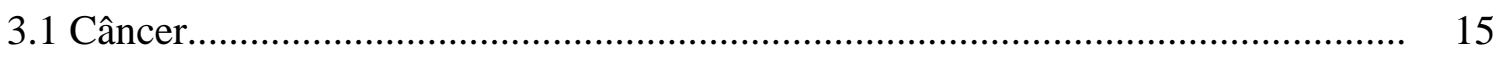

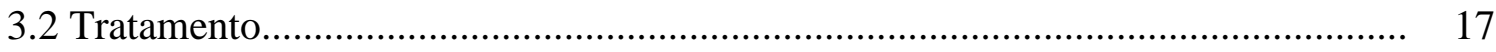

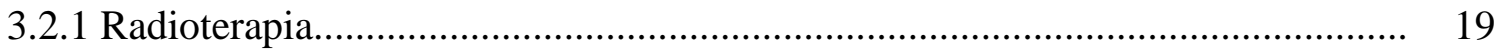

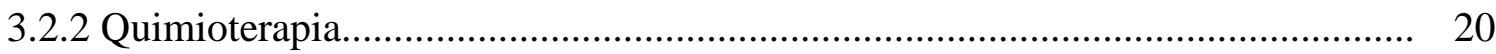

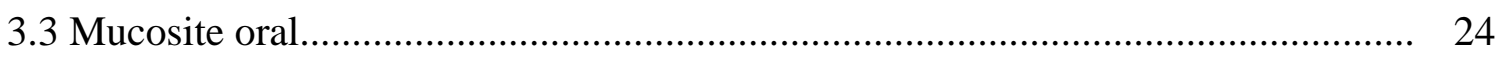

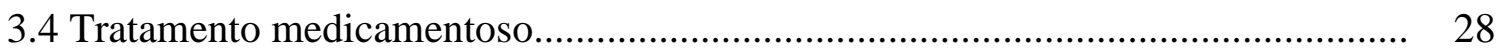

3.5 Laser em baixa intensidade................................................................... 32

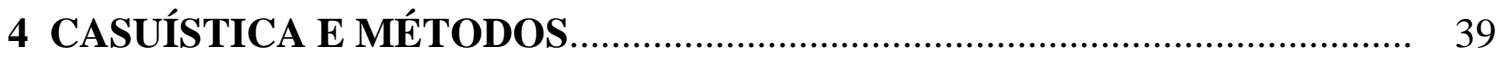

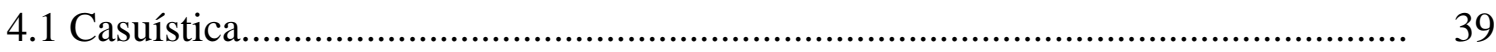

4.1.1 Ética em pesquisa com seres humanos....................................................... 39

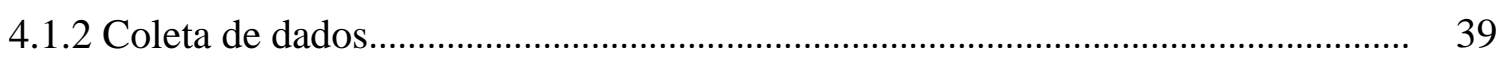

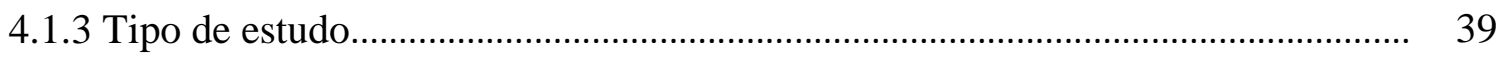

4.1.4 Local e infraestrutura........................................................................................ 40

4.1.5 População e critérios de inclusão e exclusão.......................................................... 40

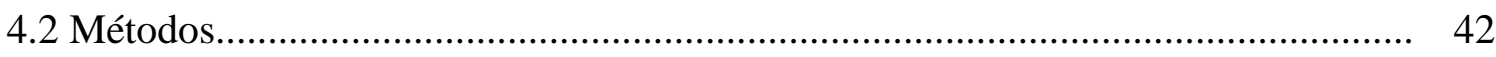

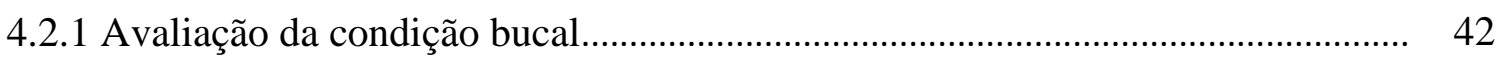

4.2.2 Parâmetros de irradiação........................................................................................ 42

4.2.3 Tratamento medicamentoso......................................................................... 43

4.2.4 Avaliação da mucosite oral.................................................................................. 45

4.2.5 Avaliação da dor em mucosa....................................................................... 45

4.2.6 Avaliação da perda de massa corpórea.............................................................. 45

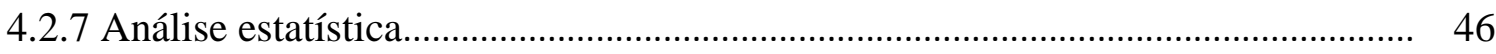

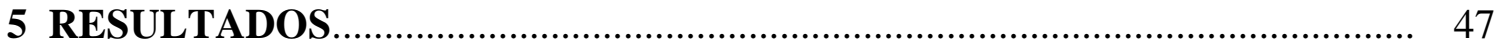

5.1 Descrição da amostra................................................................................. 47

5.2 Ocorrência de mucosite oral.......................................................................... 54 


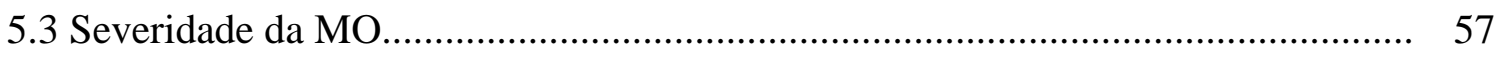

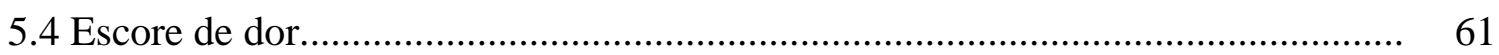

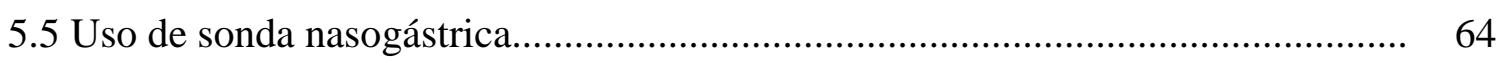

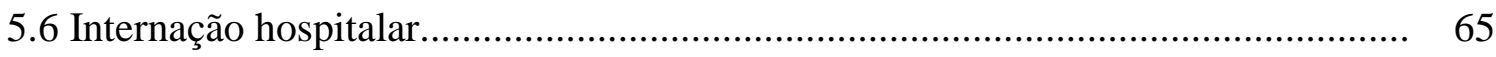

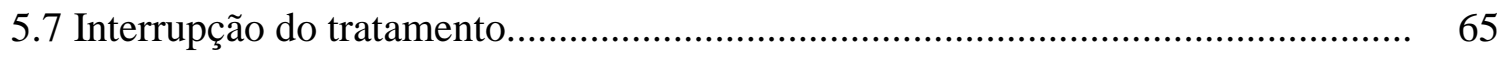

5.8 Perda de massa corpórea........................................................................... 66

6 DISCUSSÃ

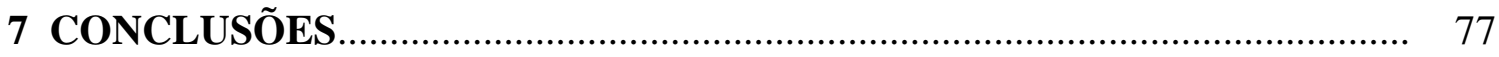

APÊNDICE A - Parecer consubstanciado................................................................ 78

APÊNDICE B - Ficha de Avaliação / Grupo 1( ) 2 ( ) 3 ( )................................... 80

APÊNDICE C - Ficha de Avaliação / Grupo 1( ) 2 ( ) 3 ( ) ).................................. 81

APÊNDICE D - Protocolo medicamentoso.......................................................... 82

APÊNDICE E - Ficha de Avaliação / Grupo 1( ) 2 ( ) 3 ( ) ).................................... 83

REFERÊNCIAS BIBLIOGRÁFICAS ..................................................... 84 


\section{1 - INTRODUÇÃO}

O câncer é um problema de saúde pública mundial, e sua incidência tem apresentado um aumento constante e gradual. Conforme a World Health Organization (WHO), 2002, são diagnosticados anualmente cerca de dez milhões de casos de câncer na população mundial, sendo o mesmo responsável por aproximadamente seis milhões de óbitos, o que representa cerca de $12 \%$ de todas as causas de morte no mundo.

O câncer de cabeça e pescoço ocupa a quinta posição na lista das neoplasias mais freqüentes, com uma incidência mundial estimada de 780.000 novos casos por ano (COLOMBO e RAHAL., 2009). No Brasil, a boca representa a quinta localização de maior incidência em homens e a sétima em mulheres; as estimativas para o ano de 2010 de novos casos por câncer são de 489.270, destes 14.120 ocorrerão em cavidade oral (BRASIL., 2009a).

Como o câncer de cabeça e pescoço, em especial o câncer de boca, é uma doença crônica que resulta em elevada morbidade e mortalidade, o diagnóstico precoce e o imediato encaminhamento do paciente ao tratamento são essenciais para a redução dos danos causados pela doença (COSTA e MIGLIORATI, 2001). Seu tratamento depende da localização, estadiamento, tipo histológico e condições gerais do paciente (ALBUQUERQUE e CAMARGO, 2007).

Os métodos de tratamento para o câncer de cabeça e pescoço consistem em Radioterapia (RT), Cirurgia (CR) e Quimioterapia (QT). Estes podem ser usados isoladamente ou em associação, adequando-se às necessidades de cada caso em particular, tendo por base os resultados esperados de tempo e qualidade de sobrevida (KOWALSKI et al., 2002).

Independente do tipo de terapia a ser utilizada, o paciente estará sempre correndo o risco de sofrer sérias complicações na cavidade bucal, particularmente quando submetido à RT e QT adjuvante (JOYSTON-BECHAL,1992). As principais complicações decorrentes do tratamento do câncer de cabeça e pescoço incluem cáries, Mucosite Oral (MO), xerostomia (diminuição do fluxo salivar), disgeusia (alterações de paladar), infecções secundárias, osteorradionecrose e trismo (JHAM e FREIRE, 2006; SAWADA et al., 2006), sendo a MO o efeito agudo de maior freqüência e o maior fator dose limitante para a RT em cabeça e pescoço (DIB et al., 2000). 
Geralmente a MO é acompanhada de destruição da mucosa e da barreira anatômica oral, atuando como uma porta de entrada para a flora microbiológica estando associada geralmente a dor severa (SONIS e COSTELLO, 1995), sendo capaz de comprometer em graus variados a qualidade de vida do paciente (DODD et al., 2000). Seu impacto entre os pacientes portadores de câncer de cabeça e pescoço é geralmente dramático, consistindo em uma condição que pode requerer hospitalização em uma população a princípio tipicamente ambulatorial, não raro resultando em modificações da terapia oncológica com interrupção do tratamento radioterápico ou redução da dose de QT (SCULLY et al., 2006). Outros problemas associados à MO são a dificuldade de deglutição de alimentos sólidos e ocasionalmente líquidos, limitação da fala e mastigação (JOYSTON-BECHAL.,1992; KOSTLER et al., 2001).

Os protocolos terapêuticos empregados, até o presente momento, para a MO decorrente do tratamento oncológico são paliativos e diversificados, e envolvem terapêuticas profiláticas e tentativas de atenuar a sintomatologia dolorosa (KOSTLER et al., 2001), sendo recomendado para o tratamento da MO o emprego de antibióticos e antifúngicos (tópicos e sistêmicos), sucralfato, analgésicos, anestésicos e antiinflamatórios (soluções para bochechos e sistêmicos), programa de cuidados e higiene oral (ALBUQUERQUE e CAMARGO, 2007; BARASCH e COKE, 2007), suplementos vitamínicos (vitaminas C, B, E e betacaroteno), cloridrato de benzidamida, glutamina e amifostina (SANDOVAL et al., 2003).

Resultados clínicos e funcionais satisfatórios têm sido obtidos no tratamento da MO com o emprego do Laser em Baixa Intensidade (LBI) (MIGLIORATI et al., 2001; SANDOVAL et al,. 2003; BARASCH e COKE.,2007; KELNER e CASTRO., 2007). O mesmo é bem tolerado pelos pacientes e tem demonstrado efeitos benéficos como aceleração do processo de cicatrização de feridas e diminuição da intensidade da dor, contribuindo para melhora da qualidade de vida dos pacientes em tratamento oncológico (SANDOVAL et al., 2003; ALBUQUERQUE e CAMARGO., 2007). Desde que empregados de forma adequada, não são observados efeitos colaterais e contraindicações, com exceção da incidência do feixe direta ou indiretamente sobre os olhos (RIBEIRO e ZEZELL., 2004).

Em conseqüência do significativo desconforto oral, tão comum em pacientes portadores de câncer de cabeça e pescoço submetidos à RT exclusiva, ou RT e QT adjuvante, ressalta-se que a adoção de condutas visando à prevenção e/ou controle destas alterações, principalmente da MO que por sua vez está fortemente associada à dor, 
comprometimento do estado geral de saúde do paciente e em casos extremos necessidade de interrupção do tratamento oncológico, são extremamente úteis e contribuem de forma significativa para a melhora da qualidade de vida dos mesmos.

Desta forma é extremamente importante avaliar os efeitos do emprego do LBI com comprimento de onda de 660nm na prevenção e tratamento da $\mathrm{MO}$ e da dor associada à mesma em pacientes portadores de câncer de cabeça e pescoço submetidos a tratamento oncológico. 


\section{2 - OBJETIVOS}

\section{Objetivo geral:}

Desenvolver estudo comparativo entre diferentes protocolos, medicamentoso e com laser em baixa intensidade de emissão em 660 nm, meio ativo de InGaAlP e potência de $100 \mathrm{~mW}$, utilizados na prevenção e tratamento da mucosite oral resultante da terapia do câncer em cabeça e pescoço em pacientes submetidos a RT exclusiva ou associada à QT.

\section{Objetivo específico:}

Avaliar, através da análise crítica dos dados obtidos durante o decorrer da pesquisa, quais os efeitos dos protocolos na prevenção e tratamento da mucosite oral e a influência dos mesmos na qualidade de vida dos pacientes, investigando as influências de variáveis demográficas (idade, gênero, profissão, procedência e grau de escolaridade), subjetivas (odinofagia, xerostomia e disgeusia) e objetivas (perda de massa corpórea, candidíase, uso de sonda nasogástrica, necessidade de internação e interrupção do tratamento oncológico em decorrência da mucosite oral). 


\section{3 - REVISÃO DE LITERATURA}

\subsection{Câncer}

Entende-se por câncer como um conjunto de doenças de variadas localizações e de diferentes tipos morfológicos que apresentam como principais características biológicas o crescimento celular descontrolado e a capacidade de se estabelecer além do tecido em que se origina (ALMEIDA et al., 2008). O mesmo é considerado uma das principais causas de morbidade e mortalidade na população mundial. Entre 80 a $90 \%$ dos cânceres têm sua gênese associada a fatores externos ao organismo e a maioria dos mesmos apresenta latência de 10 a 20 anos. O câncer de cabeça e pescoço se enquadra perfeitamente a estas considerações (CHIMENOS et al., 2008).

O câncer de cabeça e pescoço é um termo coletivo definido por bases anatômico-topográficas para descrever tumores malignos do trato aerodigestivo superior. Esta região anatômica inclui a cavidade nasal e seios paranasais, cavidade oral, faringe e laringe (CHOONG e VOKES., 2008). Um subgrupo maior dos carcinomas de cabeça e pescoço é referido como "câncer oral" surgindo nas mucosas da boca (lábios, base da língua, língua, assoalho bucal e palato duro) e faringe (compreende a orofaringe, a hipofaringe e a nasofaringe). Cerca de $40 \%$ dos cânceres de cabeça e pescoço ocorrem em cavidade oral, $15 \%$ em faringe, $25 \%$ em laringe (DOBROSSY., 2005; COLOMBO e RAHAL., 2009), e o restante nos demais sítios remanescentes como glândulas salivares, tireóide, paratireóide, porção cervical do esôfago e pele (FIG. 3.1) (RUBIRA et al., 2007). 


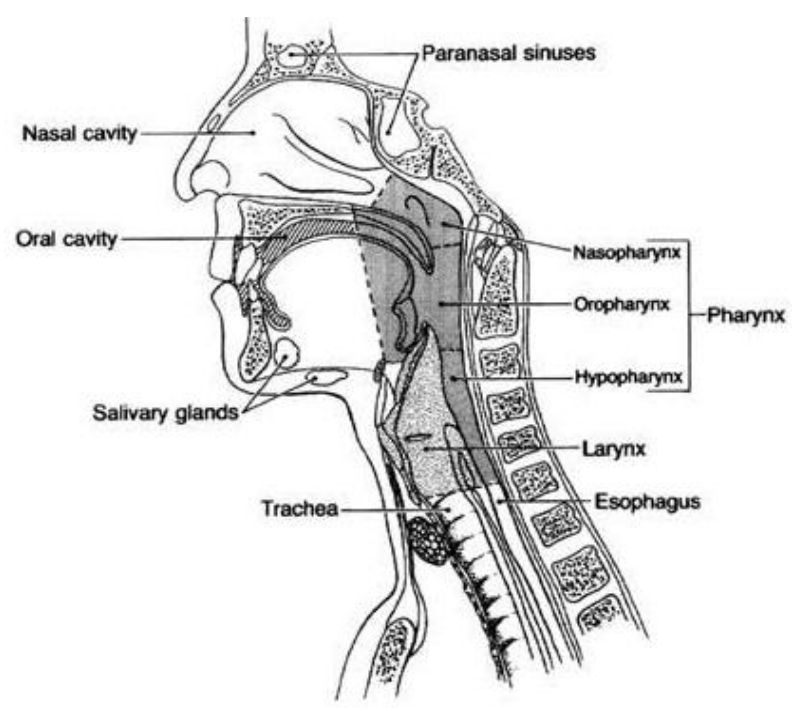

FIGURA. 3.1 Anatomia cabeça e pescoço. Fonte: Choong e Vokes, 2008.

Estima-se que, em 2020, o número de casos novos anuais seja da ordem de 15 milhões, e que cerca de $60 \%$ desses novos casos ocorrerão em países em desenvolvimento. Sabidamente de todos os casos novos de câncer que ocorrem anualmente no mundo pelo menos um terço poderiam ser prevenidos (BRASIL., 2007).

As estimativas para o ano de 2010 de novos casos por câncer para o Brasil são de 489.270 , sendo 236.240 no sexo masculino e 253.030 no sexo feminino. Destes os cânceres de maior incidência serão: próstata (52.350); mama feminina (49.240); pulmão (27.630); cólon e reto (28.110); estômago (21.500); colo de útero (18.430); cavidade oral (14.120) e esôfago (10.630) (BRASIL., 2009a).

No Brasil as neoplasias malignas constituem a segunda causa de morte por doença. Sendo a assistência nesta área extremamente onerosa, incluindo custos com a prevenção, testes diagnósticos e tratamento, assim como custos indiretos decorrentes da incapacidade de produção pelo doente, da morbidade associada à doença, do tratamento e da mortalidade. Com relação à mortalidade, os óbitos em conseqüência de tumores em cavidade oral ocupam a $10^{\mathrm{a}}$ posição em freqüência (BRASIL., 2003).

Excluindo-se o câncer de pele, o câncer oral pode ser considerado o mais comum da região de cabeça e pescoço é predominante no sexo masculino, tendo $75 \%$ dos casos diagnosticados na faixa etária dos 60 anos, sendo o Carcinoma Epidermóide (CE) responsável por cerca de 95\% dos casos ( BRASIL 2001.; COSTA et al., 2002; OLIVEIRA et al., 2006). O mesmo está frequentemente associado ao tabagismo, etilismo e a vírus oncogênicos como o HPV-18 e 16 (NEVILLE e DAY., 2002; CHOONG e 
VOKES., 2008). Língua e assoalho bucal representam os sítios anatômicos mais comuns (DEDIVITIS et al., 2004).

Os tipos mais freqüentes de neoplasias malignas orais não epidermóides são por ordem decrescente o carcinoma adenóide cístico, adenocarcinoma e o carcinoma mucoepidermóide. Os mesmos são seguidos pelos linfomas, melanomas, neoplasias odontogênicas e sarcomas (SILVA FILHO., 2000).

\subsection{Tratamento}

Apesar dos avanços dos últimos anos, o tratamento oncológico continua sendo complexo, estando geralmente associado a uma terapêutica agressiva acompanhada por hospitalizações prolongadas e a protocolos de tratamento que apresentam uma alta morbidade (DONAT e SANDOVAL., 2008), resultando, portanto, em impacto significativo na qualidade de vida do paciente ( ALMEIDA et al., 2004; VIEIRA e LOPES., 2006).

As opções de tratamento são variadas e dependem do tamanho e localização do tumor primário, status dos linfonodos, presença ou ausência de metástases à distância, aceitação e capacidade de tolerância ao tratamento por parte do paciente (NEVILLE e DAY., 2002).

As modalidades de tratamento comumente utilizadas para as neoplasias malignas são: CR, RT e QT (NEVILLE e DAY., 2002; BRENER et al., 2007; COSTA et al., 2007; RUBIRA et al., 2007; CHOONG e VOKES., 2008). Segundo Cardoso et al, 2005, a CR e a RT continuam sendo os principais e mais efetivos métodos de tratamento para os tumores de cabeça e pescoço. A QT e a imunoterapia são normalmente utilizadas como terapias adjuvantes (VIEIRA e LOPES., 2006).

O tratamento cirúrgico do câncer apresenta dois objetivos principais: ressecção e redução da neoplasia e de outros tecidos envolvidos, como os linfonodos e a remoção de órgãos endócrinos que podem modificar a disseminação da doença. Diferentemente do tratamento cirúrgico a RT e a QT não são específicos para o tecido, atuando, por sua vez, pela inibição do crescimento de células que se dividem rapidamente (VOLPATO et al., 2007).

Segundo a União Internacional Contra o Câncer (UICC) (1999) e Neville e Day (2002), o sistema de estadiamento TNM é utilizado para descrever a extensão anatômica da patologia e basea-se na pesquisa dos seguintes componentes: $\mathbf{T}$ - extensão anatômica do tumor primário; $\mathbf{N}$ - ausência ou presença de metástases em linfonodos 
regionais; $\mathbf{M}$ - ausência ou presença de metástases à distância. A adição de números a estes componentes indica a extensão do câncer, sendo que quanto maior for o estagio, pior o prognóstico para o paciente. O estadiamento do câncer oral segue listado na Tabela 1.

TABELA 1 - Estadiamento do câncer oral segundo critérios da União Internacional Contra o Câncer (UICC)

\begin{tabular}{|c|c|c|c|}
\hline Estágios & \multicolumn{3}{|c|}{ Descrição } \\
\hline 0 & Tis & N0 & M0 \\
\hline I & $\mathrm{T} 1$ & N0 & M0 \\
\hline II & $\mathrm{T} 2$ & N0 & M0 \\
\hline \multirow[t]{4}{*}{$*$ III } & $\mathrm{T} 3$ & N0 & M0 \\
\hline & $\mathrm{T} 1$ & N1 & M0 \\
\hline & $\mathrm{T} 2$ & N1 & M0 \\
\hline & $\mathrm{T} 3$ & N1 & M0 \\
\hline \multirow[t]{3}{*}{$* I V$ A } & $\mathrm{T} 4$ & N0 & M0 \\
\hline & $\mathrm{T} 4$ & $\mathrm{~N} 1$ & M0 \\
\hline & Qualquer T & $\mathrm{N} 2$ & M0 \\
\hline$*$ IV B & Qualquer T & N3 & M0 \\
\hline *IV C & Qualquer T & Qualquer N & M1 \\
\hline
\end{tabular}

* Pacientes que no momento do diagnóstico apresentarem estadiamento III e IV são considerados portadores de doença avançada.

Fonte - UICC, 1999.

Os pacientes com doença muito avançada são submetidos a cuidados paliativos, o que significa que não serão adotadas as formas terapêuticas convencionais, os mesmos recebem tratamento diferenciado, visando uma possível melhora da qualidade de vida (HONORATO et al., 2009).

É significativo o número crescente de pacientes que se apresenta aos serviços especializados com doença em fase avançada. A avaliação preliminar dos dados do Registro Hospitalar de Câncer no Hospital do Câncer / Instituto Nacional do Câncer (INCA) demonstrou que aproximadamente $60 \%$ dos pacientes que chegam ao hospital com câncer oral apresentam doença avançada nos estádios III e IV (BRASIL 2009b; HERCHENHORN e DIAS., 2004). Tal fato contribui para o aumento de seqüelas decorrentes do tratamento e diminui consideravelmente a possibilidade de cura e a sobrevida dos pacientes em questão (COSTA e MIGLIORATTI., 2001). Desta forma, a prevenção e tratamento das complicações orais decorrentes da terapia antineoplásica são importantes para melhorar a qualidade de vida, reduzir a morbidade e os custos do tratamento (OSTENE, et al; 2008). 


\subsection{1 - Radioterapia}

A RT é empregada como forma de tratamento em tumores sólidos, como os de pele, língua, laringe, cérebro, mama e colo uterino, e no tratamento de tumores não sólidos como as leucemias e linfomas. Pode ser empregada como tratamento radical visando à eliminação das células neoplásicas, assim como tratamento paliativo (SANTOS FILHO et al., 2008).

É a modalidade de tratamento não cirúrgico mais importante para o câncer, consiste na utilização das radiações ionizantes no combate a doença, com o objetivo de atingir as células neoplásicas, impedindo a sua multiplicação por mitose e/ou determinando a morte celular (BRASIL., 2002). Aumentando, portanto, a probabilidade de controle do tumor. (DONAT e SANDOVAL., 2008). Entretanto o efeito do tratamento radioterápico também será sentido nas células normais, onde produz alterações reversíveis e irreversíveis, a extensão e intensidade destes efeitos dependem da dose de irradiação, tempo e volume de tratamento, dose de distribuição e uso de outras terapias, e resultam em alterações importantes na qualidade de vida, durante e após o tratamento (RUBIRA et al., 2007; CACCELLI e RAPAPORT ., 2008).

Por sua vez a radiossensibilidade celular está relacionada ao estágio do ciclo celular e ao tempo de exposição à radiação, sendo a radiossensibilidade maior em células que apresentam maior capacidade de divisão (células neoplásicas, endotélio, osteoblastos, células da medula óssea). Estas células quando submetidas a baixas doses de radiação perdem rapidamente a capacidade de reprodução (SEMBA et al.,1994).

A maioria dos pacientes com câncer de cabeça e pescoço submetidos à RT recebe uma dose total de 50-70 Gy, como dose curativa aplicada diretamente sobre a lesão e tecidos adjacentes. Essas doses são fracionadas em um período de 5 a 7 semanas, uma vez ao dia, 5 dias por semana, com dose diária de aproximadamente 2 Gy (SEMBA et al.,1994; RAPOPORT et al., 2000; JHAM e FREIRE., 2006.). Quando necessário o paciente pode ser submetido a uma dose total de até $80 \mathrm{~Gy}$, porém nestes casos também é observado uma potencialização dos efeitos adversos associados a esta modalidade terapêutica (HERCHENHORN e DIAS., 2004).

A RT é indicada para tumores não ressecáveis ou sem morbidade grave e para aqueles que tendem a disseminar para locais contíguos previsíveis, a mesma pode ser utilizada isoladamente ou em associação com a CR e/ou QT. Ressalta-se que a RT provoca alterações bucais apenas quando atinge a região de cabeça e pescoço (COSTA et al., 2007). A presença de fatores como: hospitalização prolongada, estado nutricional precário, 
hábito de fumar, uso de antibióticos de largo espectro, mudança da microflora oral, titulação positiva para o vírus do herpes simples, infecção dentária pré-existente, higiene oral deficiente, dentes fraturados podem aumentar a incidência e a severidade das alterações orais (RAMPINI et al., 2009).

Os efeitos agudos e tardios da RT são frequentemente causa de desconforto, dificultando ou limitando as atividades normais, entre os efeitos agudos mais comumente associados a RT em cabeça e pescoço estão: mucosite, disgeusia, xerostomia e descamação da pele. Já os efeitos tardios normalmente observados são: lesões vasculares, atrofia dos tecidos, fibrose, edema, necrose dos tecidos moles, xerostomia, cáries de radiação, perda de dentes, trismo, osteorradionecrose (BONAN et al., 2005; JHAM e FREIRE., 2006; SAWADA et al., 2006; CHOONG e VOKES., 2008) e candidíase (JOYSTONBECHAL.,1992; DIB et al., 2000; RUBIRA et al., 2007).

Os tecidos afetados são aqueles presentes no campo de irradiação, consequentemente, geralmente nenhum sítio da mucosa oral é poupado (SCULLY et al., 2004). Apesar das complicações associadas ao tratamento serem potencialmente sérias, as mesmas podem ser prontamente prevenidas ou controladas através da ação de equipe multidisciplinar (NGUYEN, 1992).

\subsubsection{Quimioterapia}

A QT é capaz de alterar a integridade da mucosa, a flora microbiana que normalmente habita a cavidade oral, a quantidade e composição salivar, e a maturação epitelial (TURHAL et al., 2000).

O emprego da QT no tratamento do câncer em cabeça e pescoço apresenta como principais objetivos diminuir as metástases à distância e aumentar o controle local da doença. Porém, há alguns anos atrás, o papel da QT no tratamento do câncer de cabeça e pescoço era bastante controvertido e limitado, isso se devia ao fato da mesma apresentar maior efetividade frente a tumores com um significativo potencial de crescimento e com elevada tendência a metástases à distância, propriedades raras no $\mathrm{CE}$, que é o tipo de neoplasia com maior prevalência em cabeça e pescoço (YOGI e SINGH, 2005). Entretanto, em poucos anos importantes progressos foram obtidos em ensaios direcionados ao desenvolvimento de protocolos envolvendo QT e RT para doença irressecável com o objetivo de preservação de órgãos ou paliação em pacientes com doença recorrente ou localmente avançada (HERCHENHORN e DIAS, 2004). 
Conforme Blunk et al (1997) a QT é denominada adjuvante quando empregada concomitantemente ou, mais frequentemente, em um curto intervalo de tempo após a terapêutica local cirúrgica ou, na maioria das vezes, radioterápica. A mesma tem por objetivo a eliminação de micrometástases e/ou de células neoplásicas que tenham permanecido no leito tumoral após o tratamento empregado. Como terapia neoadjuvante entende-se a utilização da mesma anteriormente à modalidade de eleição para o tratamento local, com o objetivo maior de reduzir as dimensões do tumor primário e obter melhores condições cirúrgicas e/ou diminuição da área a ser irradiada, além da possível erradicação de prováveis micrometástases. É denominada de paliativa quando empregada em pacientes com tumores metastáticos e/ou recidivados sem possibilidades de cura.

Os agentes antineoplásicos podem ser classificados de acordo com a especificidade no ciclo celular, estrutura química e função a nível celular. Com relação à fase do ciclo celular em que atuam são classificados em ciclo independentes: atuam sobre células em diversas fases do ciclo celular, ou seja, em células tanto em divisão quanto em repouso; agentes fase específicos: atuam sobre células que se encontram em uma mesma fase do ciclo celular. Com relação ao mecanismo de ação são classificados em alquilantes: inibem a divisão celular formando uniões cruzadas entre cadeias de DNA impedindo sua replicação; antimetabólitos: inibem a divisão celular atuando sobre enzimas imprescindíveis para a síntese de bases púricas e pirimidínicas; inibidores de mitoses: inibem a divisão celular através de sua atuação sobre os microtúbulos do núcleo, impedindo sua divisão (SANDOVAL et al., 2003) e, por fim, como grupo que é denominado de miscelânea: inclui agentes antiangiogênicos e inibidores da transdução de sinal (ex: inibidores da tirosina quinase) (FERREIRA et al., 2008).

O tratamento quimioterápico basea-se no emprego de combinações de agentes (poliquimioterapia) em detrimento do tratamento com um único agente quimioterápico (monoterapia), a combinação entre drogas com diferentes mecanismos de ação busca o efeito sinérgico dos fármacos (SANDOVAL et al., 2003). Essas combinações entre agentes quimioterápicos incluem drogas ciclo-dependentes e ciclo-independentes, cobrindo tanto a fase proliferativa quanto vegetativa do ciclo celular (DREIZEN, 1990).

Segundo Machado e Sawada (2008) os principais efeitos colaterais associados ao tratamento quimioterápico são hematológicos, gastrointestinais, cardiotoxicidade, hepatotoxicidade, nefrotoxicidade, toxicidade pulmonar, vesical, alterações metabólicas, disfunção reprodutiva, toxicidade dermatológicas, reações alérgicas e anafilaxia. 
O efeito sistêmico da QT manifesta-se pela relação direta com a mielossupressão, o mesmo é observado com os efeitos clínicos da mucosa oral. A lise das células epiteliais do tecido normal é uma das razões das manifestações associadas a esta forma de terapêutica: como erosões e ulcerações, ou mesmo, a perda generalizada de superfície do epitélio. As complicações orais da QT se dão por dois mecanismos: 1 - ação direta da droga sobre os tecidos orais ou estomatoxidade direta, neste caso a mucosite ocorre em função da atrofia epitelial e necrose decorrente, e 2 - em conseqüência de alterações induzidas em outros tecidos ou estomatoxidade indireta, como a mielossupressão da medula óssea.

De acordo com Barasch e Coke (2007) as complicações orais decorrentes do tratamento quimioterápico acometem $10 \%$ dos pacientes em QT adjuvante, $40 \%$ dos pacientes em QT exclusiva e $80 \%$ dos pacientes em regime quimioterápico mieloablativo (transplantes de medula óssea), sendo que as complicações orais mais comuns são mucosite, infecção, dor, sangramentos e disfunções do paladar. Para Scully et al., (2006) a MO, especialmente na presença de neutropenia, pode predispor a bacteremia, septicemia e fungemia.

Cerca de $70 \%$ dos pacientes portadores de neoplasias malignas receberão, em algum momento do tratamento, QT antineoplásica. Dependendo do tipo, da dosagem e da freqüência de utilização dos agentes quimioterápicos, severas manifestações orais podem surgir, estas podem ser graves e interferir nos resultados da terapêutica médica, acarretando complicações sistêmicas importantes, que podem aumentar o tempo de internação hospitalar, os custos do tratamento e afetar diretamente a qualidade de vida destes pacientes (HESPANHOL et al., 2007).

Para Ostene et al., (2008) muitos pacientes imunossuprimidos por QT no intervalo de 7 a 15 dias, após o inicio do tratamento, apresentam risco de desenvolvimento de lesões dentárias ou periodontais, relacionadas a focos odontogênicos preeexistentes. Tem-se demonstrado que os microorganismos bucais são fontes comuns de bacteremia nesses pacientes. Sendo as infecções sistêmicas responsáveis por aproximadamente $70 \%$ dos óbitos em pacientes que recebem QT mielossupressiva, em que os efeitos adversos mais comumente associados à mesma são representados por neutropenia, anemia e trombopenia.

Entre as drogas antineoplásicas usadas para o tratamento do câncer de cabeça e pescoço está o metrotexate, a bleomicina, a cisplatina, a carboplatina, o 5-Fluouracil (5FU), a gencitabina, a ciclofosfamida, a doxorrubicina, a vincristina e a vinblastina, os 
taxóides (paclitaxel e docetaxel) e a vinorrelbina (BLUNK; 1997). A associação entre as drogas geralmente resultam em maior tendência a ocorrência de mucosite (VIEIRA e LOPES., 2006). Uma descrição das características e toxicidades das principais drogas quimioterápicas empregadas em pacientes portadores de câncer de cabeça e pescoço, encontra-se esquematizada na Tabela 2.

TABELA 2 - Principais quimioterápicos úteis no tratamento dos tumores de cabeça e pescoço e seus principais efeitos colaterais

\begin{tabular}{|c|c|c|}
\hline Droga & Grupo Farmacológico & Toxicidades Principais \\
\hline Bleomicina & Antibiótico antitumoral & Mucosite, dermatite e pneumonite intersticial \\
\hline Carboplatina & Derivado da platina & Mielotoxicidade com trombopenia e leucopenia \\
\hline Ciclofosfamida & Alquilante & $\begin{array}{l}\text { Leucopenia, trombopenia, alopecia, náuseas, } \\
\text { vômitos e cistite aguda hemorrágica }\end{array}$ \\
\hline Cisplatina & Derivado da platina & $\begin{array}{l}\text { Prejuízo da função tubular renal, náuseas, } \\
\text { vômitos, mielotoxicidade, ototoxicidade, } \\
\text { neuropatia periférica }\end{array}$ \\
\hline 5-Fluorouracil & Antimetabólito & Mucosite com diarréia, ulcerações e leucopenia \\
\hline Metrotexate & Antimetabólito & $\begin{array}{l}\text { Leucopenia, trombopenia, estomatite, diarréia, } \\
\text { disfunção hepática, nefrotoxicidade e } \\
\text { pneumonite }\end{array}$ \\
\hline
\end{tabular}

Fonte - Modificada de BLUNK et al., 1997.

A cisplatina é um antineoplásico efetivo quando administrado por via intraperitoneal ou intravenosa, e apresenta potencial terapêutico em uma grande variedade de neoplasias humanas e animais, principalmente no tratamento das neoplasias de testículo, ovário, melanomas, nas neoplasias de cabeça e pescoço e nos carcinomas de bexiga e pulmão. Contudo sua utilidade clínica é limitada em consequência de seus efeitos colaterais que são náusea, vômito, hipomagnesemia, supressão da medula óssea, ototoxicidade. A nefrotoxicidade é o seu principal efeito colateral, sendo a mesma considerada dose limitante (ANTUNES e BIANCHI, 2004). Já o 5-FU é um antimetabólito, comumente usado no tratamento de vários tipos de cânceres sólidos incluindo, seio, cabeça e pescoço e neoplasias malignas gastrointestinais (esôfago, estômago, colon e anal) (KUMMAR, 2000), que atua sobre as células inibindo a biossíntese dos componentes essenciais do DNA e do RNA, impedindo a multiplicação e funções normais da célula. Os antimetabólitos são particularmente ativos contra células que se encontram na fase de síntese do ciclo celular (fase S). A duração da vida das células tumorais suscetíveis determina a média de destruição das mesmas, as quais são impedidas 
de entrar em mitose pela ação dos agentes metabólicos que atuam na fase S (BRASIL, 2010).

A QT constitui uma parte importante do tratamento multidisciplinar para os pacientes com câncer de cabeça e pescoço e esôfago, em que frequentemente é empregado um esquema quimioterápico constituído por 4 a 5 dias de infusão continua de 5 -FU in bolus com cisplatina (FABRÍCIO et al., 2008). Esta combinação em associação a RT resulta em um método altamente eficaz no controle do câncer de cabeça e pescoço, porém a mesma esta associada a um aumento na incidência de MO grau 3 e 4 e de efeitos hematológicos tóxicos (SEIWERT et al,. 2007). Para Scully et al., (2003) 90\% dos pacientes tratados com cisplatina e 5-FU desenvolverão mucosite.

Com relação à MO o uso de pedras de gelo (crioterapia oral) por 5 minutos antes e 30 minutos durante a infusão com 5-FU reduz consideravelmente a severidade da mesma (BIRON et al., 2000; DODD et al., 2000; SCULLY et al., 2004). O gelo promove o resfriamento da mucosa oral acompanhado de vasoconstrição temporária, o que consequentemente reduz a exposição da mucosa ao agente quimioterápico (KOSTLER et al., 2001; SCULLY et al., 2006).

\subsection{Mucosite oral}

As células da camada basal do epitélio oral apresentam alta taxa de renovação (10 a 14 dias) sendo especialmente sensíveis aos efeitos da terapia oncológica (CARL e HAVENS, 2000). A mucosite afeta a mucosa do trato gastrointestinal e especialmente a mucosa oral e da orofaringe, sendo uma complicação comum a citotoxidade da QT e RT (KHOURI et al., 2009). A prevenção e tratamento da mesma são essenciais para a melhora da qualidade de vida e das taxas de controle da doença (BENSADOUN et al ., 2001).

A mesma é resultado da ação direta da radiação sobre as células do epitélio oral que por sua vez apresentam rápida capacidade de renovação e baixa radiorresistência, sendo especialmente radiossensíveis o epitélio de revestimento do palato mole, ventre e borda lateral de língua e assoalho bucal. A severidade das lesões está associada à qualidade de radiação, dose e tempo total de tratamento (SEMBA et al., 1994; CARL e HAVENS, 2000; BENSADOUN et al., 2001; RUBIRA et al., 2007) angulação do feixe, localização da lesão e nível de higiene oral. Os efeitos da radiação são mais intensos no lado ipsilateral a administração embora a mucosite possa ocorrer em toda a cavidade oral, já sua duração apresenta uma considerável variabilidade individual (ANDREWS e GRIFFITHS, 2001). 
Quanto a sua fisiopatologia são observados dois mecanismos: direto e indireto. Na MO direta, em um período usual de 7 a 14 dias, as células epiteliais sofrem transformações que as tornam suscetíveis aos efeitos da terapia citotóxica. Tanto a RT quanto a QT são capazes de interferir no crescimento e maturação das células epiteliais, ocasionando modificações celulares e morte. A MO indireta é resultado da invasão indireta de bactérias gram negativas e de fungos. Ocorrendo normalmente a partir de 10 a 21 dias após a administração da QT. A frequência da MO está estimada em 85\% a 100\% dos pacientes submetidos a altas doses de radiação em cabeça e pescoço (BENSADOUN et al., 2001; PETERSON, 2006).

Independente da forma de tratamento adotada, RT ou QT, as apresentações clínicas da MO são semelhantes. No caso de MO quimioinduzida dependendo das condições gerais do paciente e da abordagem terapêutica, a mucosa bucal tende a cicatrizar em 14 dias (GALVÃO et al., 2006).

Alguns indivíduos desenvolvem lesões extremamente severas, o que faz que sejam necessárias modificações no tratamento oncológico e/ou uso de analgesia parenteral. Tal ocorrência é significativa em vários pacientes em tratamento para transplante de medula óssea, em infusão continua para tratamento de câncer de seio e colon e em tratamento para câncer de cabeça e pescoço. Nos pacientes submetidos aos protocolos de alto risco a MO severa ocorre com uma freqüência superior a 60\% (SONIS, 1998). Neste caso são observadas ulcerações que penetram completamente na submucosa e causam dor intensa. Nos casos de MO branda a mucosa apresenta-se eritematosa, com lesões atróficas, porém intacta. Os pacientes referem sensibilidade semelhante àquela observada com a ingestão de alimentos quentes, sendo esta sintomatologia de fácil controle (SONIS, 2004).

A MO é o efeito agudo mais freqüente e o maior fator dose limitante para a RT em cabeça e pescoço, geralmente ocorre a partir da segunda semana de tratamento com uma dose total em torno de 20Gy. Inicialmente é observado eritema de intensidade variável, e discreto desconforto oral. Com o acúmulo da dose de radiação absorvida, e de acordo com a resposta individual do paciente, a mucosite evolui para o esbranquiçamento da mucosa, formação de pseudomembranas e de lesões ulcerativas que são notadas a partir de 30 Gy. A intensidade da dor é tão severa quanto à proporção da área comprometida; a exposição do tecido conjuntivo funciona como uma porta de entrada às infecções oportunistas (DIB et al., 2000; KOSTLER et al., 2001). Comumente são relatadas infecções por cândida e pelo vírus do herpes simples. Pacientes com neutropenia resultante 
de QT apresentam um maior risco de septicemia, particularmente envolvendo streptococos $\alpha$ hemoliticus, espécies de candida, e bactérias gram negativas (SCULLY et al., 2004).

A MO radioinduzida se intensifica com a continuidade do tratamento, doses diárias de 2 Gy em grandes volumes em cabeça e pescoço resultam em morte celular que excede a capacidade de proliferação das células da camada basal do epitélio. Como resultado, a quase totalidade dos pacientes desenvolve MO confluente por volta da terceira semana. A MO comumente persiste por duas a três semanas após o término da RT. Quatro semanas após o término do tratamento radioterápico 90 a 95\% dos pacientes apresentam remissão completa do quadro (ANDREWS e GRIFFITHS, 2001; CACELLI e RAPAPORT, 2008).

De acordo com Sonis et al, (2004) a MO é um complexo processo biológico que ocorre em 5 fases: iniciação, super-regulação, sinalização e amplificação, ulceração com inflamação e, finalmente, cicatrização. Iniciação: a injúria tecidual, que está associada à geração de fatores oxidativos, ocorre tão logo se inicia a QT e/ou RT, quando tem início o processo de mucosite por ação direta sobre o DNA. A quebra do DNA resulta em dano que compromete a camada basal do epitélio e as células da submucosa, porém, neste estágio a mucosa apresenta-se normal. Super-regulação: nesta segunda fase múltiplos eventos ocorrem simultaneamente. Fatores oxidativos causam danos ao DNA resultando em morte das células epiteliais. A ativação de fatores de transcrição em resposta aos fatores oxidativos da RT e/ou QT resultam em super-regulação de muitos genes, incluindo aqueles que resultam na produção de citocinas pró-inflamatórias, tais como o fator alfa de necrose tumoral (TNF-a), interleucinas IL-1B, e IL-6 levando a injúria tecidual e a apoptose. A super-regulação de outros genes causa a expressão de moléculas de adesão, subseqüente a ativação da ciclooxigenase-2, e conseqüente angiogenese. Sinalização e amplificação: a manifestação do efeito de destruição direta das células da mucosa adiciona atividade às citocinas pró-inflamatórias que indiretamente amplificam a injúria tecidual, iniciada pela QT e RT. Nesta fase observa-se que apesar do tecido apresenta-se biologicamente alterado, a aparência da mucosa é normal. Ulceração: a mucosite especialmente aquela induzida pela RT, frequentemente é referida como um processo inflamatório. A fase ulcerativa da mucosite é caracterizada pelo abundante infiltrado inflamatório abrangendo polimorfonucleares e demais células inflamatórias. Nesta etapa ocorre a colonização bacteriana que pode ativar os macrófagos teciduais aumentando a produção de citocinas inflamatórias que podem amplificar e acelerar o dano tecidual. As consequiências da ulceração são a amplificação adicional das citocinas, inflamação, dor, e 
em pacientes neutropênicos um aumento do risco de bacteremia e sepsis. Cicatrização: tem início a partir de um sinal da matriz extracelular, esta conduz a proliferação, diferenciação e renovação do epitélio e ao restabelecimento da microflora oral. Outros eventos podem ocorrer simultaneamente tais como a recuperação da medula óssea e o aumento do número de leucócitos. Após a fase de cicatrização a mucosa apresenta-se normal; entretanto, apesar da aparência normal, a mucosa está significativamente alterada. O paciente apresenta um maior risco de, no futuro, sofrer de episódios de mucosite e de complicações subseqüentes à terapia anticâncer.

Vários esquemas foram propostos para mensurar a mucosite em pacientes com câncer em função da presença de sinais como: eritema e ulcerações, isoladamente ou em conjunto com sintomas como dor e dificuldade de deglutição (TURHAL et al., 2000). A avaliação da MO deve ser minuciosa para que o grau de toxicidade e a terapêutica adequada possam ser definidos. Conforme Rampini et al., (2009) as escalas mais utilizadas para a avaliação das manifestações clínicas da MO estão listadas na Tabela 3 abaixo:

TABELA 3 - Comparação das escalas de mucosite

\begin{tabular}{|c|c|c|c|c|c|c|c|}
\hline Escala & toxicidade & Grau 0 & Grau 1 & Grau 2 & Grau 3 & Grau 4 & Grau 5 \\
\hline WHO & $\begin{array}{l}\text { Mucosite } \\
\text { oral }\end{array}$ & $\begin{array}{l}\text { Sem } \\
\text { alteração }\end{array}$ & Eritema & $\begin{array}{l}\text { Eritema e } \\
\text { úlcera } \\
\text { A dieta } \\
\text { sólida é } \\
\text { tolerada }\end{array}$ & $\begin{array}{l}\text { Eritema e } \\
\text { úlcera } \\
\text { Somente a } \\
\text { dieta líquida é } \\
\text { tolerada }\end{array}$ & $\begin{array}{l}\text { Eritema e } \\
\text { úlcera } \\
\text { O paciente não } \\
\text { consegue se } \\
\text { alimentar }\end{array}$ & ------ \\
\hline $\begin{array}{l}\text { NCI- } \\
\text { CTC }\end{array}$ & $\begin{array}{l}\text { Mucosite } \\
\text { orofarínge } \\
\text { a induzida } \\
\text { por QT }\end{array}$ & $\begin{array}{l}\text { Sem } \\
\text { alteração }\end{array}$ & $\begin{array}{l}\text { Eritema, } \\
\text { úlcera } \\
\text { indolor }\end{array}$ & $\begin{array}{l}\text { Eritema } \\
\text { com dor, } \\
\text { edema ou } \\
\text { úlcera. O } \\
\text { paciente } \\
\text { consegue } \\
\text { se } \\
\text { alimentar }\end{array}$ & $\begin{array}{l}\text { Eritema com } \\
\text { dor, edema ou } \\
\text { úlcera, requer } \\
\text { hidratação }\end{array}$ & $\begin{array}{l}\text { Ulceração } \\
\text { severa Requer } \\
\text { nutrição } \\
\text { parenteral ou } \\
\text { enteral ou } \\
\text { intubação } \\
\text { profilática }\end{array}$ & $\begin{array}{l}\text { Morte } \\
\text { relaciona } \\
\text { da à MO }\end{array}$ \\
\hline $\begin{array}{l}\text { NCI- } \\
\text { CTC }\end{array}$ & $\begin{array}{l}\text { Mucosite } \\
\text { orofarínge } \\
\text { a induzida } \\
\text { associada } \\
\text { ao TMO }\end{array}$ & $\begin{array}{l}\text { Sem } \\
\text { alteração }\end{array}$ & $\begin{array}{l}\text { Eritema, } \\
\text { úlcera } \\
\text { indolor }\end{array}$ & $\begin{array}{l}\text { Eritema } \\
\text { com dor, } \\
\text { edema ou } \\
\text { úlcera. O } \\
\text { paciente } \\
\text { consegue } \\
\text { se } \\
\text { alimentar }\end{array}$ & $\begin{array}{l}\text { Eritema com } \\
\text { dor, edema ou } \\
\text { úlcera, requer } \\
\text { hidratação ou } \\
\text { nutrição } \\
\text { parenteral }\end{array}$ & $\begin{array}{l}\text { Ulceração } \\
\text { severa Requer } \\
\text { intubação } \\
\text { profilática ou } \\
\text { resulta em } \\
\text { pneumonia por } \\
\text { aspiração }\end{array}$ & $\begin{array}{l}\text { Morte } \\
\text { relaciona } \\
\text { da à MO }\end{array}$ \\
\hline $\begin{array}{l}\text { NCI- } \\
\text { CTC }\end{array}$ & $\begin{array}{l}\text { Mucosite } \\
\text { orofarínge } \\
\text { a induzida } \\
\text { associada a } \\
\text { RT }\end{array}$ & $\begin{array}{l}\text { Sem } \\
\text { alteração }\end{array}$ & $\begin{array}{l}\text { Eritema, } \\
\text { úlcera } \\
\text { indolor }\end{array}$ & $\begin{array}{l}\text { Eritema } \\
\text { com dor, } \\
\text { edema ou } \\
\text { úlcera. O } \\
\text { paciente } \\
\text { consegue } \\
\text { se } \\
\text { alimentar }\end{array}$ & $\begin{array}{l}\text { Reação com } \\
\text { pseudomembra } \\
\text { na }\end{array}$ & $\begin{array}{l}\text { Necrose e/ou } \\
\text { ulceração } \\
\text { profunda ou } \\
\text { sangramento } \\
\text { não induzido } \\
\text { por trauma. } \\
\text { Necessita de } \\
\text { nutrição } \\
\text { enteral ou } \\
\text { parenteral }\end{array}$ & $\begin{array}{l}\text { Morte } \\
\text { relaciona } \\
\text { da à MO }\end{array}$ \\
\hline
\end{tabular}


TABELA 3 - Comparação das escalas de mucosite

\begin{tabular}{|c|c|c|c|c|c|c|}
\hline RTOG & $\begin{array}{l}\text { Mucosite } \\
\text { oral aguda } \\
\text { causada } \\
\text { por RT }\end{array}$ & $\begin{array}{l}\text { Sem } \\
\text { alteração }\end{array}$ & $\begin{array}{l}\text { Dor } \\
\text { branda } \\
\text { não } \\
\text { requer } \\
\text { analgésico }\end{array}$ & $\begin{array}{l}\text { Apresenta } \\
\text { áreas de } \\
\text { úlceras } \\
\text { com } \\
\text { sangramen } \\
\text { to. Requer }\end{array}$ & $\begin{array}{l}\text { Úlceras } \\
\text { confluentes } \\
\text { Requer uso de } \\
\text { narcóticos }\end{array}$ & $\begin{array}{l}\text { Ulceração, } \\
\text { hemorragia ou } \\
\text { necrose }\end{array}$ \\
\hline
\end{tabular}

Fonte - Rampini et al., 2009.

\subsection{Tratamento medicamentoso}

A prevenção da MO inicia-se com uma avaliação prévia ao tratamento oncológico, e consiste na otimização da higiene oral, profilaxia dental e erradicação de focos de infecção. Primeiramente as intervenções visam à manutenção da higiene oral, correção da má nutrição com a ingestão de uma dieta calórica o que contribui significativamente para o bem estar do paciente e redução dos efeitos associados à MO. Não existe intervenção farmacológica largamente reconhecida como efetiva na prevenção e tratamento da MO radioinduzida (JOHNSON, 2001; MCGUIRE et al., 2006). Sendo o manejo da mesma em pacientes com câncer essencialmente paliativo (BENSADOUN et al., 1999; SCULLY et al., 2004; BONAN et al., 2005) apresentando como objetivos principais o alívio dos sintomas e a prevenção de complicações secundárias como a desidratação, caquexia e infecções, permitindo uma melhor qualidade de vida (KOSTLER et al., 2001).

Vários tratamentos tópicos e sistêmicos são direcionados a prevenção e controle dos efeitos agudos decorrentes da QT e/ou RT, porém poucos têm apresentado significativo efeito preventivo (BENSADOUN et al., 2001; LOPES et al., 2006; VOLPATO et al., 2007; RAMPINI et al., 2009). Entre os vários agentes terapêuticos usados na prevenção e tratamento da MO estão: glutamina, sucralfato, esteróides, imunoglobulinas, amifostine, antibióticos, antifúngicos, clorexidina, vitamina $\mathrm{E}$, benzidamina, anestésicos locais e bochechos com antissépticos, porém nenhum destes mostrou-se efetivo no alívio, assim como na redução da intensidade ou duração das lesões (KOSTLER et al., 2001; SANDOVAL et al., 2003; SCULLY et al., 2003).

O uso do protetor labial promove a hidratação da mucosa resultando em alívio do desconforto e prevenção da MO (COSTA et al., 2007). Para as candidíases orais associadas à RT de cabeça e pescoço utiliza-se a nistatina 100.000UI suspensão oral, quatro vezes ao dia ou mais (ALMEIDA et al., 2004). O uso de dexametasona visa o tratamento das ulcerações e inflamações da mucosa, o paciente deve enxaguar a boca, de 
duas a quatro vezes ao dia e orientado a não deglutir (MIGLIORATI e MIGLIORATI, 2000; GUIMARÃES JUNIOR, 2005).

Para Baldisserotto et al., (2009) o uso de clorexidina para o controle de placa deve ser recomendado de acordo com a necessidade de cada paciente e deve ser avaliado pelo cirurgião-dentista.

Labbate et al., (2003) realizaram estudo clínico com o objetivo de avaliar a eficiência da clorexidina na prevenção e tratamento da MO radioinduzida. Foram analisados 21 portadores de câncer de cabeça e pescoço, distribuídos em dois grupos: Grupo placebo com 11 pacientes submetidos a dois bochechos diários com água destilada e Grupo medicamentoso, dez pacientes submetidos a dois bochechos diários com clorexidina $0,12 \%$. Os pacientes foram analisados semanalmente para detecção de alterações mucosas através da escala World Health Organization (WHO) e preenchimento de questionário de qualidade de vida com ênfase nos aspectos de dor, apetite, paladar e hábitos alimentares. Foi constatada MO mais intensa, assim como maiores intensidades de dor no grupo placebo, portanto, a clorexidina contribuiu para a diminuição dos efeitos deletérios e da intensidade da dor associadas à MO sem apresentar reflexo persistente na qualidade de vida dos pacientes. Ao final do estudo foi constatada uma tendência à perda total de paladar em todos os pacientes.

Dib e Curi (2002) em estudo prospectivo realizado no Centro de Tratamento e Pesquisa Hospital do Câncer A.C. Camargo, com intuito de avaliar uma série de medidas que constituem uma abordagem preventiva e terapêutica para as complicações orais agudas da RT, com o objetivo de evitar casos de MO severa que possam acarretar a interrupção do tratamento oncológico propusseram a abordagem profilática e terapêutica citada abaixo (TAB. 4): 
TABELA 4 - Abordagem profilática e terapêutica indicada para as complicações orais radioinduzidas agudas

\begin{tabular}{lll}
\hline Indicação/Medicamentos & Posologia & Abordagem
\end{tabular}

\section{Mucosite oral}

Soro fisiológico $0,9 \%$

Bochechos 4x/dia

A partir do início da RT

Hidróxido de alumínio e Bochechos 4x/dia com 1 A partir do início da RT magnésio, suspensão oral, sabor não ácido

colher de sopa. Tomar 1

colher de sobremesa $4 \mathrm{x} / \mathrm{dia}$

\section{Mucosite e dor}

Cetoprofeno $150 \mathrm{mg}$, comprimidos

1 comprimido $2 \mathrm{x} / \mathrm{dia}$

Quando necessário

Cetoprofeno $20 \mathrm{mg}$, gotas Tomar 50 gotas de $6 / 6 \mathrm{hs}$

Quando necessário ou de 8/8 hs

Cloridrato de lidocaína

$100 \mathrm{mg}$,

carboximetilcelulose

Tomar 1 colher de sopa Quando necessário

sódica $125 \mathrm{mg}$, solução

viscosa para uso oral

$3 x /$ dia

\section{Xerostomia}

Cloridrato de pilocarpina

$2 \%$ (colírio)

Tomar, via oral, 2 a 5 Queixa de secura na boca ou gotas três vezes ao dia espessamento do fluxo salivar

Gel oral base de

Usar quando necessário

Queixa de secura na boca ou

Lactoperoxidase espessamento do fluxo salivar

Protetor labial (comum) Usar quando necessário Lábios ressecados

\section{Candidíase oral}

Miconazol 2\%, gel oral

Aplicar naboca ou Evidência clínica de candidíase comissuras labiais $4 x /$ dia oral

Cetoconazol 200mg

Tomar 1 comprimido vezes ao dia por 21 dias

2 Evidência clínica de candidíase orofaríngea

Fonte - Dib \& Curi, 2002.

Kostler et al., (2001) após revisão de 139 artigos, concluíram que, apesar do emprego em larga escala, não existe suporte científico para a indicação do uso de sulcralfato, misoprosol, pentoxifilina, uridina e alupurinol para a prevenção da MO. Entretanto intervenções não-farmacológicas, incluindo crioterapia, protetores de radiação, tratamento com laser de baixa intensidade e higiene oral, assim como uma infinidade de 
drogas têm sido avaliados com sucesso como agentes profiláticos e terapêuticos para a MO. Incluindo anestésicos locais e substâncias antimicrobianas, mas, mais recentemente, substâncias citoprotetoras, como amifostina e uma série de citocinas, que apresentam potencial de, em breve, tornar-se terapia padrão. Abordagens promissoras, mas ainda não suficientemente avaliadas incluem o uso de substância anti-séptica, como iodo povidine e benzidamina, vitamina E, ácido retinóico, beta caroteno e citocinas como TGF- $\beta 3$. Novos agentes como a interleucina-11, ácido dehidroascórbico, fator de crescimento de queratinócitos e fator de crescimento epidérmico, que aceleram o crescimento, diferenciação e migração celular no epitélio estão sendo avaliados. Além de todas estas intervenções mecânicas e farmacológicas os autores ressaltam a importância dos efeitos positivos obtidos através de atendimento médico humanizado.

Já para Barasch et al., (2006) após revisão, análise e debate de 55 artigos obtiveram unanimidade nas seguintes conclusões: é recomendado em adultos o uso de clorexidina para o tratamento da MO quimioinduzida, e de antibióticos em pastilhas para a sua prevenção, assim como o uso de sulcralfato para o tratamento da MO radioinduzida; em respeito ao uso de anestésicos tópicos, apesar dos mesmos consistirem em escolha obvia para paliação da dor, as evidências com relação a sua eficiência no tratamento da mucosite são insuficientes, sendo os anestésicos mais comumente usados a lidocaína e benzocaina, o mesmo é observado com relação ao emprego de analgésicos tópicos, como o sulfato de morfina ou o fentanil.

Turhal et al., (2000) após revisão de literatura com intuito de verificar a eficácia do tratamento no alívio do desconforto resultante da MO, afirmaram que o sucralfato, especialmente para mucosite radioinduzida, demostraram uma tendência ao alivio dos sintomas sem, contudo apresentar significância estatística, em ensaio para a mucosite quimioinduzida não foram observados nenhum benefício.

Segundo Scully et al., (2004) o desconforto ocasionado pela mucosite pode ser reduzido através da adoção das seguintes condutas: eliminação dos irritantes orais (fumo, álcool e alimentos duros e/ou picantes); manutenção de boa higiene oral; refrigeração oral com pedras de gelo em pacientes que receberam QT com 5-FU; aplicação de analgésicos tópicos, antes das refeições, para o combate da dor e disfagia. Estes incluem: agentes anestésicos com lidocaína, diclonina, ou difenidramina que promovem alívio da sintomatologia dolorosa; benzidamina que reduz a dor e a severidade da MO radioinduzida; enxaguatório com doxepina que promove efeito analgésico prolongado; agentes de revestimento, incluindo bioadesivo de hidroxipropilcelulose (Zilactin®) que 
além de ser usado para paliação da dor apresenta atividade anti-Herpes Simples Vírus (HSV).

Pacientes submetidos à QT em altas doses, principalmente aqueles submetidos a regimes quimioterápicos mielossupressivos ou imunossupressivos, frequentemente recebem agentes antibióticos e antifúngicos profilaticamente ou durante os períodos de leucopenia induzida pela QT (VOLPATO et al., 2007).

As formas leves de MO podem ser tratadas com boa higiene oral, incluindo escova de dentes de cerdas macias e enxaguatórios com solução salina. É indicado o uso de vários agentes paliativos tópicos no tratamento de MO leve e moderada; entretanto, até a presente data é pobre a eficácia dos enxaguatórios bucais no controle das mesmas. Enxaguatórios bucais e dentifrícios contendo irritantes químicos, álcool, fenol, aromáticos, e óleos glicerinados prolongam a mucosite e devem ser evitados. Na mucosite severa frequentemente é obtido algum sucesso com o uso de anestésico tópico em spray $\left(\right.$ Citocaina $\left.^{\circledR}\right)$, elixir de acetominofem com codeína, ou enxaguatórios de tetraciclina, nistatina, hidrocortisona, e maleato de clofeniramina. O uso dos mesmos se dá antes das refeições com o intutito de permitir a manutenção de uma dieta adequada. Pacientes com dor severa decorrente de MO podem requerer administração sistêmica de medicamentos como morfina $(0,3 \mathrm{mg} / \mathrm{kg})$ ou metadona $(0,1 \mathrm{mg} / \mathrm{kg})$ a cada duas ou cinco horas. Para os casos de dor severa prolongada o uso de morfina endovenosa pode ser necessário (MEALEY et al., 1994).

O uso de anestésicos locais para o alívio da dor pode acarretar diminuição de sensibilidade, aumentando o risco de traumatismo e inibindo a deglutição reflexa (BIRON et al., 2000).

\subsection{Laser em baixa intensidade}

A aplicação do Laser em Baixa Intensidade (LBI) atua como um implemento do processo curativo em geral, seu efeito se baseia na multiplicação celular, formação de fibras colágenas e elásticas, regeneração de vasos, cicatrização do tecido ósseo, repitelização do tecido lesado (RIBEIRO e ZEZELL, 2004; GALDAMES; et al., 2007; SIMÕES et al., 2009), efeito antiinflamatório, redução do edema e estimulação da função nervosa (RIBEIRO e ZEZELL, 2004).

$\mathrm{O}$ efeito produzido pela laserterapia baseia-se na capacidade de modular diversos processos metabólicos que transformam a luz do LBI em energia útil para o funcionamento celular. É observada a absorção da luz visível pelos cromóforos na cadeia 
respiratória mitocondrial, acarretando um aumento na produção de Adenosina Trifosfato (ATP) e consequentemente aumento na proliferação celular e na síntese protéica o que beneficia a reparação tecidual (KARU, 1988).

A mesma autora e colaboradores em período mais recente (2004) relataram que a ocorrência de alguns mecanismos primários de ação são resultantes da fotoexcitação de estados eletrônicos como mudança do estado redox dos componentes da cadeia respiratória, liberação de óxido nítrico do centro catalítico do citocromo e oxidase (reação redox), formação de oxigênio singleto, aquecimento transitório local de cromóforos absorvedores e aumento subsequiente da produção do ânion superóxido (geração de espécies reativas de oxigênio - ROS). Após a estimulação dos fotorreceptores, ocorre uma cascata de reações bioquímicas celulares, que não precisa de posterior ativação da luz, sendo observadas a transdução do sinal e cadeias de amplificação. É observado que uma variação buscando oxidação é associada à estimulação da vitalidade celular e uma variação buscando redução é associada à inibição. Células com pH abaixo do normal (estado redox alterado direcionado para a redução) são consideradas mais sensíveis à ação estimuladora da luz do que aquelas com parâmetro próximo ao normal.

LBI são lasers de baixa energia, sem potencial fototérmico, utilizados para biomodulação. Os mais usados estão na faixa do vermelho (632 a 780nm), com fótons de energia inferiores a 2,0 elétron-volt $(\mathrm{eV})$, com energia de ligação inferior à energia de ligação molecular e do DNA, não quebrando ligações químicas e não sendo capazes de induzir mutação e carcinogênese (CISNEROS, 2000).

França et al., (2009) realizaram estudo clínico com o objetivo de investigar os efeitos do laser na prevenção e tratamento da MO induzida em hamsters. Os animais foram divididos em quatro grupos: crioterapia preventiva, laser preventivo, laser terapêutico e grupo controle terapêutico. A MO foi induzida através de injeção intraperitoneal de 5-FU. Os procedimentos preventivos foram executados em mucosa jugal direita, sendo que a mucosa jugal esquerda não recebeu qualquer procedimento terapêutico ou preventivo. Os parâmetros para o uso do laser foram: comprimento de onda de $660 \mathrm{~nm}$, potência de $30 \mathrm{~mW}$, densidade de energia de $1,2 \mathrm{~J} / \mathrm{cm}^{2}$, tempo de 40 segundos, spot de $3 \mathrm{~mm}^{2}$. A crioterapia foi realizada com fragmentos de gelo aplicados 5 minutos antes da infusão com 5-FU e 10 minutos depois. O grupo controle não foi submetido a qualquer tratamento. Foram avaliados os graus de MO e a perda de massa corpórea. Os animais submetidos à laserterapia apresentaram uma melhor evolução clínica, cicatrização mais eficiente e maior quantidade de tecido de granulação. Os animais do grupo submetido à crioterapia perderam 
$15.16 \%$ de sua massa corpórea inicial, enquanto os animais submetidos à laserterapia perderam aproximadamente $9 \%$ nos cinco primeiros dias. A menor perda de massa corpórea apresentada pelo grupo laser foi atribuída a menor incidência de dor, menor desconforto e consequentemente melhores condições de alimentação. Os autores concluíram que o uso do LBI apresentou um efeito positivo na redução da severidade e no tratamento da $\mathrm{MO}$

Sandoval et al., (2003) executaram estudo com a finalidade de verificar a eficiência do LBI na redução da dor e na severidade da MO radio e/ou quimioinduzida. Foram avaliados 18 pacientes, entre fevereiro e julho de 2002, sendo oito pacientes do sexo feminino e dez do sexo masculino, com idade entre 4 a 82 anos, portadores de diferentes tipos de neoplasias malignas. Destes nove foram submetidos à QT, três a RT para câncer de cabeça e pescoço, cinco a RT e QT concomitante e um a QT de condicionamento para transplante de medula óssea. As aplicações de laser ocorreram diariamente, sob os seguintes parâmetros: Comprimento de onda de $660 \mathrm{~nm}$, potência de $30 \mathrm{~mW}$, densidade de energia de $2 \mathrm{~J} / \mathrm{cm}^{2}$, de forma pontual, com tempo de um minuto e seis segundos por ponto. O tempo gasto ao total de cada sessão era dependente do número e da extensão das lesões. A severidade da MO foi avaliada através de escala baseada em características clínicas e de escala para avaliação de toxicidade oral desenvolvida pelo INCA, tendo como base a capacidade de deglutição, e a dor avaliada por escala visual antes e depois de cada aplicação. Com relação aos resultados $66 \%$ dos pacientes referiram alívio imediato da dor. Com base na escala funcional a MO grau 3 foi reduzida em $42.85 \%$ dos casos, e a MO grau 4, de acordo com escala baseada em aspectos clínicos, foi reduzida em $75 \%$ dos pacientes que apresentavam esta condição no início da laserterapia. Portanto, o LBI demonstrou efeitos benéficos durante o manejo da MO, contribuindo para a melhora da qualidade de vida dos pacientes em tratamento oncológico. Não foram realizadas análises estatísticas em relação à duração e severidade da MO em decorrência da diversidade de patologias e dos respectivos métodos de tratamento.

Em estudo desenvolvido com 11 pacientes por Migliorati et al., (2001) com a finalidade de avaliar o papel da laserterapia de baixa intensidade no controle da dor associada à MO decorrente do tratamento relacionado ao transplante de medula óssea foi empregado o laser de GaAlAs (Mucolaser, MMOptics®, São Carlos, Brasil) com comprimento de onda de $780 \mathrm{~nm}, 60 \mathrm{~mW}$ de potência, densidade de energia de $2 \mathrm{~J} / \mathrm{cm}^{2}$, com sessões diárias de 35 minutos. A laserterapia deve início 5 dias antes ao transplante e continuou até o $5^{\circ}$ dia pós-transplante. A severidade da mucosite foi clinicamente avaliada 
usando-se a escala World Health Organization (WHO), enquanto a dor foi mensurada através da Escala Análoga Visual (VAS). Todos os pacientes concluíram o tratamento, e a maioria associou a laserterapia ao alívio da dor e apesar das altas doses de QT não foram constatados sangramentos e infecções.

Campos et al., (2008) realizaram estudo para avaliar a melhoria da qualidade de vida em paciente oncológica submetida à laserterapia. Paciente de 15 anos de idade, portadora de carcinoma mucoepidermóide, submetida à excisão cirúrgica e posteriormente a 35 sessões de RT. Foi constatada ao exame clínico a presença de múltiplas lesões ulceradas em cavidade bucal (Grau III de MO pela WHO). A paciente foi orientada com relação à higiene bucal e submetida à LBI durante a RT. Foi utilizado laser de diodo (MMOptics®, São Carlos, Brasil), em modo de contato, com diâmetro do spot de 0.04 $\mathrm{cm}^{2}$, comprimento de onda de $660 \mathrm{~nm}, 40 \mathrm{~mW}$ de potência e densidade de energia de $6 \mathrm{~J} / \mathrm{cm}^{2}$, sendo $0,24 \mathrm{~J}$ por ponto, durante 6 segundos por ponto em toda a cavidade oral. Adicionalmente a fim de promover um melhor efeito analgésico, foi utilizada irradiação com laser de diodo de alta intensidade (ZAP® Lasers, Pleasant Hill, CA, USA) com 1W de potência por $10 \mathrm{~s} / \mathrm{cm}$ de cada lesão, com um total de aproximadamente $10 \mathrm{~J} / \mathrm{cm}^{2}$ aplicado em todas as ulcerações, 3 vezes por semana durante 6 semanas. Após a primeira sessão de laser foi relatada diminuição da dor e da xerostomia. Melhora significativa foi observada após a quinta sessão, embora com MO grau II a paciente relatava estar livre de dor, possibilitando a reabilitação através de placa obturadora palatina. Após a $17^{\mathrm{a}}$ sessão não foram observados sinais de MO. Pode-se observar que a laserterapia contribuiu para a melhora tanto da função oral como da qualidade de vida da paciente em questão.

Nes e Posso (2005) estudaram a ação do LBI no alívio da dor decorrente de MO quimioinduzida. Foram analisados 13 pacientes adultos submetidos à QT entre o período de 15 de março a 15 de agosto em Hospital no estado de São Paulo, Brasil. O laser utilizado foi de AsGaAl (Thera Lase, DMC, Brasil), de forma pontual, com comprimento de onda de $830 \mathrm{~nm}$, potência de $250 \mathrm{~mW}$, diâmetro do spot de $0,60 \mathrm{~mm}$, energia aplicada de $35 \mathrm{~J} / \mathrm{cm}^{2}$ e duração, por sessão, de 30 minutos. Os pacientes foram submetidos à laserterapia por 5 dias consecutivos, sendo a intensidade da dor mensurada antes e após laserterapia através da escala VAS. Os resultados foram significativos e demonstraram redução de dor em $67 \%$ quando comparada à intensidade da dor antes e imediatamente após laserterapia.

Schubert et al., (2007) realizaram estudo randomizado duplo cego com a finalidade de avaliar a eficácia do LBI na prevenção da MO em 70 pacientes submetidos a 
transplante de medula óssea expostos a QT exclusiva ou a QT associada a RT, foram comparados dois comprimentos de onda, 650nm e 780nm. Os pacientes foram divididos em três grupos: laser de GaAlAs com comprimento de onda de $650 \mathrm{~nm}$ e potência de $40 \mathrm{~mW}$, laser de GaAlAs com comprimento de onda de $780 \mathrm{~nm}$ e potência de $60 \mathrm{~mW}$ e placebo. Os pacientes receberam diariamente laserterapia em mucosa labial inferior, mucosa jugal direita e esquerda, ventre e borda lateral de língua, e assoalho bucal, sendo a dose de energia dispensada de $2 \mathrm{~J} / \mathrm{cm}^{2}$. A laserterapia deve início no primeiro dia de condicionamento e foi realizada diariamente até o segundo dia após o transplante. A dor associada à MO foi mensurada nos dias $0,4,7,11,14,18$, e 21 pós-transplante. A mensuração da gravidade da MO foi realizada por clínicos em medicina oral treinados e calibrados que desconheciam a qual grupo de tratamento pertenciam os pacientes. Foram utilizadas respectivamente para mensuração da severidade e da dor da MO as escalas “Oral Mucositis Index" (OMI) e VAS. Após consolidação dos dados concluiu-se que o laser com comprimento de onda de $650 \mathrm{~nm}$, em comparação com o laser de $780 \mathrm{~nm}$, foi mais eficiente na redução da dor e da severidade da MO. O uso do laser foi bem tolerado e não foram observados efeitos adversos.

Khouri et al., (2009) realizaram estudo com pacientes submetidos à QT de altas doses e/ou RT para transplante de medula óssea com a finalidade de comparar a laserterapia ao tratamento convencional na redução da frequiência e da severidade da MO. Foram avaliados 22 pacientes, divididos randomicamente em dois grupos: Grupo I: irradiado com laser de InGaAlP com comprimento de onda de 660nm e laser de GaAlAs com comprimento de onda de $780 \mathrm{~nm}$, ambos com potência de $25 \mathrm{~mW}$, densidade de energia de $6,3 \mathrm{~J} / \mathrm{cm}^{2}, 10$ segundos por ponto em contato com a mucosa em associação ao tratamento convencional. Os dois lasers foram aplicados diariamente de forma alternada, sendo o laser de comprimento de onda $660 \mathrm{~nm}$ indicado para reparação tecidual e o laser de $780 \mathrm{~nm}$ devido ao seu maior poder de penetração indicado para analgesia. Foram irradiados vermelhão e mucosa do lábio superior e inferior, mucosa jugal direita e esquerda, assoalho bucal, borda lateral de língua direita e esquerda e ventre de língua; Grupo II: submetido apenas ao tratamento convencional, que consistia em uma solução para bochecho contento antiinflamatório (benzidamina), antifúngico (nistatina), agente anestésico (neututocaina) e água destilada. As escalas WHO e Oral Mucositis Assessment Scales (OMAS) foram utilizadas para avaliar os resultados. O grupo I apresentou menor freqüência de MO $(\mathrm{p}=0,02)$ e menor média de acordo com as escalas WHO e OMAS ( $<<0,01$ e $p=0,01$, respectivamente). A aplicação do laser reduziu a frequiência e a gravidade da MO, 
sugerindo que o mesmo pode ser usado como uma forma de prevenção e tratamento da mesma.

Simões et al., (2009) estudaram a eficácia do laser como método preventivo contra a MO radioinduzida em 39 pacientes com câncer de cabeça e pescoço, foram comparados os resultados obtidos entre laser de baixa e alta intensidade. Os pacientes foram divididos em três grupos. Grupo I: irradiados três vezes por semana com LBI; Grupo II: associação entre lasers de baixa e alta intensidade, três vezes por semana; Grupo III: pacientes irradiados com LBI uma vez por semana. O LBI utilizado foi o de InGaAlP, de forma pontual e por contato, com comprimento de onda de $660 \mathrm{~nm}$, potência de $40 \mathrm{~mW}$, densidade de energia de $6 \mathrm{~J} / \mathrm{cm}^{2}$, energia por ponto de $0,24 \mathrm{~J}$, seis segundos por ponto. $\mathrm{O}$ laser de alta intensidade foi o de GaAlAs com comprimento de onda de $808 \mathrm{~nm}$, potência de 1W. Esta terapia foi utilizada somente nos pacientes que apresentaram ulcerações já na primeira visita. As irradiações foram perpendiculares à superfície da mucosa oral de um modo desfocado em uma distância de $1 \mathrm{~cm}$ da lesão, cada lesão foi irradiada por 10 segundos (5 segundos com movimentos horizontais e cinco com movimentos verticais) com densidade de energia de $10 \mathrm{~J} / \mathrm{cm}^{2}$. Todos os protocolos de laserterapia acarretaram à manutenção dos escores de mucosite oral no mesmo nível até a última sessão RT. Os pacientes submetidos laserterapia três vezes por semana mantiveram os níveis de dor. No entanto, os pacientes submetidos a laserterapia uma vez por semana relataram aumento significativo da intensidade da dor, a associação entre de baixa / alta intensidade resultou em aumento do tempo de cicatrização. Para os autores o LBI se destaca em consequiência de seus efeitos analgésicos e biomoduladores, destacando-se ainda pelo fato de não ser invasiva.

Segundo Biron et al., (2000) o uso do LBI de hélio-neônio é um procedimento promissor, sendo largamente demonstrado que a laserterapia retarda o início, diminui a severidade, encurta a duração da MO especialmente nos pacientes submetidos a transplante de medula óssea. Entretanto as aplicações curativas do laser aparentam ser menos efetivas do que seu uso profilático. Aparentemente a técnica deve ser melhorada para atingir a precisão em seu mecanismo de ação, tornando possível a elaboração de planos de tratamento específicos para as diferentes regiões da mucosa bucal.

Para Bensadoun et al., (2001) e Schubert et al., (2007) devido às diferenças significativas entre a metodologia de diferentes estudos, infelizmente não é possível determinar qual a forma de laserterapia com LBI irá proporcionar o melhor resultado na prevenção e/ou tratamento da MO radio e/ou quimioinduzida. Entretanto apesar das 
diferentes metodologias empregadas em diferentes estudos foi observado redução da morbidade nos pacientes tratados com laser quando comparados com os pacientes controle com conseqüente melhora da qualidade de vida (RAMPINI et al ., 2009). 


\section{4 - CASUÍSTICA E MÉTOdOS}

\section{1 - Casuística}

\subsection{1 Ética em pesquisa com seres humanos}

Este estudo foi aprovado pelo Comitê de Ética em Pesquisa com seres humanos da Fundação de Medicina Tropical do Tocantins, filiada ao Conselho Nacional de Pesquisa em Seres Humanos (CONEP), conforme protocolo no 212/2009/CEP (APÊNDICE - A). Foram obtidas autorização e aprovação do Conselho através de carta específica, sendo que os voluntários assinaram termo de consentimento livre esclarecido com orientações sobre a pesquisa.

\subsubsection{Coleta de dados}

O primeiro contato com o paciente se deu através de entrevista realizada no momento da primeira consulta ao cirurgião-dentista, quando lhe foi explicado o tipo de pesquisa a ser desenvolvida e apresentado o termo de livre consentimento esclarecido. A coleta de dados foi realizada na primeira consulta odontológica, antes do início da radioterapia, através de instrumentos específicos de avaliação (fichas clínicas e questionários) os quais forneceram as informações relevantes para este estudo (APÊNDICE - B e C).

\subsubsection{Tipo de estudo}

Estudo clínico prospectivo e randomizado com coleta de dados primários através da qual se procurou entender a realidade estudada. O estudo clínico foi realizado por um único examinador, sendo ele o próprio pesquisador. 


\subsubsection{Local e infraestrutura}

O estudo foi desenvolvido durante maio de 2009 e outubro de 2010 no Serviço de Prevenção e Diagnóstico do Câncer Bucal localizado no Centro de Alta Complexidade do Hospital Regional de Araguaína - Dr. Iderval da Silva Sobrinho, anexo ao serviço de Radioterapia do respectivo Hospital. O serviço em questão conta com sala equipada com consultório odontológico completo (FIG. 4.1) (Cadeira odontológica, dois mochos, equipo, autoclave, dois equipamentos de laser Photon Lase III / DMC, amalgamador, fotopolimerizador, eletrocautério, jato profilático, instrumental e material de consumo para tratamento cirúrgico, periodontal e restaurador).

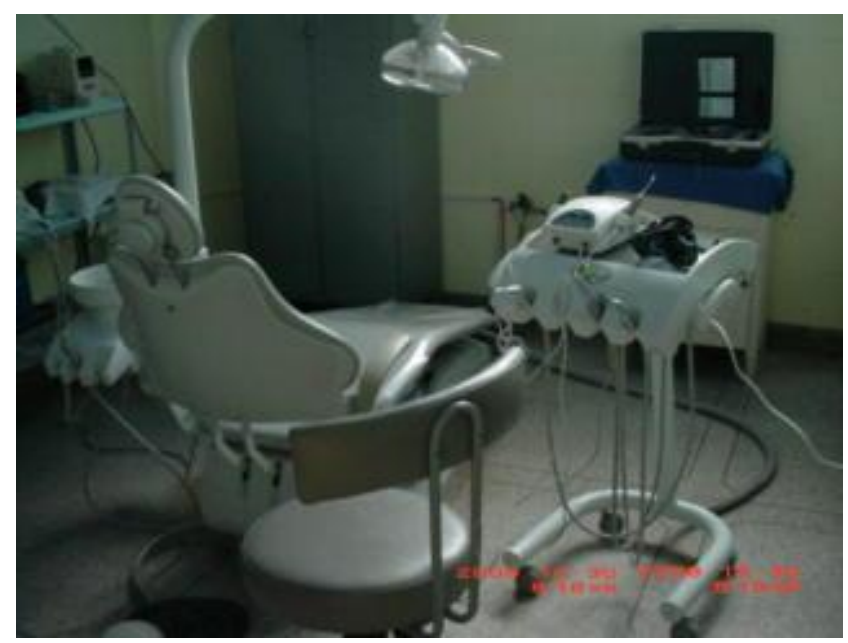

FIGURA 4.1- Consultório

\subsubsection{População e critérios de inclusão e exclusão}

O estudo foi realizado em um grupo de pacientes voluntários, de ambos os sexos, com idade superior a 21 anos, portadores de câncer de cabeça e pescoço e não submetidos à radioterapia prévia na região de interesse. $\mathrm{O}$ tratamento padrão para os pacientes portadores de câncer de cabeça e pescoço do Centro de Alta Complexidade do Hospital Regional de Araguaína consiste em cirurgia e/ou radioterapia exclusiva ou em associação com quimioterapia. As doses de radioterapia foram prescritas após planejamento específico para cada paciente, cujo campo de irradiação envolvia a cavidade bucal e/ou o complexo maxilo-mandibular (dose total: 6000 - 8000cGy / dose diária fracionada: 180 - 200cGy). A radioterapia foi realizada diariamente com o uso de acelerador linear Primus Mid (Siemens), com fótons com 6MeV de energia. Os campos utilizados foram o cérvico-facial direito e esquerdo e o das fossas supraclaviculares. 
Quando necessário as drogas quimioterápicas utilizadas em associação ao tratamento radioterápico consistiram em cisplatina e/ou 5 fluorouracil em dois protocolos pré-estabelecidos selecionados de acordo com a necessidade de cada paciente:

\section{- Protocolo I}

Cisplatina $80 \mathrm{mg} / \mathrm{m}^{2}$ associada a 5-Fluorouracil $1000 \mathrm{mg} / \mathrm{m}^{2}$

Endovenoso em infusão, 28/28 dias.

\section{- Protocolo II}

Cisplatina $40 \mathrm{mg} / \mathrm{m}^{2}$ semanal durante o tratamento radioterápico.

Os pacientes foram incluídos nos grupos de estudo conforme critérios préestabelecidos e foram randomizados de acordo com a ordem de adesão dos mesmos ao estudo constituindo 3 grupos:

- Grupo 1 (Controle) - Constituído por 11 pacientes que receberam orientações e tratamento medicamentoso para a prevenção e tratamento da mucosite oral, antes do início e durante toda RT. As orientações e tratamento medicamentoso consistiram em orientação de higiene bucal e dieta, uso de antifúngicos, antiinflamatórios, antibióticos e analgésicos (TAB. 4.1)

- Grupo 2 - Constituído por 9 pacientes que receberam orientações e tratamento medicamentoso (TAB 4.1), para a prevenção e tratamento da mucosite oral, antes do início e durante toda RT, sendo submetidos à laserterapia diária, a partir do início da ulceração referente à mucosite (grau 2) até o final do tratamento radioterápico, com sua execução vinculada às sessões de RT.

- Grupo 3 - Constituído por 11 pacientes que receberam orientações e tratamento medicamentoso (TAB 4.1) antes do início e durante toda RT e laserterapia diária, a ser iniciada imediatamente antes do início da radioterapia, sendo a mesma empregada até o final do tratamento radioterápico, com sua execução vinculada às sessões de RT.

Foram fatores de elegibilidade o comprimento total das seguintes etapas: tratamento odontológico antes do início da radioterapia, acompanhamento diário, de acordo com as sessões de RT, para os pacientes do grupo 1, 2 e 3 e avaliação oral dos pacientes após o término do tratamento oncológico. 


\subsection{Métodos}

\subsubsection{Avaliação da condição bucal}

No período que antecedeu a radioterapia os pacientes foram submetidos a uma criteriosa avaliação e posterior tratamento odontológico gratuito que consistiu em: anamnese, exame físico intra e extra-oral, exame radiográfico (radiografia panorâmica), plano de tratamento e preparo odontológico pré-tratamento oncológico e orientações básicas a respeito de sua saúde oral (APÊNDICE - D).

O preparo odontológico pré-tratamento oncológico consistiu em: orientação do paciente com relação à higiene oral e ao uso de prótese (Dib e Curi, 2002; Cardoso et al., 2005), exodontia de dentes com prognóstico duvidoso ou ruim (Nguyen, 1992; Migliorati e Migliorati, 2000), eliminação da placa e cálculo e estabilização da doença periodontal (Migliorati e Migliorati, 2000), tratamento restaurador dos dentes cariados e fraturados (Nguyen, 1992; Migliorati e Migliorati, 2000), instituição de medidas de higiene oral como escovação com creme dental fluoretado após as refeições (Sonis et al., 1996; Cardoso et al., 2005; Barasch e Coke, 2007) e enxágües com solução antibacteriana e antifúngicas (Dib e Curi, 2002).

\subsubsection{Parâmetros de irradiação}

O equipamento utilizado foi o Photon lase III, DMC Equipamentos, São Carlos, São Paulo, Brasil, cujos parâmetros empregados para este estudo clínico foram: comprimento de onda de $660 \mathrm{~nm}$, vermelho, potência de $100 \mathrm{~mW}$, meio ativo InGaAlP, frequiência de modo contínuo, modo de aplicação pontual, energia de $2 \mathrm{~J}$ por ponto (GenotKlastersky et al., 2008). O laser era aplicado uma vez ao dia, 5 dias por semana pontualmente e perpendicularmente ao tecido. A ponteira era desinfetada com álcool $70 \%$ e envolvida em filme plástico. Os pacientes assim como o operador usaram óculos para proteção. Foram irradiados 30 pontos fixos independente de a área estar ulcerada, e a distância entre os pontos era de aproximadamente $1 \mathrm{~cm}$. As aplicações ocorreram diariamente em mucosa labial inferior (3 pontos), mucosa labial superior ( 3 pontos), lado direito e esquerdo da mucosa jugal (5 pontos), ventre ( 2 pontos), dorso, borda lateral de língua e assoalho bucal (3 pontos) (FIG. 4.2), tempo utilizado de 20s por ponto e tempo total por sessão de aproximadamente 13 minutos. Caso o ponto de aplicação a ser irradiado estivesse a menos de $1 \mathrm{~cm}$ da área tumoral a laserterapia não era realizada neste local (Bensadoun et al.,1999). 

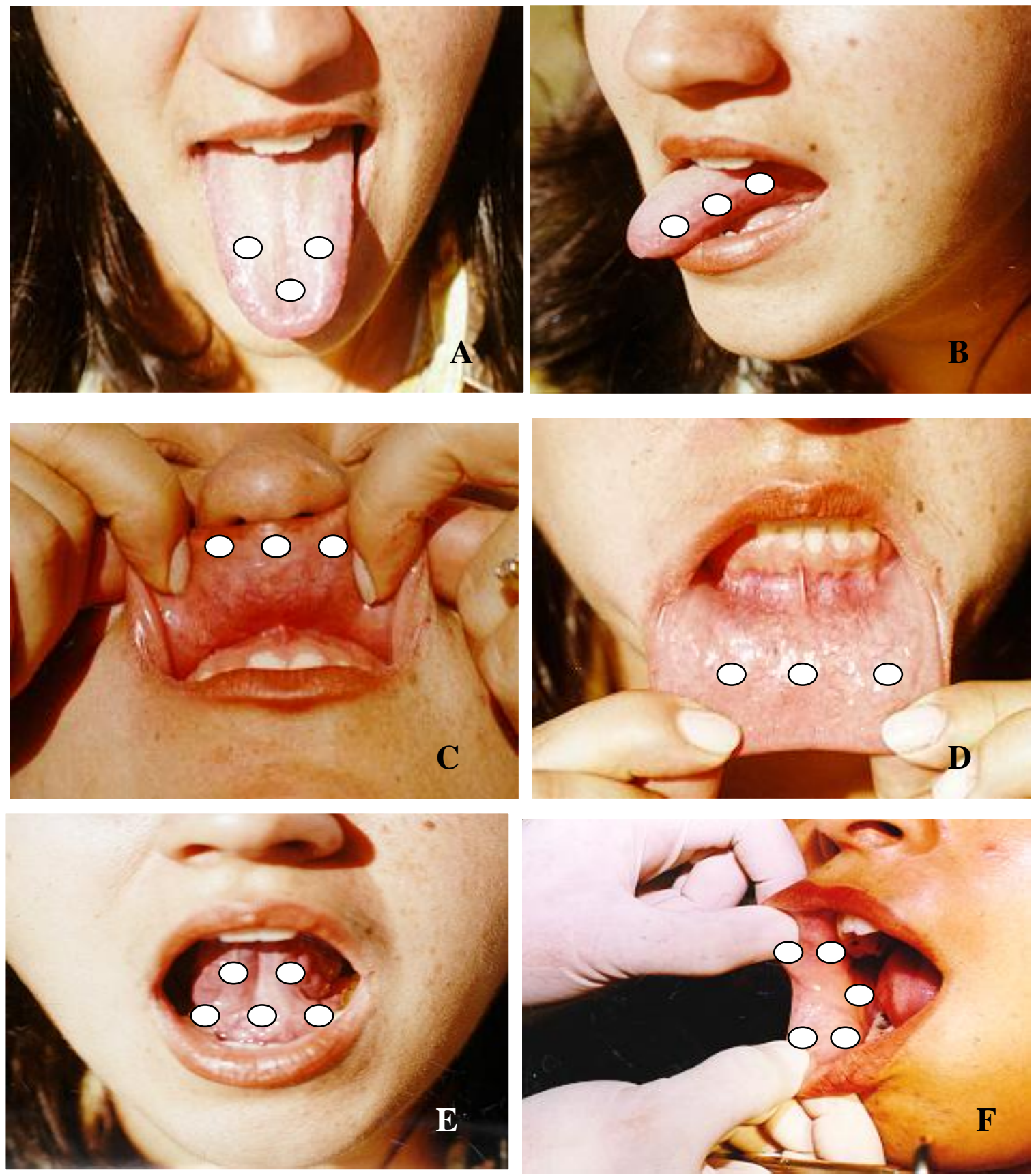

FIGURA 4.2 - Pontos a serem irradiados com LBI: A - Dorso de língua; B - Borda lateral de língua; C - Mucosa labial superior; D - Mucosa labial inferior; $E$ - ventre de língua e assoalho de boca; F - Mucosa jugal

\subsubsection{Tratamento medicamentoso}

As condutas medicamentosas adotadas no tratamento da mucosite oral radio e quimioinduzidas foram pautadas literatura especializada, experiência clínica e em resultados de protocolos de pesquisa desenvolvidos em várias instituições especializadas. Consistem em um conjunto de medidas profiláticas e terapêuticas para a abordagem dos efeitos adversos agudos radioinduzidos. Podem ser aplicadas de forma isolada ou em 
associação, além de ajustadas de acordo com necessidades individuais dos pacientes. A medicação instituída deve ser mantida até o término do tratamento radioterápico ou enquanto persistirem os quadros sintomatológicos relacionados às complicações orais agudas decorrentes do tratamento oncológico (APÊNDICE - D ).

A abordagem medicamentosa preventiva e terapêutica utilizada neste estudo clínico para o tratamento da mucosite oral induzida pelo tratamento oncológico para câncer de cabeça e pescoço segue citado abaixo (TAB. 4.1):

TABELA 4.1 - Medicamentos utilizados para a prevenção e tratamento da mucosite oral nos pacientes submetidos a tratamento para câncer de cabeça e pescoço no Centro de Alta Complexidade do Hospital Regional de Araguaína

\begin{tabular}{|c|c|c|}
\hline Medicamentos & Posologia & Abordagem \\
\hline $\begin{array}{l}\text { Nistatina suspensão oral } \\
\text { 100.000UI }\end{array}$ & Bochechos 4x/dia & A partir da radioterapia \\
\hline Hidróxido de alumínio & Bochechos 2 a 4x/dia & A partir da radioterapia \\
\hline Soro fisiológico $0,9 \%$ & Bochechos 4x/dia & A partir da radioterapia \\
\hline Protetor labial* & $\begin{array}{l}\text { Usar quando necessário } \\
\text { (Ressecamento labial) }\end{array}$ & A partir da radioterapia \\
\hline Sucralfato** & $\begin{array}{l}\text { Bochechar e engolir um } \\
\text { frasconete antes } \\
\text { principais refeições }\end{array}$ & $\begin{array}{l}\text { A partir do quadro de } \\
\text { odinofagia }\end{array}$ \\
\hline Dexametasona elixir** & Bochechar 4x/dia & $\begin{array}{l}\text { A partir da ulceração e } \\
\text { inflamação da mucosa }\end{array}$ \\
\hline Clorexidina $0,12 \%$ sem álcool & Bochechar 2x/dia & $\begin{array}{l}\text { Para pacientes com feridas } \\
\text { cirúrgicas,lesões infectadas, } \\
\text { pós-exodontias e para } \\
\text { prevenção da cárie e controle } \\
\text { de placa bacteriana }\end{array}$ \\
\hline
\end{tabular}




\subsubsection{Avaliação da mucosite oral}

Foi realizada diariamente, sendo o grau de mucosite classificado conforme tabela de avaliação baseada no grau de mucosite oral de acordo com a toxicidade oral segundo a Organização Mundial de Saúde (OMS) (FIG. 4.3).

\begin{tabular}{|c|c|c|c|c|c|}
\hline \multicolumn{6}{|c|}{ GRAUS DE MUCOSITE } \\
\hline Escala & 0 & 1 & 2 & 3 & 4 \\
\hline $\begin{array}{l}\text { Toxicidade } \\
\text { oral (OMS) }\end{array}$ & Nenhuma & $\begin{array}{l}\text { Sensibilidade e } \\
\text { eritema }\end{array}$ & $\begin{array}{l}\text { Eritema, } \\
\text { úlcera, } \\
\text { pode } \\
\text { deglutir } \\
\text { alimentos } \\
\text { sólidos }\end{array}$ & $\begin{array}{l}\text { Úlcera, } \\
\text { eritema } \\
\text { extenso, } \\
\text { não pode } \\
\text { deglutir } \\
\text { dieta } \\
\text { sólida }\end{array}$ & $\begin{array}{l}\text { Úlcera, } \\
\text { mucosite } \\
\text { extensa, não } \\
\text { é possível } \\
\text { deglutição }\end{array}$ \\
\hline
\end{tabular}

FIGURA 4.3 - Grau de mucosite oral de acordo com a toxicidade oral (OMS).

\subsubsection{Avaliação da dor em mucosa}

A avaliação da dor provocada pela mucosite oral decorrente do tratamento oncológico foi realizada conforme escala de Faces Wong- Baker (FIG. 4.4), com a qual o paciente foi solicitado a fazer uma auto-avaliação diária da intensidade da dor imediatamente antes da avaliação oral e/ou da laserterapia, sendo a mesma registrada em ficha de registro da disfunção oral e dor (APÊNDICE - E). Os dados obtidos foram avaliados estatisticamente em seguida.

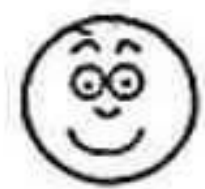

0

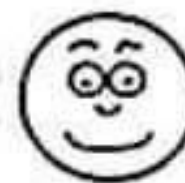

2

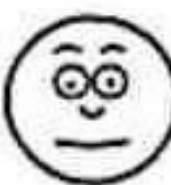

4

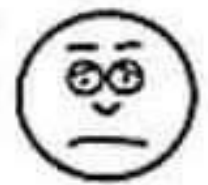

6

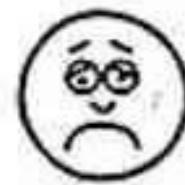

8

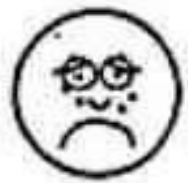

10

FIGURA 4.4 - Escala de Faces Wong-Baker utilizada para avaliação da dor. Classificação da dor: 0 - sem dor; 2 e 4 - dor leve; 6 - dor moderada; 8 - dor intensa; 10 - dor insuportável.

\subsubsection{Avaliação da perda de massa corpórea}

Realizada diariamente através da pesagem dos pacientes em balança específica para este fim, sendo a massa corpórea anotada em ficha clínica (APÊNDICE - E) e ao término do tratamento, após a obtenção da média de massa perdida em quilos por grupo, os dados obtidos foram avaliados estatisticamente. 


\subsubsection{Análise estatística}

Foram realizadas comparações entre três protocolos empregados para a prevenção e tratamento da mucosite oral induzida por tratamento oncológico em pacientes portadores de câncer em cabeça e pescoço, identificando qual a freqüência, severidade e escore de dor da mucosite oral, assim como a necessidade de uso de sonda nasogástrica, internação e interrupção do tratamento em consequência da mesma.

Para observações descritivas foi utilizado o delineamento inteiramente casualizado, com emprego no estudo de dispersão de freqüência através do índice de Quiquadrado $\left(\mathrm{X}^{2}\right)$, análise de variância de Kruskal-Wallis utilizando teste de comparação múltipla de Dunn's para variáveis não paramétricas, enquanto que para variáveis paramétricas utilizou-se análise de variância “one way" empregando para a comparação múltipla entre grupos teste de Bonferrone. Foi utilizado para realização destes cálculos estatísticos o software Prism ${ }^{\circledR} 5$ for Windons (Graph Pad Software, Inc). Os resultados foram considerados significantes quando $\mathrm{p}<0,05$. 


\section{5 - RESULTADOS}

\subsection{Descrição da amostra}

Com relação aos dados demográficos dos 31 participantes deste estudo foi observado que 77,5\% (24/31) pertencem ao gênero masculino. A idade variou entre 28 a 83 anos (média de idade de 55,5 anos). No que diz respeito à faixa etária 74,2\% (23/31) dos pacientes apresentavam mais de 51 anos. Quanto ao nível de escolaridade observou-se que 90,4\% (28/31) dos indivíduos apresentavam baixa escolaridade ou eram analfabetos. Com relação a atividade profissional 25,8\% (8/31) eram aposentados, 29\% (9/31) lavradores e $32,2 \%(10 / 31)$ exerciam outras atividades tipicamente urbanas. As mulheres apresentavam uma menor diversidade de ocupações, estando ligadas basicamente ao trabalho doméstico (13\%). A maioria dos pacientes era procedente de áreas urbanas (TAB. 5.1).

TABELA 5.1 - Distribuição em número e porcentagem dos pacientes segundo gênero, idade, grau de escolaridade, profissão e procedência $(n=31)$

\begin{tabular}{lcc}
\hline Gênero & Número & Porcentagem \\
\hline Masculino & 24 & $77,5 \%$ \\
Feminino & 07 & $22,5 \%$ \\
\hline Idade & 08 & $25,8 \%$ \\
\hline Menor que 50 & 23 & $74,2 \%$ \\
Maior que 51 & & \\
\hline Grau de escolaridade & & $22,5 \%$ \\
& 07 & $67,9 \%$ \\
\hline Analfabetos & 21 & $6,4 \%$ \\
Ensino fundamental & 02 & $3,2 \%$ \\
Ensino médio & 01 & \\
Ensino superior & & $77,5 \%$ \\
\hline Procedência & & $22,5 \%$ \\
& 24 & \\
\hline Urbana & 07 & $25,8 \%$ \\
Rural & & $29 \%$ \\
\hline Profissão & & $13 \%$ \\
\hline Aposentados & 08 & $32,2 \%$ \\
Lavradores & 09 & \\
Do lar & 04 & \\
Outros & 10 & \\
\hline
\end{tabular}


Foram analisados os dados referentes ao câncer, seu tratamento e a frequência e severidade de MO em 31 pacientes portadores de câncer em cabeça e pescoço submetidos à RT exclusiva ou associada à QT adjuvante e/ou a procedimento cirúrgico, sendo os três grupos de estudo constituidos respectivamente por 11, 9 e 11 pacientes (TAB. 5.2).

TABELA 5.2 - Distribuição dos pacientes dos grupos 1, 2 e 3: dados associados ao câncer de cabeça e pescoço, aos seus tratamentos, ocorrência e grau máximo de mucosite oral (CR-Cirurgia, RT - Radioterapia e QT - quimioterapia)

GRUPO 1

\begin{tabular}{|c|c|c|c|c|c|c|}
\hline $\mathbf{N}^{\mathbf{o}}$ & Localização & Tipo histológico & Estadiamento & Tratamento & M. oral & $\begin{array}{c}\text { Gr.máx. } \\
\text { MO }\end{array}$ \\
\hline 1 & Nasofaringe & Carc. linfoepitelioma & IV & RT e QT & SIM & 2 \\
\hline 2 & Língua & Carc. epidermóide & IV & CR, RT e QT & SIM & 4 \\
\hline 3 & Laringe & Carc. epidermóide & IV & CR, RTe QT & NÃO & 0 \\
\hline 4 & Palato duro & Carc. Adenóide cistico & IV & CR, RT e QT & SIM & 2 \\
\hline 5 & Lábio superior & Carc. epidermóide & IV & RT & SIM & 3 \\
\hline 6 & Laringe & Carc. epidermóide & IV & RT e QT & SIM & 2 \\
\hline 7 & Ass. bucal & Carc. epidermóide & IV & CR, RT e QT & SIM & 4 \\
\hline 8 & Língua & Carc. epidermóide & IV & CR, RT e QT & SIM & 4 \\
\hline 9 & P. amigdaliano & Carc. epidermóide & IV & RT e QT & SIM & 3 \\
\hline 10 & Parótida & Carc. epidermóide & IV & CR, RT e QT & SIM & 1 \\
\hline $\begin{array}{r}11 \\
\text { GRI } \\
\end{array}$ & PO $2^{\text {Parótida }}$ & Adenocarcinoma & II & CR e RT & SIM & 1 \\
\hline $\mathbf{N}^{\mathbf{o}}$ & Localização & Tipo histológico & Estadiamento & Tratamento & M. oral & $\begin{array}{l}\text { Gr.máx } \\
\text { MO }\end{array}$ \\
\hline 1 & Lábio inferior & Carc. epidermóide & III & CR e RT & SIM & 2 \\
\hline 2 & Língua & Carc. epidermóide & III & CR, RT e QT & SIM & 4 \\
\hline 3 & Pi amigdaliano & Carc. epidermóide & IV & RT e QT & SIM & 2 \\
\hline 4 & Ass. bucal & Carc. epidermóide & IV & CR, RT e QT & SIM & 4 \\
\hline 5 & Prega vocal & Carc. epidermóide & IV & RT e QT & SIM & 2 \\
\hline 6 & L. amigdaliana & Carc. epidermóide & IV & CR, RT e QT & SIM & 2 \\
\hline
\end{tabular}


TABELA 5.2 - Distribuição dos pacientes dos grupos 1, 2 e 3: dados associados ao câncer de cabeça e pescoço, aos seus tratamentos, ocorrência e grau máximo de mucosite oral (CR-Cirurgia, RT - Radioterapia e QT - quimioterapia)

\begin{tabular}{|c|c|c|c|c|c|c|}
\hline 7 & Pescoço & Sarc. de partes moles & III & CR e RT & SIM & 3 \\
\hline$* 8$ & Orofaringe & Carc. epidermóide & IV & RT e QT & SIM & 1 \\
\hline 9 & Gl. submandib & Carc. epidermóide & III & CR e RT & SIM & 3 \\
\hline \multicolumn{7}{|c|}{ GRUPO 3} \\
\hline $\mathbf{N}^{\circ}$ & Localização & Tipo histológico & Estadiamento & Tratamento & M. oral & $\begin{array}{l}\text { Gr.max. } \\
\text { MO }\end{array}$ \\
\hline 1 & Laringe & Carc. epidermóide & II & $\mathrm{RT}$ & NÃO & 0 \\
\hline 2 & Laringe & Carc. epidermóide & III & CR, RT e QT & NÃO & 0 \\
\hline 3 & Laringe & Carc. epidermóide & IV & CR, RT e QT & NÃO & 0 \\
\hline 4 & Laringe & Carc. epidermóide & IV & CR, RT e QT & SIM & 1 \\
\hline 5 & Parótida & Carc. Adenóide cístico & III & CR e RT & SIM & 2 \\
\hline 6 & Língua & Carc. epidermóide & IV & RT e QT & SIM & 4 \\
\hline 7 & Pescoço & Carc. epidermóide & Não se aplica & RT e QT & NÃO & 0 \\
\hline 8 & Língua & Carc. epidermóide & III & CR, RT e QT & SIM & 3 \\
\hline 9 & Língua & Carc. epidermóide & III & RT e QT & SIM & 1 \\
\hline 10 & Laringe & Carc. epidermóide & IV & CR, RT e QT & SIM & 1 \\
\hline 11 & Laringe & Carc. epidermóide & IV & RT e QT & SIM & 2 \\
\hline
\end{tabular}

$\mathrm{Na}$ análise dos dados, referentes ao câncer de cabeça e pescoço, foi observado que 83,8\% (26/31) dos pacientes eram portadores de carcinoma epidermóide. As localizações mais freqüentes dos tumores primários foram 45,2\% (14/31) em cavidade oral, com destaque para língua com um total de 19,6\% (6/31) dos casos, e 25,8\% (8/31) em laringe (TAB. 5.3).

Quanto ao estadiamento 64,5\% (20/31) dos pacientes apresentavam doença em estádio IV (FIG. 5.1), 25,8\% (8/31) em estádio III, 6,4\% (2/31) em estádio II e em 3,2\% (1/31) o estadiamento não se aplicava. Dos 28 pacientes estadiados clinicamente com doença avançada (estadiamento III e IV) 96,4\% (27/28) foram submetidos a tratamentos associados. O único paciente em estadiamento IV submetido a RT exclusiva como forma de tratamento, assim o foi em consequência da irresecabilidade da lesão e de suas 
condições gerais de saúde que contraindicavam a realização de QT adjuvante (TAB 5.2 e 5.3).
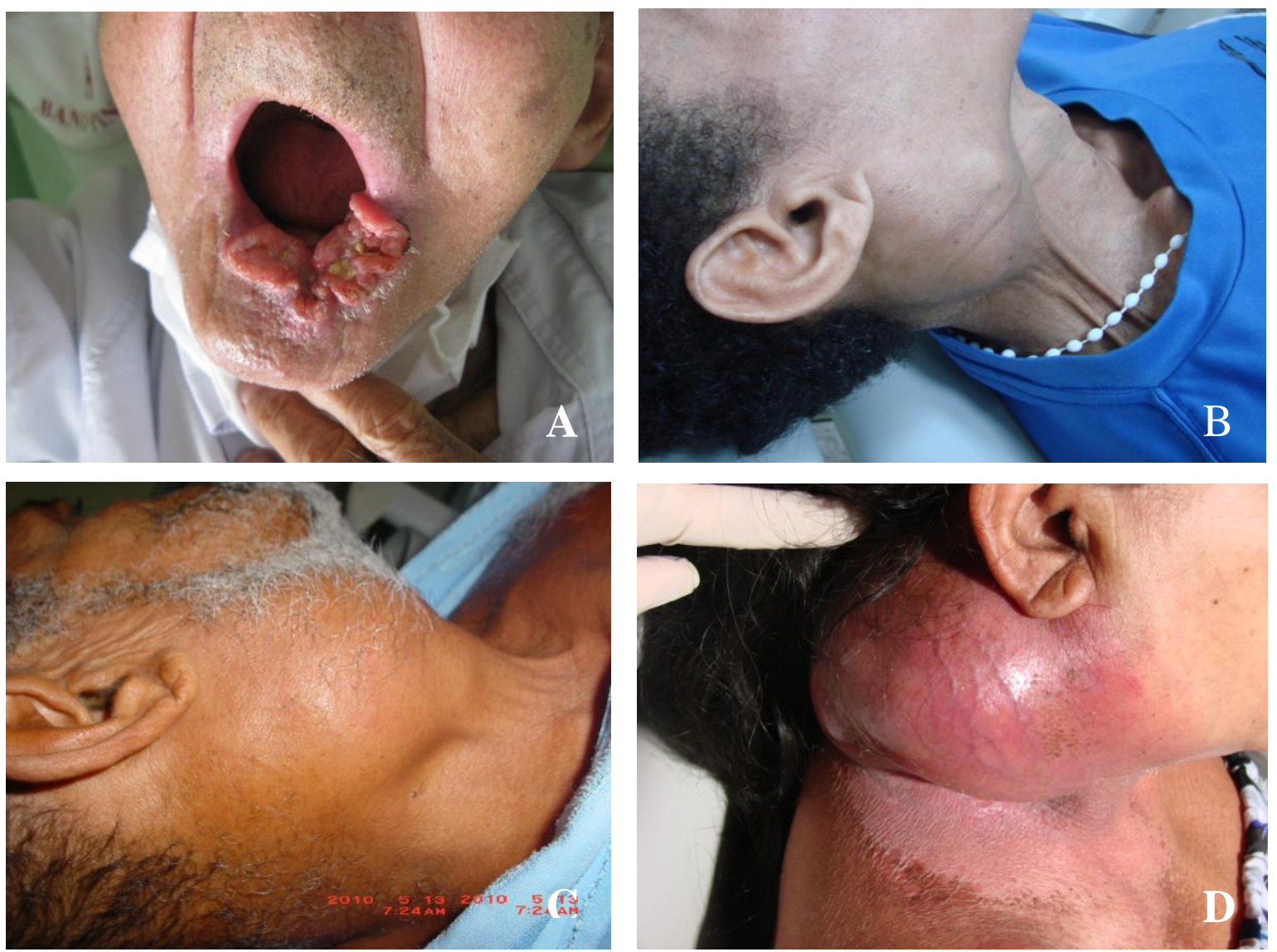

FIGURA 5.1 - Pacientes de diferentes grupos de estudo apresentando estadiamento III (A) e IV (B, C e D). Caracterizados respectivamente por tumorações com infiltração em tecidos adjacentes e/ou presença de metástases regionais significativas e/ou metástases à distância

No que diz respeito aos métodos de tratamento oncológico oferecidos aos participantes deste estudo 6,4\% (2/31) foram submetidos exclusivamente a RT, 32,2\% (10/31) a RT e QT, 45,2\% (14/31) a CR, RT e QT e 16,1\% (5/31) a RT e CR (TAB. 5.3).

Do total de pacientes 77,4\% (24/31) foram submetidos à RT e QT adjuvante independente de serem submetidos ou não a CR (TAB. 5.3). Dos pacientes submetidos a QT adjuvante 12,5\% (3/24) foram submetidos a esquema quimioterápico constituído por quatro a cinco dias de infusão contínua de 5-FU in bolus com cisplatina em ambiente hospitalar e $87,5 \%(21 / 24)$ a cisplatina $40 \mathrm{mg} / \mathrm{m}^{2}$ semanal durante o tratamento radioterápico (TAB. 5.4). 
TABELA 5.3 - Número e porcentagem de pacientes segundo tipo histológico, localização, estadiamento do câncer e tratamento $(n=31)$

\begin{tabular}{|c|c|c|}
\hline Tipo Histológico & Número & Percentagem \\
\hline Carcinoma epidermóide & 26 & $83,8 \%$ \\
\hline Carcinoma adenóide cístico & 02 & $6,4 \%$ \\
\hline Sarcoma de partes moles & 01 & $3,2 \%$ \\
\hline Carc. linfoepitelioma & 01 & $3,2 \%$ \\
\hline Adenocarcinoma & 01 & $3,2 \%$ \\
\hline \multicolumn{3}{|l|}{ Tumor primário } \\
\hline Cavidade oral & 14 & $45,2 \%$ \\
\hline Gl. Salivares maiores & 04 & $12,9 \%$ \\
\hline Laringe & 08 & $25,8 \%$ \\
\hline Faringe & 02 & $6,4 \%$ \\
\hline Pescoço & 02 & $6,4 \%$ \\
\hline Prega vocal & 01 & $3,2 \%$ \\
\hline \multicolumn{3}{|l|}{ Estadiamento } \\
\hline Não se aplica & 01 & $3,2 \%$ \\
\hline I & --- & --- \\
\hline II & 02 & $6,4 \%$ \\
\hline III & 08 & $25,8 \%$ \\
\hline IV & 20 & $64,5 \%$ \\
\hline \multicolumn{3}{|l|}{ Tratamento } \\
\hline RT & 02 & $6,4 \%$ \\
\hline CR e RT & 05 & $16,1 \%$ \\
\hline RT e QT & 10 & $32,2 \%$ \\
\hline CR, RT e QT & 14 & $45.2 \%$ \\
\hline
\end{tabular}


TABELA 5.4 - Distribuição por grupos do número e porcentagem de pacientes segundo tratamento quimioterápico a que foram submetidos

\begin{tabular}{c|c|c|c|c}
\hline \multirow{2}{*}{ Grupos } & \multirow{2}{*}{$\mathbf{N}^{\mathbf{0}}$ de pacientes } & $\begin{array}{c}\text { Submetidos à } \\
\text { quimioterapia }\end{array}$ & Cisplatina & Cisplatina+5 FU \\
\cline { 4 - 5 } & & $9(82 \%)$ & $7(77,7 \%)$ & $2(22,2 \%)$ \\
\hline Grupo 1 & $11(100 \%)$ & $6(66,6 \%)$ & $5(83,3 \%)$ & $1(16,6 \%)$ \\
\hline Grupo 2 & $9(100 \%)$ & $9(82 \%)$ & $9(100 \%)$ & $0(0 \%)$ \\
\hline Total & $31(100 \%)$ & $24(77,4 \%)$ & $21(87,5 \%)$ & $3(12,5 \%)$ \\
\hline
\end{tabular}

Dos pacientes participantes deste estudo 61,2\% (19/31) eram tabagistas, $25,8 \%$ (8/31) ex-tabagistas e 13\% (4/31) nunca haviam fumado. Com relação ao consumo de álcool 61,2\% (19/31) pacientes eram etilistas, 19,4\% (6/31) ex-etilistas e 19,4\% (6/31) negaram o consumo de bebida alcoólica. Neste estudo clínico foram considerados extabagistas e ex-etilistas aqueles pacientes que haviam abandonado o vício há mais de dois anos. Tal conduta também foi adotada por Abdo et al. (2002). Do total de pacientes 45,2\% (14/31) associavam o consumo de tabaco e álcool antes do diagnóstico (TAB. 5.5). Todos os pacientes foram orientados, a partir do momento do diagnóstico, a suspender tais hábitos.

TABELA 5.5 - Número e porcentagem de pacientes segundo hábitos associados ao desenvolvimento de câncer em cabeça e pescoço

Hábitos associados à genese do câncer de cabeça e pescoço

\begin{tabular}{l|c|c}
\hline Fumantes & 19 & $61,2 \%$ \\
\hline Ex-fumantes & 08 & $25,8 \%$ \\
\hline Nunca fumaram & 04 & $13 \%$ \\
\hline Etilistas & 19 & $61,2 \%$ \\
\hline Ex-etilistas & 06 & $19,4 \%$ \\
\hline Nunca beberam & 06 & $19,4 \%$ \\
\hline Fumantes e etilistas & 14 & $45,2 \%$ \\
\hline
\end{tabular}


Entre os efeitos colaterais agudos comuns ao tratamento para o câncer de cabeça e pescoço os manifestados com maior frequência pelos pacientes deste estudo clínico foram xerostomia (diminuição ou cessação do fluxo salivar) em 96,7\% (30/31), disgeusia (distúrbios de paladar) em 90,3\% (28/31), odinofagia (dor ao deglutir) em 90,3\% (28/31), mucosite oral em 83,8\% (26/31), e candidíase em 22,5\% (7/31) (FIG. 5.2).
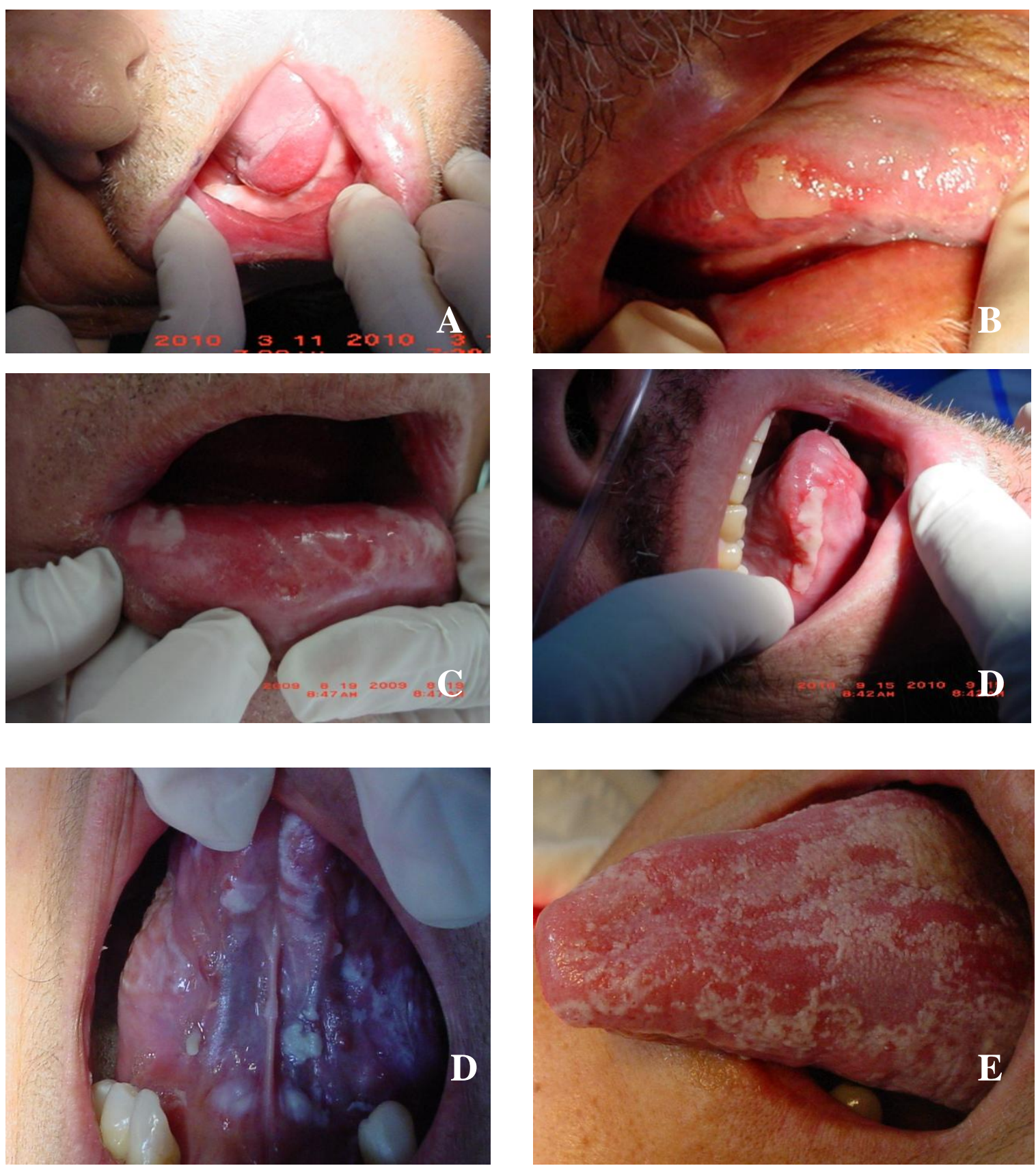

FIGURA 5.2 - Apresentações clínicas de complicações decorrentes do tratamento oncológico- mucosite oral: A - Grau 1; B - Grau 2; C - Grau 3; D Grau 4; E e F - Candidíase pseudomembranosa em ventre, dorso e borda lateral de língua 


\subsection{Ocorrências de mucosite oral}

Neste estudo clínico foram analisados um total de 31 pacientes, sendo que 83,8\% (26/31) desenvolveram algum grau de MO. Assim, dos pacientes do grupo 1, 90,9\% (10/11) desenvolveram algum grau de MO. Para o grupo 2, 100\% (9/9) desenvolveram algum grau de MO, porém um dos pacientes apresentou apenas MO grau 1, não sendo submetido a laserterapia conforme o protocolo pré-estabelecido, assim seus dados foram excluidos da análise estatística de comparação. Para os 11 pacientes que integravam o grupo 3, 66,7\% (7/11) apresentaram algum grau MO. Não houve diferença estatisticamente significante com relação à ocorrência de MO quando comparado o número de pacientes dos 3 grupos de estudo (Kruskal-Wallis p=0,0711).

Entretanto, quando analisada a ocorrência de MO por pacientes durante as sessões de tratamento, verificou-se a existência de significância estatística e a presença de diferenças entre os grupos de estudo. Demomstrando que o grupo 3 é estatisticamente diferente do grupo 1 e 2, e que os grupos 1 e 2 são estatisticamente iguais (TAB. 5.6).

TABELA 5.6 - Análise estatística entre os grupos de estudo para ocorrência de MO durante as sessões de tratamento

\begin{tabular}{l|c|c}
\hline Tabela de análise & \multicolumn{2}{c}{} \\
\hline Teste de Kruskal-Wallis & \multicolumn{2}{|c}{} \\
Valor P & & $<0.0001$ \\
Número de grupos & & 3 \\
Estatística & Diferença das somas & Significância p< 0.05 \\
\hline Teste de Dunn's & 16.86 & Não \\
\hline Grupo 1 x & 36.41 & Sim \\
Grupo 1 x 3 & 19.56 & Sim \\
Grupo $2 \times 3$ & & \\
\hline
\end{tabular}

Quando comparadas estas diferenças entre os grupos 1 e 3 observou-se um fator de proteção significativo, conforme tabela 5.7 Quí-quadrado. Possibilitando inferir que o emprego do laser não inibiu a ocorrência de MO na maioria dos pacientes do grupo 3, mas ao observar por sessão esta ocorrência, verificou-se que os pacientes do referido grupo, ou seja, aqueles submetidos a laserterapia a partir da primeira sessão de RT apresentaram uma menor ocorrência da mesma, com Qui-quadrados significativos entre as 
$9^{\mathrm{a}}$ e $18^{\mathrm{a}}$ sessões, que correspondem às $2^{\mathrm{a}}, 3^{\mathrm{a}}$ e $4^{\mathrm{a}}$ semanas de tratamento, exibindo um fator de proteção (Odds Ratio) para o seu estabelecimento.

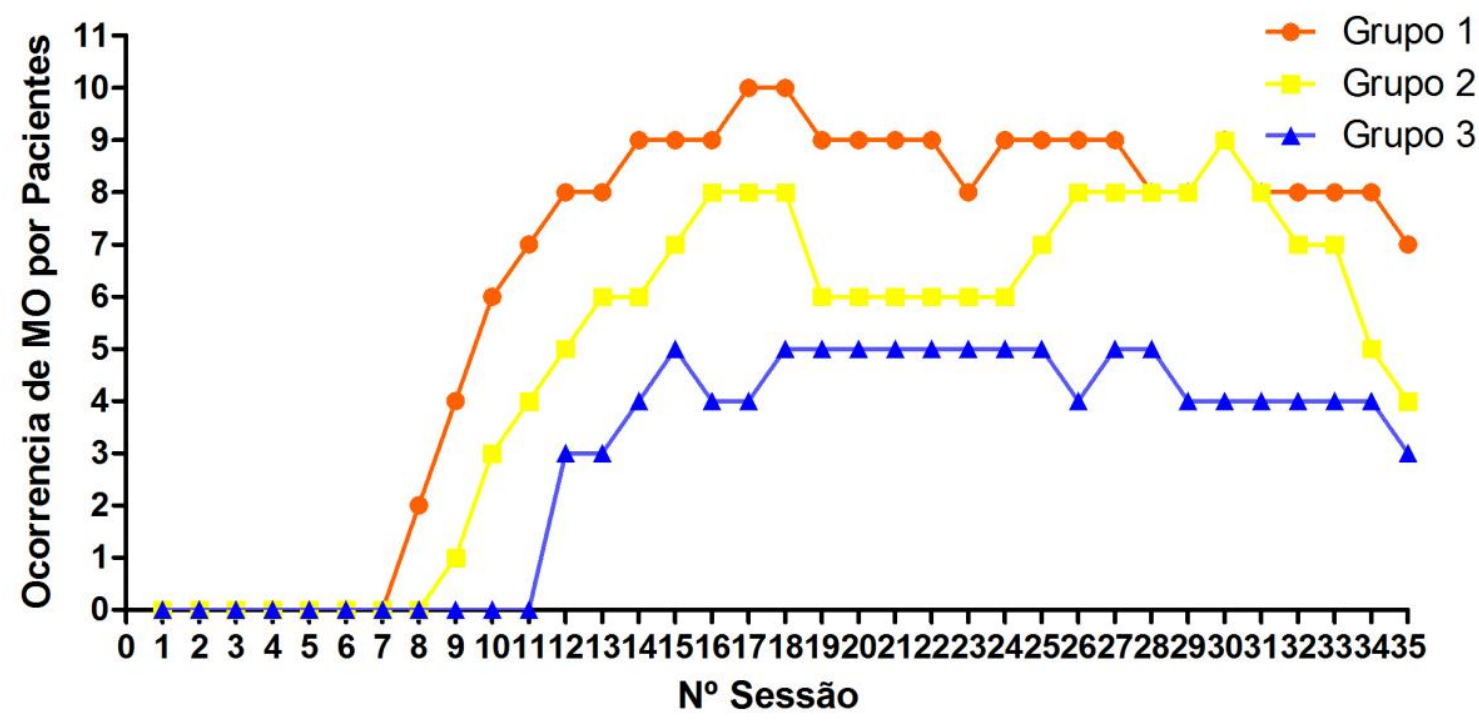

FIGURA 5.3 - Representação gráfica da ocorrência de MO por pacientes* segundo sessões de tratamento. * A ocorrência de MO foi analisada a partir de seu surgimento até a $35^{\mathrm{a}}$ sessão de tratamento

A MO teve início na $8^{\circ}, 9^{\circ}$ e $12^{\circ}$ sessão respectivamente para os grupos 1,2 , e 3 (FIG. 5.3), demonstrando que a utilização do laser a partir da primeira sessão de RT retardou em 4 sessões a ocorrência de MO. Proporcionando assim, entre as $8^{\circ}$ e $11^{\circ}$ sessões um risco relativo igual à zero $(\mathrm{P}=0.0014)$, demonstrando que o laser foi um fator de prevenção de ocorrência para a MO. Na $12^{\mathrm{a}}$ sessão, o risco relativo apresentado foi de 0,25 $(\mathrm{P}=0,0102)$, demonstrando que o laser em sua forma preventiva mostrou-se 0,25 vezes mais efetivo na prevenção da ocorrência da MO (TAB. 5.7). 
TABELA 5.7 - Qui-quadrado para fator de proteção referente à ocorrência de MO

\begin{tabular}{|c|c|c|c|c|c|c|}
\hline $\begin{array}{l}\text { Sessões de } \\
\text { Tratamento }\end{array}$ & $\mathrm{Q}^{2}$ & $\mathrm{P}$ & $\mathrm{RR}$ & IC - RR & OR & IC - OR \\
\hline $8^{a}$ & 2.2 & 0,1380 & 0 & Infinito & 0.1652 & 0.007035 a 3.880 \\
\hline $9^{a}$ & 4,889 & $0,027^{*}$ & 0 & Infinito & 0.072 & 0.0033 a 1.552 \\
\hline $10^{\mathrm{a}}$ & 8.25 & $0.0041 *$ & 0 & Infinito & 0.03679 & 0.001740 a 0.7779 \\
\hline $11^{\mathrm{a}}$ & 10.27 & $0.0014^{*}$ & 0 & Infinito & 0.02609 & 0.001218 a 0.5585 \\
\hline $12^{\mathrm{a}}$ & 6.6 & $0.0102 *$ & 0.25 & $\begin{array}{c}0.06779 \mathrm{a} \\
0.9220\end{array}$ & 0.08333 & 0.01097 a 0.6328 \\
\hline $13^{a}$ & 4.545 & $0.033^{*}$ & 0.375 & $\begin{array}{c}0.1338 \mathrm{a} \\
1.051\end{array}$ & 0.1406 & 0.02152 a 0.9188 \\
\hline $14^{\mathrm{a}}$ & 4.701 & $0.0301 *$ & 0.44 & $\begin{array}{c}0.1938 \mathrm{a} \\
1.019\end{array}$ & 1270 & 0.01781 a 0.9054 \\
\hline $15^{\mathrm{a}}$ & 3.143 & 0.0763 & $\begin{array}{ll}---- \\
\end{array}$ & $\begin{array}{ll}---- \\
\end{array}$ & $\begin{array}{ll}---- \\
\end{array}$ & $\begin{array}{ll}---- \\
\end{array}$ \\
\hline $16^{\mathrm{a}}$ & 4.701 & $0.0301 *$ & 0.44 & $\begin{array}{c}0.1938 \mathrm{a} \\
1.019\end{array}$ & 0.127 & 0.01781 a 0.9054 \\
\hline $17^{\mathrm{a}}$ & 7.071 & $0.0078^{*}$ & 0.44 & $\begin{array}{c}0.1790 \mathrm{a} \\
0.8938\end{array}$ & 0.05714 & 0.005208 a 0.6270 \\
\hline $18^{\mathrm{a}}$ & 5.238 & $0.0221 *$ & 0.5 & $\begin{array}{c}0.2548 \mathrm{a} \\
0.9810\end{array}$ & 0.08333 & 0.00775 a 0.8952 \\
\hline $19^{a}$ & 3.143 & 0.0763 & 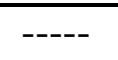 & $\begin{array}{ll}---- \\
\end{array}$ & $\begin{array}{ll}---- \\
\end{array}$ & $\begin{array}{l}---- \\
\end{array}$ \\
\hline $20^{a}$ & 3.143 & 0.0763 & $\begin{array}{ll}---- \\
\end{array}$ & $\begin{array}{l}---- \\
\end{array}$ & $\begin{array}{ll}---- \\
\end{array}$ & $\begin{array}{l}---- \\
\end{array}$ \\
\hline $21^{\mathrm{a}}$ & 3.143 & 0.0763 & ----- & ----- & ----- & ----- \\
\hline $22^{a}$ & 3.143 & 0.0763 & $\begin{array}{l}---- \\
-1\end{array}$ & $\begin{array}{l}---- \\
-\end{array}$ & 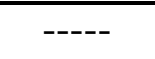 & $\begin{array}{l}---- \\
\end{array}$ \\
\hline $23^{a}$ & 1.692 & 0.1933 & $\begin{array}{ll}---- \\
\end{array}$ & $\begin{array}{l}---- \\
\end{array}$ & $\begin{array}{ll}---- \\
\end{array}$ & $\begin{array}{ll}---- \\
\end{array}$ \\
\hline $24^{\mathrm{a}}$ & 3.143 & 0.0763 & $\begin{array}{ll}---- \\
\end{array}$ & ----- & ----- & ----- \\
\hline $25^{\mathrm{a}}$ & 3.143 & 0.0763 & $\begin{array}{l}---- \\
\end{array}$ & $\begin{array}{ll}---- \\
\end{array}$ & ----- & ----- \\
\hline $26^{\mathrm{a}}$ & 4.701 & $0.0301 *$ & 0.44 & $\begin{array}{c}0.1938 \mathrm{a} \\
1.019 \\
\end{array}$ & 0.127 & 0.01781 a 0.9054 \\
\hline $27^{\mathrm{a}}$ & 3.143 & 0.0763 & $\begin{array}{l}---- \\
\end{array}$ & $\begin{array}{ll}---- \\
\end{array}$ & $\begin{array}{l}---- \\
\end{array}$ & $\begin{array}{ll}---- \\
\end{array}$ \\
\hline $28^{\mathrm{a}}$ & 1.692 & 0.1933 & ----- & ----- & ----- & ----- \\
\hline $29^{a}$ & 2.933 & 0.0868 & $\begin{array}{ll}---- \\
\end{array}$ & $\begin{array}{l}---- \\
\end{array}$ & $\begin{array}{l}---- \\
\end{array}$ & $\begin{array}{l}---- \\
\end{array}$ \\
\hline $30^{\mathrm{a}}$ & 4.701 & $0.0301^{*}$ & 0.44 & $\begin{array}{c}0.1938 \mathrm{a} \\
1.019 \\
\end{array}$ & 0.127 & 0.01781 a 0.9054 \\
\hline $31^{\mathrm{a}}$ & 2.933 & 0.0868 & $\begin{array}{l}---- \\
\end{array}$ & $\begin{array}{l}---- \\
\end{array}$ & $\begin{array}{l}---- \\
\end{array}$ & 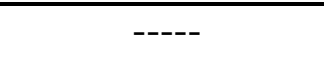 \\
\hline $32^{\mathrm{a}}$ & 2.933 & 0.0868 & $\begin{array}{l}---- \\
\end{array}$ & $\begin{array}{l}---- \\
\end{array}$ & $\begin{array}{l}---- \\
\end{array}$ & $\begin{array}{l}---- \\
\end{array}$ \\
\hline $33^{\mathrm{a}}$ & 2.933 & 0.0868 & ---- & ----- & ----- & $\begin{array}{l}---- \\
\end{array}$ \\
\hline $34^{\mathrm{a}}$ & 2.933 & 0.0868 & $\begin{array}{l}---- \\
\end{array}$ & $\begin{array}{l}---- \\
\end{array}$ & $\begin{array}{l}---- \\
\end{array}$ & ----- \\
\hline $35^{\mathrm{a}}$ & 8.33 & $0.0039 *$ & 0.3 & $\begin{array}{c}0.1164 \mathrm{a} \\
0.7734\end{array}$ & 0.0311 & 0.001357 a 0.7131 \\
\hline
\end{tabular}




\subsection{Severidade de MO}

Com relação aos graus de MO foi observado clinicamente que os pacientes do grupo 3 apresentaram, durante o tratamento oncológico, menor severidade de MO do que os pacientes do grupo 1 e 2. Verificando a figura 5.4 e a tabela 5.8 observou-se que os pacientes do grupo 3, quando comparados aos pacientes dos demais grupos de estudo, apresentaram graus mais amenos de MO durante todo o tratamento e sinalizaram ao final do mesmo com uma tendência a redução das médias dos graus de MO. Com relação a obtenção do grau máximo de MO, este ocorreu geralmente entre a $17^{\mathrm{a}}$ e a $30^{\mathrm{a}}$ sessão, equivalente a $4^{\mathrm{a}}$ e $6^{\mathrm{a}}$ semanas de RT. Não sendo obrigatoriamente coincidente ou imediatamente precedido ou sucedido pelo escore máximo de dor ocasionado pela mesma. Maior coincidência entre grau máximo de MO e escore máximo de dor ocorreram no grupo $2(33,3 \%)$ (TAB. 5.9).

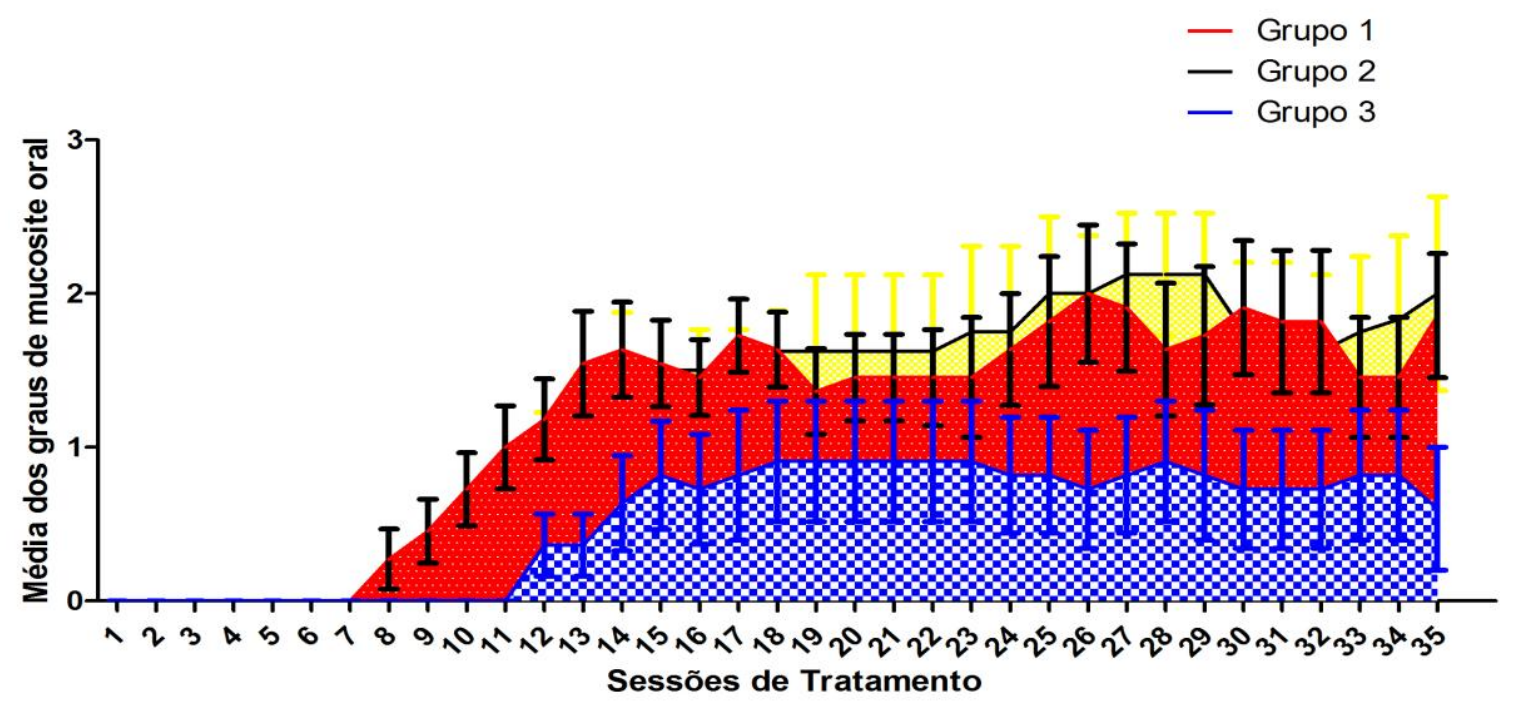

FIGURA 5.4 - Representação gráfica das médias e desvio padrão dos graus de MO durante sessões de tratamento dos pacientes, segundo grupos de estudo. * As média dos graus de MO foram analisados a partir de seu surgimento até a $35^{\text {a }}$ sessão de tratamento 
TABELA 5.8 - Análise da representação gráfica 5.4 determinando a área sob a curva para as médias dos graus de MO segundo sessões de tratamento para os grupos de estudo

\begin{tabular}{|l|c|c|c|}
\hline Linha de base & Grupo 1 & Grupo 2 & Grupo 3 \\
\hline Área total & 40.47 & 40.83 & 18.21 \\
Área total dos picos & 40.47 & 40.83 & 18.21 \\
Número de picos & 1.000 & 1.000 & 6.000 \\
Pico Máximo X (sessões) & 26.00 & 27.00 & 1.000 \\
Pico máximo de Y (média dos & 2.000 & 2.125 & 0.9091 \\
graus de MO) & & & \\
\hline
\end{tabular}

TABELA 5.9 - Ocorrência de grau e escore máximo de dor de MO durante RT e ao final da mesma, segundo diferentes grupos de estudo

GRUPO 1 - Tratamento medicamentoso

\begin{tabular}{|c|c|c|c|c|c|c|}
\hline Pac & $\begin{array}{l}\text { Grau Máx } \\
\text { de MO }\end{array}$ & Sessão de RT & $\begin{array}{l}\text { Esc. Máx de } \\
\text { dor }\end{array}$ & $\begin{array}{l}\text { Sessão de } \\
\text { RT }\end{array}$ & $\begin{array}{l}\text { Grau de MO } \\
\text { ao final da } \\
\text { RT } \\
\end{array}$ & $\begin{array}{l}\text { Esc. de dor } \\
\text { ao final da } \\
\text { RT }\end{array}$ \\
\hline 1 & 2 & $8^{a}$ & 2 & $19^{a}$ & 2 & 2 \\
\hline 2 & 4 & $26^{\mathrm{a}}$ & 10 & $27^{\mathrm{a}}$ & 4 & 6 \\
\hline 3 & $0 *$ & ---- & 0 & ---- & 0 & 0 \\
\hline 4 & 2 & $12^{\mathrm{a}}$ & 6 & $20^{\mathrm{a}}$ & 1 & 4 \\
\hline 5 & 3 & $29^{a}$ & 6 & $28^{\mathrm{a}}$ & 1 & 6 \\
\hline 6 & 2 & $10^{\mathrm{a}}$ & 2 & $11^{\mathrm{a}}$ & 2 & 0 \\
\hline 7 & 4 & $25^{\mathrm{a}}$ & 4 & $15^{\mathrm{a}}$ & 0 & 0 \\
\hline 8 & 4 & $23^{\mathrm{a}}$ & 8 & $13^{\mathrm{a}}$ & 3 & 2 \\
\hline 9 & 3 & $30^{\mathrm{a}}$ & 2 & $28^{a}$ & 2 & 2 \\
\hline 10 & 1 & $17^{\mathrm{a}}$ & 0 & ---- & 1 & 0 \\
\hline 11 & 1 & $14^{\mathrm{a}}$ & 4 & $16^{\mathrm{a}}$ & 0 & 4 \\
\hline
\end{tabular}

\footnotetext{
*Pacientes que não desenvolveram MO durante o tratamento oncológico.
} 
TABELA 5.9 - Ocorrência de grau e escore máximo de dor de MO durante RT e ao final da mesma, segundo diferentes grupos de estudo

GRUPO 2 - Tratamento medicamentoso e laser a partir do início da ulceração referente à mucosite grau 2

\begin{tabular}{|c|c|c|c|c|c|c|}
\hline Pac & $\begin{array}{l}\text { Grau Máx } \\
\text { de MO }\end{array}$ & Sessão de RT & $\begin{array}{l}\text { Esc. Máx de } \\
\text { dor }\end{array}$ & $\begin{array}{l}\text { Sessão de } \\
\text { RT }\end{array}$ & $\begin{array}{l}\text { Grau máx. de } \\
\text { MO ao final } \\
\text { da RT }\end{array}$ & $\begin{array}{l}\text { Esc. de dor } \\
\text { ao final da } \\
\text { RT }\end{array}$ \\
\hline 1 & 2 & $33^{\mathrm{a}}$ & 2 & $1^{\mathrm{a}}$ & 2 & 2 \\
\hline 2 & 4 & $23^{\mathrm{a}}$ & 4 & $17^{\mathrm{a}}$ & 3 & 4 \\
\hline 3 & 2 & $13^{\mathrm{a}}$ & 8 & $25^{\mathrm{a}}$ & 2 & 6 \\
\hline 4 & 4 & $19^{a}$ & 6 & $19^{a}$ & 4 & 6 \\
\hline 5 & 2 & $14^{\mathrm{a}}$ & 4 & $31^{\mathrm{a}}$ & 0 & 4 \\
\hline 6 & 2 & $14^{\mathrm{a}}$ & 4 & $14^{\mathrm{a}}$ & 1 & 2 \\
\hline 7 & 3 & $14^{\mathrm{a}}$ & 2 & $14^{\mathrm{a}}$ & 2 & 0 \\
\hline $8^{*}$ & 1 & $30^{a}$ & 8 & $35^{a}$ & 1 & 8 \\
\hline 9 & 3 & $20^{a}$ & 4 & $18^{\mathrm{a}}$ & 2 & 0 \\
\hline
\end{tabular}

*Paciente $\mathrm{n}^{\circ} 8$ não desenvolveu MO grau 2 não sendo submetido a laserterapia, portanto seus dados não fizeram parte da análise estatística.

GRUPO 3 - Tratamento medicamentoso e laser diário iniciado imediatamente antes do início da RT, sendo empregado até o final da mesma

\begin{tabular}{|c|c|c|c|c|c|c|}
\hline Pac & $\begin{array}{l}\text { Grau Máx de } \\
\text { MO }\end{array}$ & Sessão de RT & $\begin{array}{l}\text { Esc. Máx de } \\
\text { dor }\end{array}$ & $\begin{array}{l}\text { Sessão de } \\
\text { RT }\end{array}$ & $\begin{array}{l}\text { Grau máx. de } \\
\text { MO ao final } \\
\text { da RT }\end{array}$ & $\begin{array}{l}\text { Esc. Máx de } \\
\text { dor ao final } \\
\text { da } \mathrm{RT}\end{array}$ \\
\hline 1 & 0* & ---- & 4 & $35^{\mathrm{a}}$ & 0 & 4 \\
\hline 2 & 0* & ---- & 4 & $13^{\mathrm{a}}$ & 0 & 2 \\
\hline 3 & 0* & ---- & 2 & $14^{\mathrm{a}}$ & 0 & 2 \\
\hline 4 & 1 & $14^{\mathrm{a}}$ & 0 & ---- & 0 & 0 \\
\hline 5 & 2 & $27^{\mathrm{a}}$ & 0 & --- & 1 & 0 \\
\hline 6 & 4 & $17^{\mathrm{a}}$ & 4 & $4^{\mathrm{a}}$ & 4 & 0 \\
\hline 7 & 0* & ---- & 4 & $12^{\mathrm{a}}$ & 0 & 2 \\
\hline 8 & 3 & $14^{\mathrm{a}}$ & 6 & $11^{\mathrm{a}}$ & 3 & 4 \\
\hline 9 & 1 & $12^{\mathrm{a}}$ & 4 & $11^{\mathrm{a}}$ & 1 & 0 \\
\hline 10 & 1 & $15^{\mathrm{a}}$ & 0 & ---- & 0 & 0 \\
\hline 11 & 2 & $18^{\mathrm{a}}$ & 8 & $28^{\mathrm{a}}$ & 0 & 4 \\
\hline
\end{tabular}

*Pacientes que não desenvolveram MO durante o tratamento oncológico. 
Para verificação da severidade de MO entre os grupos de estudo foi realizada análise de variância do tipo não paramétrica de Kruskal-Wallis determinando que existem diferenças estatisticamente significantes entre os grupos. Quando comparado um grupo ao outro, pelo teste Multíplo de Dunn's, revelaram-se ser iguais os grupos 1 e 2, e estatisticamente diferente o grupo 3 dos demais grupos (FIG. 5.5 e TAB. 5.10).

Analisando a tabela 5.9 é possível observar que apesar de apresentarem graus amenos de MO, grau 1 e 2 respectivamente, o paciente número 8 do grupo 2 e o paciente número 11 do grupo 3 evoluiram com dor intensa (escore 8). A princípio tal intensidade de dor não pode ser atribuida à MO, sendo esta associada possivelmente a outras complicações bucais, tais como: xerostomia e odinofagia. Porém, é possível observar que o paciente do grupo 3, apresentou maior intensidade de dor na $18^{\mathrm{a}}$ sessão que representa a $4^{\mathrm{a}}$ semana de tratamento, concluindo o mesmo ( $35^{\mathrm{a}}$ sessão) com escore de dor 4. Já o paciente do grupo 2 apresentou maior escore de dor na $30^{\text {a }}$ sessão de tratamento ( $6^{\mathrm{a}}$ semana) mantendo a mesma intensidade da dor até a conclusão do mesmo que ocorreu na $35^{\text {a }}$ sessão ( $7^{\text {a }}$ semana). Portanto, é importante observar que o paciente do grupo 3 , submetido a laserterapia diária a partir da primeira sessão de RT evoluiu com redução da intensidade da dor, concluindo o tratamento em situação mais confortável, do que o paciente número 8 do grupo 2, que não foi submetido a laserterapia, pois não apresentou ulcerações em boca (MO grau 2), que cursou com a mesma intensidade de dor até o final do tratamento.

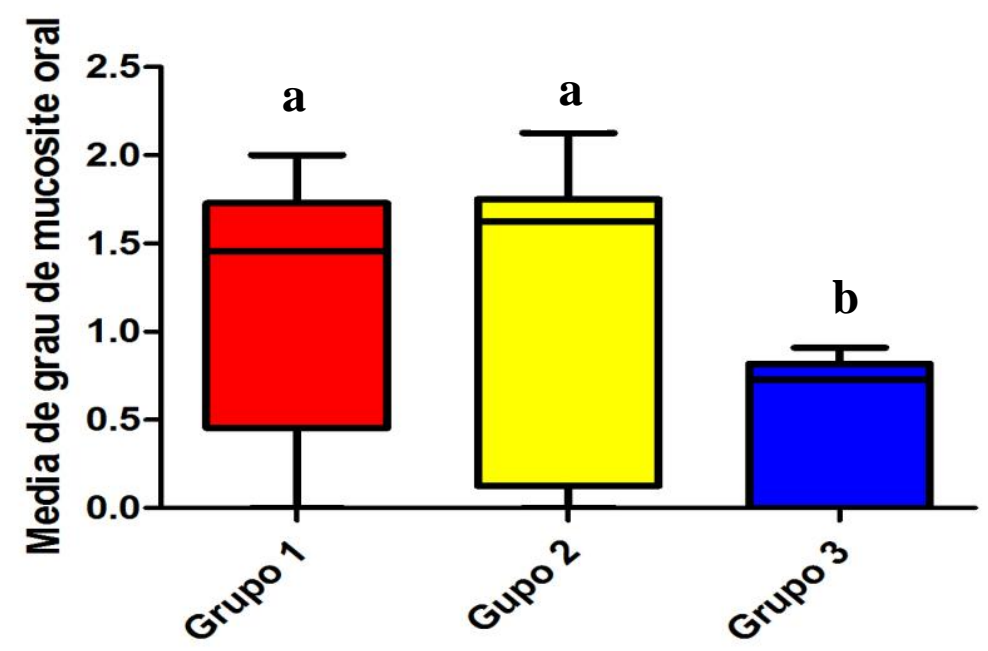

FIGURA 5.5 - Médias e desvio padrão dos graus de MO durante as sessões de RT, segundo grupos de estudo 
TABELA 5.10 - Análise estatística entre os grupos para intensidade de mucosite oral entre os grupos de estudo

\begin{tabular}{|c|c|c|}
\hline Tabela de análise & & \\
\hline Teste de Kruskal-Wallis & & \\
\hline Valor P & & $<0.0001$ \\
\hline Número de grupos & & 3 \\
\hline Estatística & & 19.62 \\
\hline Teste de Dunn's & Diferença das somas & Significância $p<0.05$ \\
\hline Grupo 1 x 2 & -1.829 & Não \\
\hline Grupo 1 x 3 & 26.73 & Sim \\
\hline Grupo 2 x 3 & 28.56 & Sim \\
\hline
\end{tabular}

Com relação a análise das médias dos graus de MO foi possível observar que os pacientes do grupo 3 apresentaram menor média do que aquelas observadas nos pacientes dos grupos 1 e 2 respectivamente (FIG. 5.5).

\subsection{Escore de dor}

Com relação às médias do escore de dor no decorrer das 35 sessões de RT não foram observadas diferenças estatisticamente significantes entre os grupos 1 x 3 , entretanto, diferenças estatisticamente significantes foram obtidas entre os grupos 1 x 2 e 2 x 3 (FIG. 5.6) (TAB 5.11). Porém, ao analisar as médias do escore de dor a partir da $20^{\circ}$ sessão de RT, equivalente ao início da $5^{\mathrm{a}}$ semana de tratamento, foi constatada a presença de diferenças estatisticamente significantes entre os três grupos de estudo (FIG. 5.7 e TAB 5.12). Comprovando que o uso do LBI a partir da primeira sessão de RT mostrou-se efetivo na diminuição da dor e consequentemente do desconforto bucal, contribuindo para uma melhor qualidade de vida dos pacientes em tratamento oncológico.

Para o grupo 3 o pico máximo de dor ocorreu na $13^{\circ}$ sessão apresentando 2 como média do escore de dor, enquanto a média de escore de dor para os grupo 1 e 2 foram respectivamente de 3,273 e 3.5, com os picos máximos de dor ocorrendo nas $31^{\circ}$ e $26^{\circ}$ sessões. Assim, comprovando que as médias de intensidade da dor foram maiores e ocorreram mais tardiamente nos grupos 1 e 2 (FIG. 5.8).

Quando comparadas as médias de intensidade de dor ao final do tratamento é possível observar que os grupos 3 e 2 apresentaram tendência a diminuição das mesmas, o 
mesmo não ocorrendo com relação ao grupo 1 que ao final do tratamento sinalizaram claramente o contrário (FIG.5.8).

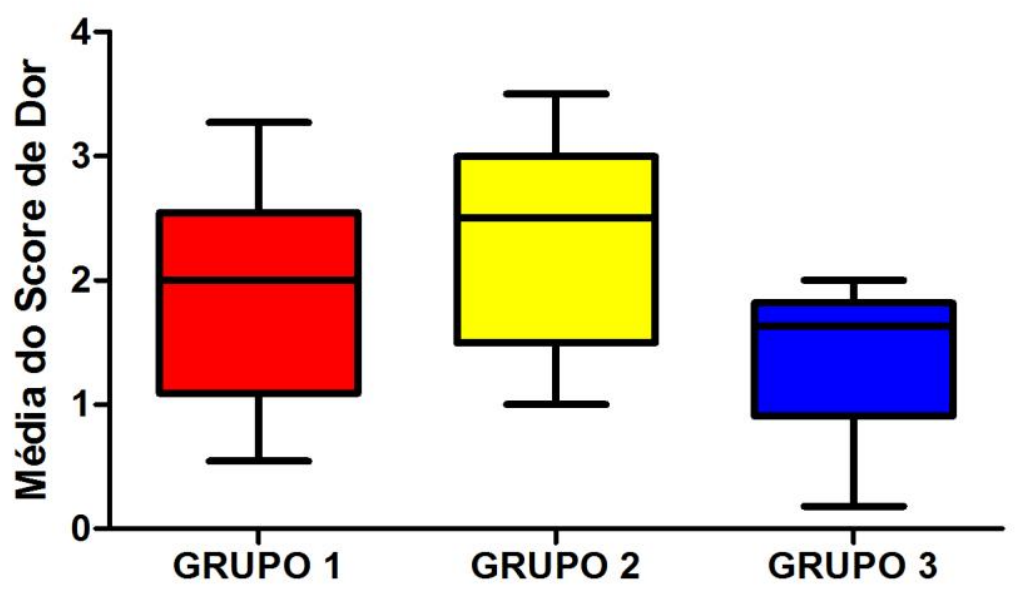

FIGURA 5.6 - Médias do escore de dor e desvio padrão segundo grupos de estudo no decorrer do tratamento

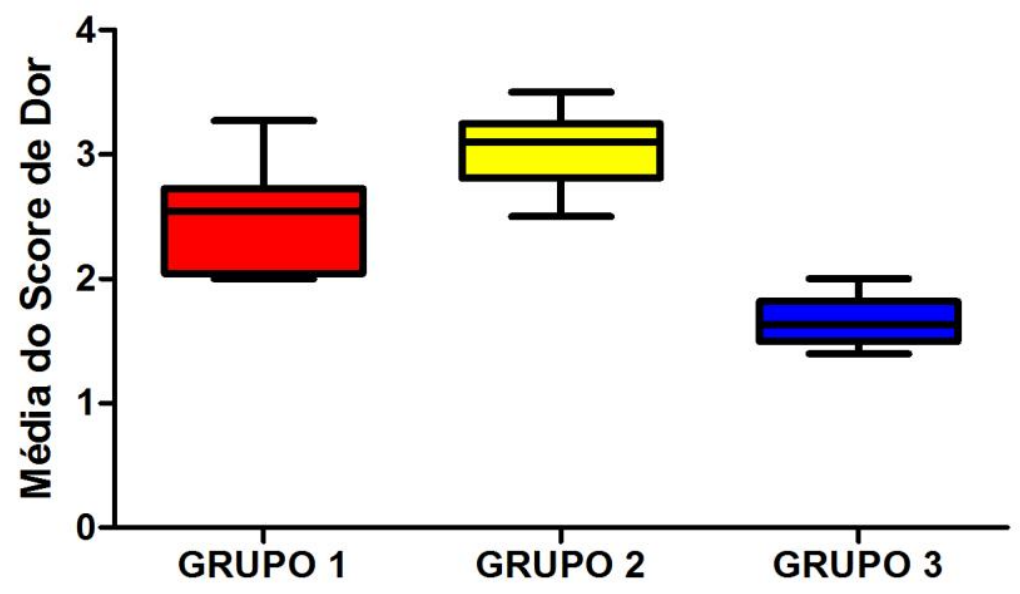

FIGURA 5.7 - Médias do escore de dor segundo grupos de estudo a partir da $20^{\mathrm{a}}$ sessão de tratamento 


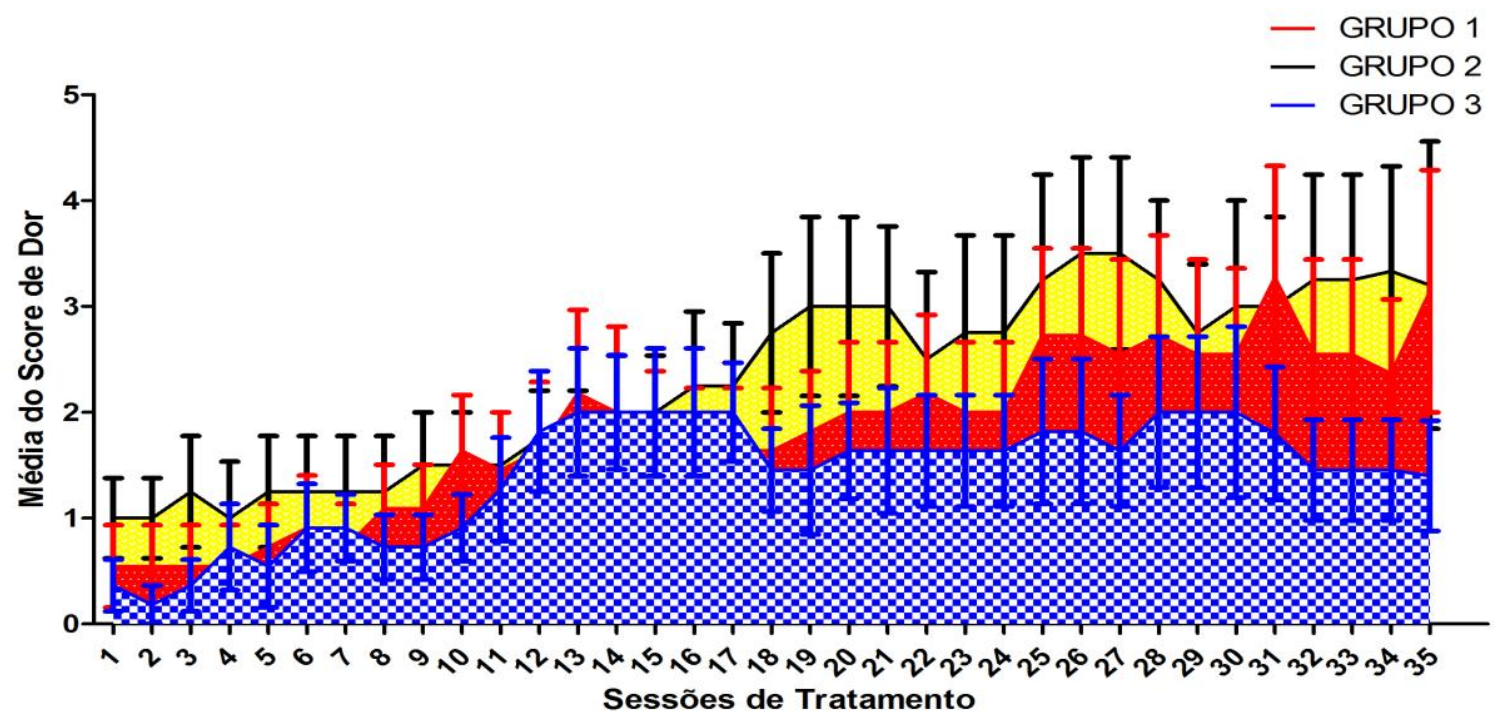

FIGURA 5.8 - Representação gráfica das médias de escore de dor durante o tratamento oncológico segundo grupos de estudo

TABELA 5.11 - Análise de variância das médias do escore de dor segundo grupos de estudo no decorrer do tratamento

One Way Análise de variância

\begin{tabular}{lccc}
\hline Valor de $\mathrm{p}$ & & & $\mathrm{P}<0.0001$ \\
Número de grupos & & & 3 \\
$\mathrm{~F}$ & & & 12.83 \\
$\mathrm{R}$ & & & 0.201 \\
\hline ANOVA & SS & DF & MS \\
\hline Tratamento & 14.1 & 2 & 7.05 \\
Residual & 56.05 & 102 & 0,5495 \\
Total & 70.15 & 104 & IC \\
\hline Bonferroni & D. Média & Significância & -0.9047 a- 0.04204 \\
\hline Grupo 1 x 2 & -0.4734 & Sim & -0.007502 a 0.8551 \\
Grupo 1 x 3 & 0.4238 & Não & 0.4659 a 1.329 \\
Grupo 2 x 3 & 0.8972 & Sim &
\end{tabular}


TABELA 5.12 - Análise de variância das médias do escore de dor após a $20^{\circ}$ sessão de tratamento

One Way Análise de variância

Valor de $\mathrm{p}$

$\mathrm{P}<0.0001$

Número de grupos

$\mathrm{F}$

85.05

$\mathrm{R}$

0.7908

\begin{tabular}{lccc}
\hline ANOVA & SS & DF & MS \\
\hline Tratamento & 15.61 & 2 & 7.807 \\
Residual & 4.131 & 45 & 0.09180 \\
Total & 19.75 & 47 & \\
\hline Bonferroni & D. Média & Significância & IC $\mathbf{9 5 \%}$ \\
\hline Grupo1 x 2 & -0.5883 & Sim & 0.857 a 0.3219 \\
Grupo 1 x 3 & 0.8032 & Sim & 0.5369 a 1.070 \\
Grupo 2 x 3 & 1.392 & Sim & 1.125 a 1.658 \\
\hline
\end{tabular}

\subsection{Uso de sonda nasogástrica}

Não foram observadas diferenças estatisticamente significantes entre os grupos de estudo com relação ao uso de sonda nasogástrica em decorrência da $\mathrm{MO}$, obtendo os seguintes valores para o Teste exato de Fisher quando comparado os Grupo 3 x 2 com $\mathrm{p}=0,5459$; Grupos 3 x 1 com $\mathrm{p}=0,5865$; e Grupos $2 \times 1$ com $\mathrm{p}=1$. Entretanto, clinicamente foi observado a necessidade do seu uso em três pacientes do grupo 1 (FIG. 5.9), dois pacientes do grupo 2 e em somente um paciente do grupo 3.
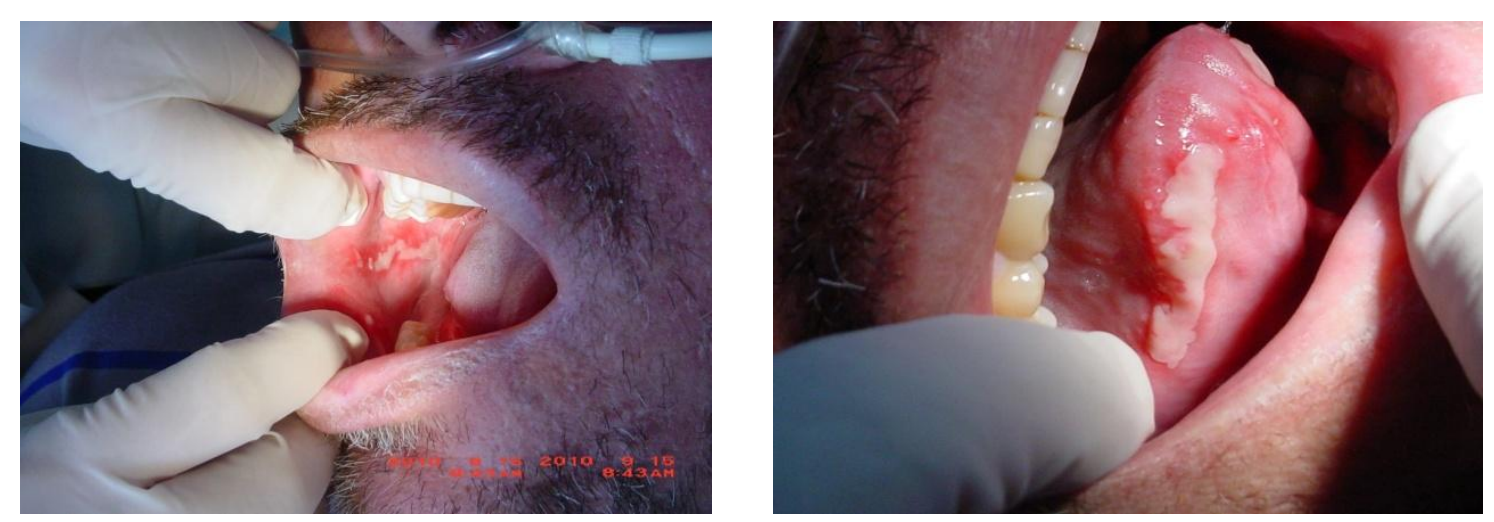

FIGURA 5.9 - Uso de sonda nasogástrica em paciente do grupo 1 com MO grau 4 em mucosa jugal e borda lateral de língua 


\subsection{Internação hospitalar}

Não foram observadas diferenças estatisticamente significantes entre os grupos de estudo com relação a internação hospitalar em decorrência da MO, sendo a mesma necessária em apenas 1 paciente do Grupo 1 que no momento da internação apresentava MO grau 4, uso de sonda nasogástrica e dor insuportável associada à mesma. A internação durou 5 dias e o paciente foi liberado após remissão da dor e melhora de seu quadro clínico (TAB. 5.13).

TABELA 5.13 - Tratamentos e ocorrência de complicações decorrentes da MO segundo diferentes grupos de estudo

\begin{tabular}{|c|c|c|c|c|c|c|c|}
\hline Pac & Grupo & Localização & Tratamento & $\begin{array}{l}\text { Porc. de de } \\
\text { perda de m. } \\
\text { corpórea. }\end{array}$ & $\begin{array}{l}\text { Uso de } \\
\text { SNG }\end{array}$ & $\begin{array}{l}\text { Internação } \\
\text { hospitalar }\end{array}$ & $\begin{array}{l}\text { Interrupção } \\
\text { do } \\
\text { tratamento }\end{array}$ \\
\hline 2 & 1 & Língua & CR, RT e QT & $13,8 \%$ & Sim & Sim & Não \\
\hline 7 & 1 & $\begin{array}{c}\text { Assoalho } \\
\text { bucal }\end{array}$ & CR, RT e QT & $11,6 \%$ & Sim & Não & Não \\
\hline 8 & 1 & Língua & CR, RT e QT & $7 \%$ & Sim & Não & Não \\
\hline 2 & 2 & Língua & CR, RT e QT & $5,9 \%$ & Sim & Não & Não \\
\hline 4 & 2 & $\begin{array}{c}\text { Assoalho } \\
\text { bucal }\end{array}$ & CR, RT e QT & $16 \%$ & Sim & Não & Não \\
\hline 6 & 3 & Língua & RT e QT & $6,6 \%$ & Sim & Não & Não \\
\hline
\end{tabular}

\subsection{Interrupção do tratamento}

Não foi observada a necessidade de interrupção do tratamento em decorrência da MO, para nenhum dos participantes deste estudo. Entretanto, um paciente do grupo $1 \mathrm{e}$ um paciente do grupo 2 interromperam o tratamento oncológico respectivamente em conseqüência de problemas respiratórios e comprometimento acentuado de seu quadro clínico geral. No momento da interrupção do tratamento os pacientes apresentavam respectivamente graus 3 e 1 de MO. A interrupção e a retomada do tratamento oncológico foram determinadas por ordem do médico responsável pelos pacientes em questão. 


\subsection{Perda de massa corpórea}

Para obtenção da comparação das médias de perda de massa corpórea foi realizada análise de variância seguida do teste de Bonferroni (TAB 5.14). A média de massa corpórea perdida entre os grupos foi praticamente equivalente $(\mathrm{P}=0,0906)$. Quando a perda de massa corpórea foi comparada no início ( $\left.1^{\mathrm{a}} \mathrm{sessão}\right)$ e no final do tratamento $\left(35^{\mathrm{a}}\right.$ sessão), observou-se que entre os grupos 1 e 3 as médias de perda de massa corpórea foram equivalentes, respectivamente $5.600(8,9 \%)$ e $5.791 \mathrm{~kg}(8,7 \%)$. A média de perda de massa corpórea foi maior nos pacientes do grupo 2, sendo a mesma de $8.125 \mathrm{~kg}(12,96 \%)$ (TAB 5.15). É possível inferir através da análise da figura 5.10 que a partir da $20^{\mathrm{a}}$ sessão de RT, a média de perda de massa corpórea foi mais pronunciada nos pacientes do grupo 2, mantendo-se desta forma até a conclusão do tratamento ( $35^{\mathrm{a}}$ sessão).

Entretanto, no decorrer de toda a RT a média de massa corpórea perdida pelos pacientes em relação a cada grupo de estudo foi respectivamente, G1: -3,405 (DP: 1,598); G2: - 4,130 (DP: 2,883); e G3: -3,002 (DP: 1,753) (FIG. 5.11 e TAB. 5.16).

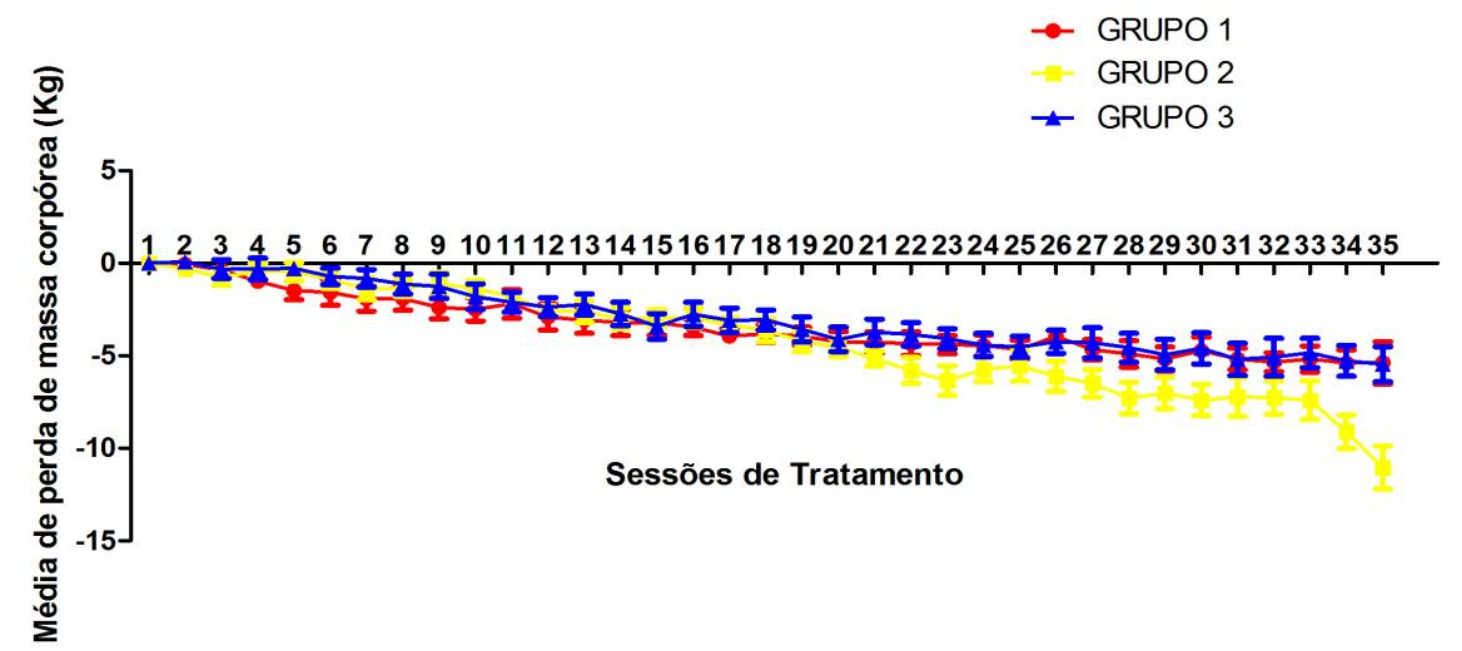

\footnotetext{
FIGURA 5.10 - Representação gráfica da redução de massa corpórea por grupo de estudo ao longo do tratamento
} 


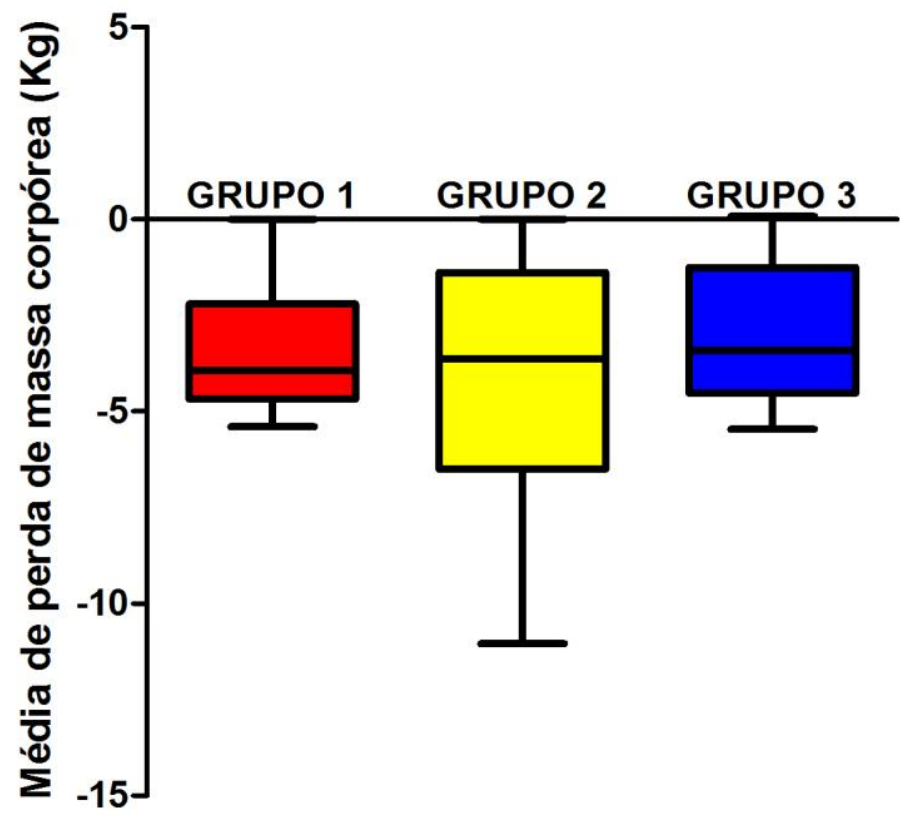

FIGURA 5.11 - Representação gráfica da média de redução de massa corpórea por grupo de estudo

TABELA 5.14 - Análise de variância das médias de perda de massa corpórea segundo grupos de estudo

One Way Análise de variância

Valor de P $\mathrm{P}=0.0906$

Número de grupos 3

$\mathrm{F}$

$\mathrm{R}$

0.04598

\begin{tabular}{|c|c|c|c|}
\hline ANOVA & SS & DF & MS \\
\hline Tratamento & 22.84 & 2 & 11.42 \\
\hline Residual & 473.9 & 102 & 4.646 \\
\hline Total & 496.7 & 104 & \\
\hline Bonferroni & D. Média & Significância & IC $\quad 95 \%$ \\
\hline Grupo 1 × 2 & 0.7245 & Não & -0.5297 a 1.979 \\
\hline Grupo 1 x 3 & -0.4027 & Não & -1.657 a 0.8514 \\
\hline Grupo $2 \times 3$ & -1.127 & Não & -2.381 a 0.1269 \\
\hline
\end{tabular}


TABELA 5.15 - Distribuição dos pacientes: dados associados à perda de massa corpórea entre a $1^{\mathrm{a}}$ e $35^{\mathrm{a}}$ sessão de $\mathrm{RT}$ em Kg e porcentagem e sua relação com grau máximo de MO e escore máximo de dor durante o tratamento

\section{GRUPO 1}

$N^{\circ}$ Massa corp ao

início do

tratamento

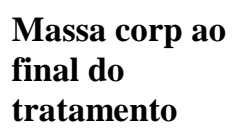

$1 \quad 53.000$

48.100

$2 \quad 75.000$

64.600

54.900

$3 \quad 58.700$

64.600

$4 \quad 68.700$

45.000

$5 \quad 49.500$

48.900

$6 \quad 51.100$

59.800

$\begin{array}{ll}7 & 67.700\end{array}$

39.400

51.100

63.000

67.900

$11 \quad 73.300$

Total de massa
corp perdida
em Kg e $\%$

$4.900 / 9.2 \%$

$10.400 / 13.8 \%$

$3.800 / 6,4 \%$

$4.100 / 5.9 \%$

$4.500 / 9,0 \%$

$2.200 / 4,3 \%$

$7.900 / 11,6 \%$

$3.000 / 7.0 \%$

$6.200 / 10,8 \%$

$9.500 / 13 \%$

$5.400 / 7,3 \%$

Grau máximo de MO

Escore máximo de dor durante $o$ tratamento

Média de perda de massa corpórea dos pacientes obtida através da comparação entre a $1^{\mathrm{a}}$ e $35^{\mathrm{a}}$ sessão de RT em Kg: 5.600Kg. Média de perda de massa corpórea em \%: 8,9.

\section{GRUPO 2}

$\begin{array}{ll}\mathrm{N}^{\circ} & \text { Massa corp } \\ \text { ao início do } \\ \text { tratamento }\end{array}$

Massa corpórea
ao final do
tratamento

Total de massa corpórea perdida

50.000

76.200

49.500

50.400

50.700

55.800

52.400
41.500

58.000

48.200

64.400

*Paciente $\mathrm{n}^{\circ} 8$ não desenvolveu MO

fizeram parte da análise estatística.

Média de perda de massa corpórea obtida através da comparação entre a $1^{\mathrm{a}}$ e $35^{\mathrm{a}}$ sessão de $\mathrm{RT}$ em $\mathrm{Kg}$ : $8.125 \mathrm{Kg}$. Média de perda de massa corpórea em \%: 12,96.

1

8 $6.400 / 9,9 \% \quad 3 \quad 4$

8 .

(1)

$\begin{array}{ll}\text { Grau máximo } & \begin{array}{l}\text { Escore máximo de } \\ \text { dor durante o } \\ \text { de MO }\end{array} \\ \text { tratamento }\end{array}$

$3.400 / 6,3 \%$

$4.800 / 5,9 \%$

$12.400 / 20,3 \%$

2

8

$9.600 / 16 \%$

4

6

$11.200 / 18,1 \%$

2

4

$9.600 / 14,6 \%$

2

4

$7.600 / 12,6 \%$

3

2

$6.700 / 17 \%$

2

4

8

4

4

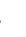




\section{GRUPO 3}

\begin{tabular}{|c|c|c|c|c|c|}
\hline $\mathbf{N}^{\mathbf{o}}$ & $\begin{array}{l}\text { Massa corp } \\
\text { ao início do } \\
\text { tratamento }\end{array}$ & $\begin{array}{l}\text { Massa corp ao } \\
\text { final do } \\
\text { tratamento }\end{array}$ & $\begin{array}{l}\text { Total de massa } \\
\text { corpórea perdida }\end{array}$ & $\begin{array}{l}\text { Grau máximo } \\
\text { de MO }\end{array}$ & $\begin{array}{l}\text { Escore máximo de } \\
\text { dor durante or } \\
\text { tratamento }\end{array}$ \\
\hline 1 & 69.900 & 64.200 & $5.700 / 8,1 \%$ & 0 & 4 \\
\hline 2 & 63.200 & 55.900 & $7.300 / 11,5 \%$ & 0 & 4 \\
\hline 3 & 74.700 & 66.600 & $8.100 / 10,8 \%$ & 0 & 2 \\
\hline$* 4$ & 62.900 & 64.200 & $+1.300 / 2.0 \%$ & 1 & $\mathbf{0}$ \\
\hline 5 & 93.800 & 90.100 & $3.700 / 3,9 \%$ & 2 & 0 \\
\hline 6 & 49.500 & 46.200 & $3.300 / 6,6 \%$ & 4 & 4 \\
\hline 7 & 42.400 & 37.100 & $5.300 / 12,5 \%$ & 0 & 4 \\
\hline 8 & 67.200 & 58.100 & $9.100 / 13,5 \%$ & 3 & 6 \\
\hline 9 & 60.200 & 54.400 & $5.800 / 9,6 \%$ & 1 & 4 \\
\hline 10 & 86.100 & 77.400 & $8.700 / 10,1 \%$ & 1 & 0 \\
\hline 11 & 66.900 & 58.900 & $8.000 / 11,9 \%$ & 2 & 8 \\
\hline
\end{tabular}

TABELA 5.16 - Análise de variância das médias de perda de massa corpórea segundo grupos de estudo

One Way Análise de variância

\begin{tabular}{lccc}
\hline Massa corpórea & Grupo 1 & Grupo 2 & Grupo 3 \\
\hline Valor máximo de perda & -5.391 & -11.04 & -5.460 \\
Mediana & -3.936 & -3.625 & -3.409 \\
Valor mínimo de perda & 0.0000 & 0.0000 & 0.08182 \\
\hline Média & $\mathbf{- 3 . 4 0 5}$ & $\mathbf{- 4 . 1 3 0}$ & $\mathbf{- 3 . 0 0 2}$ \\
Desvio padrão & 1.598 & 2.883 & 1.753 \\
Erro padrão & 0.2701 & 0.4873 & 0.2964 \\
\hline
\end{tabular}


Apesar de não existirem diferenças estatisticamente significantes entre os grupos de estudo para a média de perda de massa corpórea durante o decorrer do tratamento oncológico (TAB. 5.14), observa-se que a perda de massa corpórea por paciente foi mais acentuada no grupo 2, e que esta não obrigatoriamente coincidiu com os graus mais intensos de MO (graus 3 e 4) (TAB 5.15). É importante observar que, apesar de um maior número de pacientes do grupo 3 não apresentar MO, este fator não foi determinante na média da perda de massa corpórea, podendo a mesma estar associada a outros fatores como odinofagia, xerostomia, disgeusia, dificuldades de mastigação e deglutição, assim como a dor ocasionada pelo câncer, cuja análise não foi objetivo deste estudo. Porém, analisando-se a Tabela 5.15, chama atenção o fato de apenas um paciente, participante do grupo 3, apresentar ganho de massa corpórea durante o tratamento oncológico. 


\section{6 - DISCUSSÃO}

Apesar das diversificadas metodologias empregadas em diferentes estudos, resultados clínicos e funcionais satisfatórios têm sido obtidos no tratamento da MO com o emprego do LBI sendo observada redução da morbidade nos pacientes tratados com laser quando comparados com os pacientes controle, com consequiente melhora da qualidade de vida dos mesmos (Biron et al., 2000; Rampini et al., 2009).

Durante o período de maio de 2009 a outubro de 2010, um total de 53 pacientes foram randomizados para desenvolvimento de estudo clínico, destes 22 não puderam por motivos de ordem clínica, pessoal ou particular completar o esquema de tratamento proposto, enquanto que 31 pacientes completaram corretamente o esquema de tratamento preconizado. Todos os pacientes foram submetidos à RT em região de cabeça e pescoço sendo permitida a associação com CR e/ou QT.

Com relação à faixa etária, gênero, procedência e escolaridade, os achados corroboram os dados encontrados por Abdo et al., (2002) e Brener et al., (2007) que relataram uma maior incidência da doença em homens a partir da $4^{\mathrm{a}}$ década de vida, com baixo grau de instrução e provenientes em sua maioria de zona urbana.

Dos pacientes participantes deste estudo $61,2 \%$ faziam ou fizeram uso isolado ou em associação de tabaco e álcool. Tais dados são condizentes com aqueles relatados por Brasil (1996), demonstrando um claro envolvimento do fumo e do álcool com o câncer, sendo esta associação responsável por um maior aumento do risco que a soma de cada fator isolado. O aumento do risco de desenvolvimento do câncer bucal pelo efeito simultâneo do tabaco e do álcool também foi relatado por Neville e Day (2002).

A análise de dados referentes ao câncer de cabeça e pescoço no que diz respeito ao tipo histológico e localização está de acordo com Dobrossy (2004) para o qual a maioria dos cânceres de cabeça e pescoço são do tipo carcinoma epidermóide e ocorrem, preferencialmente, em cavidade oral e laringe. Porém esta análise difere de Sawada et al. (2006), que observaram laringe como o sítio anatômico mais comum para o câncer de cabeça e pescoço.

No que diz respeito ao estadiamento, apesar deste estudo clínico apresentar um maior índice de pacientes com doença avançada, cerca de 90\%, os dados são condizentes com os relatados por Brasil (2009b) e Herchenhorn e Dias (2004) em que 
aproximadamente $60 \%$ dos pacientes que chegam ao hospital com câncer de cabeça e pescoço apresentam doença avançada nos estádios III e IV.

Segundo estudo desenvolvido por Rapoport et al., (2001) a seleção do tratamento deve levar em consideração às necessidades de cada caso em particular, tendo como base os resultados esperados de tempo e qualidade de vida. Para os tumores em estádio II o mesmo resultado oncológico pode ser obtido com CR ou RT. Para os pacientes com estadiamento III e IV, ressecáveis associa-se a CR à RT e/ou QT. O mesmo é dito por Specenier e Vermorken (2008). Nossos dados estão de acordo com a afirmação dos autores acima, visto que a maioria dos pacientes portadores de doença em estadiamento III e IV foram submetidos a tratamentos associados.

Este estudo clínico deve o cuidado de igualar as condições de higiene oral dos pacientes, oferecendo tratamento odontológico de suporte pré, trans e pós-tratamento oncológico com o intuito de prevenir e/ou minimizar as complicações orais decorrentes do tratamento oncológíco. Tal conduta é aceita por Mcguire et al., (2006), para os quais a prevenção da MO inicia-se com uma avaliação prévia ao tratamento oncológico, e consiste na otimização da higiene oral, profilaxia dental e erradicação de focos de infecção. Tal fato é corroborado por Sonis (1998) e Rampini et al., (2009), para os quais a presença de fatores como infecção dentária pré-existente, higiene oral deficiente e dentes fraturados podem aumentar a incidência e a severidade das alterações bucais decorrentes do tratamento do câncer de cabeça e pescoço.

Estudos realizados por Dib et al., (2000) e Rubira et al., (2007) sobre a abordagem multidisciplinar das complicações orais da RT em pacientes com câncer de cabeça e pescoço permitiram concluir que a mucosite, xerostomia, disgeusia são complicações comuns a este tipo de tratamento, sendo a MO o efeito agudo de maior freqüência e o maior fator dose limitante para a RT em cabeça e pescoço. Para Caccelli e Rapoport (2008) a xerostomia é a segunda alteração bucal mais comum do tratamento oncológico, sendo precedida apenas pela MO. Neste estudo a xerostomia apresentou maior incidência que a MO o que nos faz acreditar que a adoção de medidas preventivas e terapêuticas, incluindo a utilização do LBI em sua forma preventiva atuou minimizando a ocorrência e severidade da mesma.

Compreendemos como emprego preventivo do LBI, sua aplicação sobre a mucosa oral de pacientes portadores de câncer de cabeça e pescoço submetidos a RT exclusiva ou a RT associada a QT, na ausência de qualquer sintomatologia clínica de 
mucosite instalada. Assim, como entendemos como emprego terapêutico, sua aplicação sobre a mucosa oral após a ocorrência de sinais clínicos associados à MO.

A avaliação dos dados referentes à ocorrência de MO segundo o número de pacientes mostrou que os pacientes do grupo 3 não apresentaram diferença estatística significante quando comparados aos pacientes dos demais grupos. Porém, clinicamente o uso do LBI em sua forma preventiva se mostrou mais eficiente na prevenção da MO do que as outras formas de tratamento aqui empregadas. Entretanto, quando analisada a ocorrência de MO por pacientes durante as sessões de RT, verificou-se a existência de significância estatística entre os grupos de estudo, demonstrando que o grupo 3 foi estatisticamente diferente do grupo 1 e 2, não havendo diferença estatisticamente significativa entre os dois últimos grupos citados anteriormente. Estes dados corroboram a eficiente ação preventiva do laser na inibição da ocorrência de MO.

Tais dados são condizentes com aqueles relatados por Bensadoun et al. (1999), que realizaram estudo randomizado com 30 pacientes portadores de câncer em cabeça e pescoço submetidos a tratamento radioterápico, obtendo bons resultados na diminuição da incidência e da gravidade da dor da MO radioinduzida. Resultados semelhantes foram obtidos por Genot-Klastersky et al. (2008) em dois estudos clínicos prospectivos com a finalidade de testar a eficiência do LBI na prevenção da MO radio e/ou quimioinduzida. O primeiro com 26 pacientes portadores de tumores sólidos tratados com QT, e o segundo com 36 pacientes portadores de tumores hematológicos tratados com QT e RT intensivas antes do transplante de medula, estudo randomizado com 18 pacientes tratados com LBI e 18 com laser placebo.

Foi encontrada diferença estatística significante entre os diferentes grupos quanto a severidade dos graus de MO, evidenciando que os pacientes do grupo 3, submetidos à laserterapia preventiva, evoluíram com graus mais amenos de MO do que os pacientes do grupo 2 e 1, respectivamente submetidos a laser a partir do surgimento de MO grau 2 e a tratamento medicamentoso exclusivo. Não foram observadas diferenças estatisticamente significativas entre os grupos 1 e 2. Os dados deste estudo clínico estão de acordo com Cowen et al., (1997) que realizaram estudo randomizado duplo cego com 30 pacientes submetidos a transplante de medula óssea e RT com o intuito de comparar a evolução da MO, mostrando que o uso do LBI retardou o início, reduziu a severidade e a duração da MO, promovendo a redução da dor decorrente da mesma, e considerando a aplicação do laser em sua forma preventiva mais efetiva que a curativa para a prevenção e tratamento da MO induzida por tratamento oncológico. 
A mesma opinião é compartilhada por Biron et al., 2000, segundo os quais o uso do LBI é um procedimento promissor, sendo largamente demonstrando que a laserterapia retarda o início, diminui a severidade, encurta a duração da MO especialmente nos pacientes submetidos a transplante de medula óssea. Sendo as aplicações curativas do laser aparentemente menos efetivas do que seu uso preventivo.

Dib et al., (2000) em seu trabalho sobre fatores de risco para a MO severa induzida por RT avaliou 100 pacientes concluindo que os quadros mais severos de MO foram observados a partir da $5^{\mathrm{a}}$ semana de tratamento, e geralmente estavam associados a importante sintomatologia dolorosa e significativo impacto sobre a capacidade de ingestão de alimentos.

Neste estudo clínico a avaliação dos dados referentes ao escore de dor durante o tratamento oncológico não demonstrou diferença estatisticamente significativa entre o grupo 3 e o grupo 1. Sendo a mesma encontrada quando comparados os grupos 1 e 2 e 2 e 3. Porém ao se analisar as médias de escore de dor a partir da $5^{\mathrm{a}}$ semana de tratamento constatou-se a presença de diferenças estatisticamente significativas entre os grupos. Demonstrando que o uso do laser em sua forma preventiva resultou em menores médias de escore de dor, contribuindo para a melhora da qualidade de vida dos pacientes em questão.

Não observamos diferenças estatisticamente significativas entre os grupos com relação ao emprego de sonda nasogástrica em consequência da MO induzida por tratamento oncológico, sendo necessário seu uso em três pacientes do grupo 1, dois pacientes do grupo 2 e em somente um paciente do grupo 3. Sendo que neste último caso o paciente era etilista e consumiu bebida alcoólica durante o decorrer do tratamento, o que nos faz pensar que o álcool atuou como fator irritante agravando o quadro de mucosite já existente. Tal hipotese é corroborada por Dib et al., (2000), Scully et al., (2004) e Rampini et al., (2009) que relataram que o uso do álcool e tabaco contribuem para o aumento da incidência e/ou agravamento da MO radioinduzida.

Neste estudo todos os pacientes que apresentaram necessidade de colocação de sonda nasogástrica em decorrência da MO eram portadores de carcinoma epidermóide em cavidade oral com destaque para localização em língua $(66,6 \%)$, todos foram submetidos a RT e QT adjuvante. Tais dados estão de acordo com a literatura para e demonstram que a MO é uma complicação extremamente comum aos pacientes portadores de câncer de cabeça e pescoço submetidos a tratamento oncológico, onde a associação entre RT e QT resulta na potencialização da severidade da mesma acarretando desconforto e comprometimento nutricional. 
Esta observação está de acordo com Mendes et al., (2006) para os quais o estado nutricional é um importante dado a ser avaliado no paciente oncológico, em especial nos portadores de câncer em cabeça e pescoço, pois está associado à tolerância ao tratamento, às complicações, ao prognóstico e ao tempo de hospitalização, sendo a terapia nutricional com sondas indicada para os pacientes com risco nutricional e na presença de desnutrição (perda de peso superior a $10 \%$ em relação ao peso habitual).

Com relação à necessidade de internação hospitalar em decorrência da MO está foi necessária em apenas um paciente do grupo 1. Este paciente era portador de CE em língua e evoluiu com MO grau 4 e dor de intensidade máxima. A necessidade de internação de apenas um paciente é creditada à adoção de medidas preventivas e terapêuticas para complicações orais, prontamente adotadas durante todo o tratamento oncológico tal raciocínio está de acordo com Mcguire et al., (2006).

Para Lees, (1999) a MO dificulta a ingestão de alimentos, resultando em piora do estado nutricional e desidratação, representando a principal causa de hospitalização e ocasionalmente interrupção de tratamentos antineoplásicos em pacientes portadores de câncer de cabeça e pescoço. Porém neste estudo, não foi observada, em nenhum dos participantes, a necessidade de interrupção do tratamento em decorrência da MO. Acreditamos que a não interrupção do tratamento possa ser justificada, em parte pela minimização da incidência e gravidade da MO através da adoção de condutas preventivas e terapêuticas pré e trans-tratamento oncológico. Esta observação está de acordo com Nguyen (1992), Dib et al., (2000), Bensadoun et al., (2001) que afirmaram que ações preventivas adotadas pré e trans-tratamento atuam minimizando a incidência e a severidade da mucosite oral radioinduzida contribuindo para a melhor qualidade de vida do paciente oncológico.

Em estudo desenvolvido por Donaldson (1977) a média de perda de massa corpórea em pacientes portadores de câncer de cabeça e pescoço, após seis a oito semanas de RT foi de $3,7 \mathrm{Kg}$.

Em nosso estudo não foram observadas diferenças estatisticamente significativas entre os grupos com relação à média de perda de massa corporal. A perda de massa corpórea ocorreu em 30 dos 31 participantes, com exceção de um participante do grupo 3 que ao término do tratamento havia apresentado ganho de $1,3 \mathrm{Kg}$ de massa corpórea, sendo a média de perda de massa corpórea por grupo no decorrer do tratamento respectivamente de $3,405,4,130$ e $3,002 \mathrm{Kg}$. 
Menor média de perda de massa corpórea foi observada no grupo 3, ou seja, nos pacientes submetidos a laserterapia a partir da $1^{\text {a }}$ sessão de RT. Este resultado está de acordo com os relatados por França et al., (2009) que realizaram estudo com o objetivo de investigar os efeitos do LBI na prevenção e tratamento da MO induzida por 5-FU em hamsters, mostrando que o grupo de animais submetidos à crioterapia apresentou perda de massa corpórea durante os primeiros cinco dias significativamente maior (15.16\%) do que o grupo submetido à laserterapia preventiva $(8,97 \%)$. Tal fato foi atribuído, em parte, a menor dor e desconforto oral, o que resultou em melhor condição de alimentação. Sugerindo, portanto, que o laser apresenta efeito positivo no tratamento da MO.

Segundo estudo comparativo entre pacientes bem nutridos e mal nutridos desenvolvido por Van Bokhorst de Van der Schueren et al., 1998 com 66 pacientes portadores de $\mathrm{CE}$ em cabeça e pescoço a má nutrição é caracterizada por perda de $10 \%$ ou mais de massa corpórea em um período de 6 meses e está associada há uma maior risco de ocorrência de complicações principalmente infecciosas. Os pacientes desse estudo que apresentaram redução da massa corpórea igual ou maior que $10 \%$ durante os últimos seis meses foram descritos como severamente desnutridos e apresentaram diminuição significativa da expressão de HDA-DR em monócitos, sendo a mesma considerada como fator de risco para infecção e morte.

Neste estudo clínico os pacientes do grupo 2 apresentaram média de perda de massa corpórea entre a $1^{\mathrm{a}}$ e $35^{\mathrm{a}}$ sessão de $12,9 \%$, porém não foi observada presença de quadros infecciosos mais severos, exceto dois casos de candidíase pseudomembranosa, que também se fez presente em três pacientes do grupo 1 (8.8\%) e dois pacientes do grupo 3 (8.7\%). Segundo Dib et al., (2000) e Scully et al., (2004) a candidíase é uma infecção oportunista relativamente comum em pacientes portadores de câncer de cabeça e pescoço submetidos a tratamento oncológico.

Apesar dos resultados promissores obtidos com o laser em baixa intensidade empregado de forma preventiva, mais pesquisas precisam ser realizadas a fim de reiterar os benefícios obtidos com o mesmo na prevenção e tratamento da $\mathrm{MO}$ radio e/ou radioquimioinduzida em pacientes portadores de câncer de cabeça e pescoço. 


\section{7 - CONCLUSÕES}

Os resultados obtidos permitiram concluir que:

Não foram observadas diferenças estatisticamente significativas na prevenção da MO entre o número de indivíduos tratados exclusivamente com tratamento medicamentoso e aqueles tratados com tratamento medicamentoso e laserterapia preventiva apesar de haver tendência para tal. Porém, clinicamente foi possível observar que os pacientes submetidos à laserterapia preventiva apresentaram menor frequência de mucosite oral do que os pacientes submetidos exclusivamente a tratamento medicamentoso.

A aplicação do laser em sua forma preventiva apresentou resultados mais efetivos na diminuição da severidade dos graus e do escore de dor associado à MO induzida por tratamento oncológico do que aqueles obtidos exclusivamente com tratamento medicamentoso e com tratamento medicamentoso e laserterapia para a MO já instalada.

O uso do laser mostrou-se mais eficiente clinicamente na prevenção de intercorrências como o uso de sonda nasogástrica e internação hospitalar, entretanto, com relação à perda de massa corpórea, não foi possível observar diferenças significantes entre os grupos. 
APÊNDICE A - Parecer consubstanciado

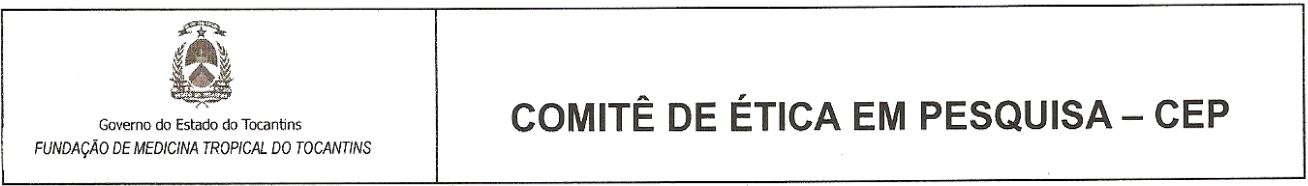

\begin{tabular}{|c|c|c|}
\hline \multicolumn{2}{|c|}{ PARECER CONSUBSTANCIADO } & \multirow{3}{*}{$\begin{array}{c}\text { PROCESSO No } \\
212\end{array}$} \\
\hline PROJETO DE PESQUISA & $\mathbf{X}$ & \\
\hline TRABALHO DE CONCLUSÃO DE CURSO & & \\
\hline
\end{tabular}

O parecer consubstanciado do relator será utilizado como subsídio para o Comitê de Ética em Pesquisa da Fundação de Medicina Tropical do Tocantins elaborar seu parecer final.

1 - Identificação da Proposta de Projeto de Pesquisa/Trabalho de Conclusão de Curso

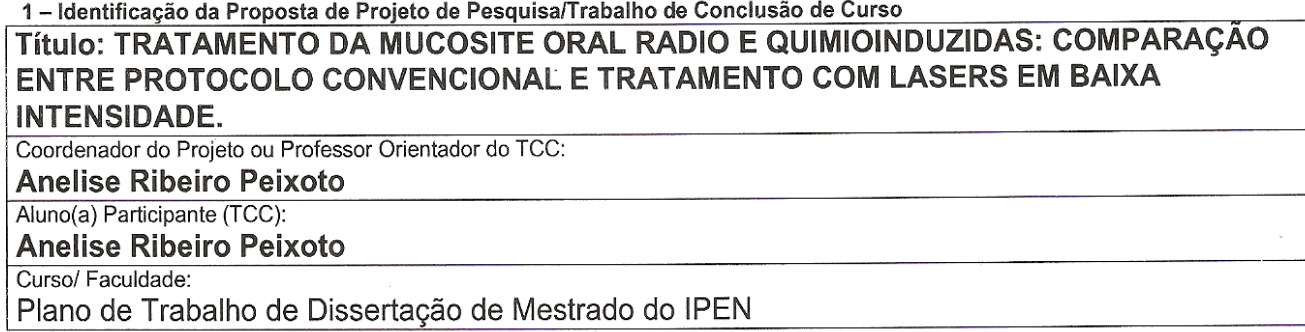

2-Análise do Projeto de Pesquisa/Trabalho de Conclusão de Curso

O projeto de pesquisa se propõe a comparar três diferentes protocolos utilizados na prevenção e tratamento da mucosite oral em pacientes portadores de tumores de cabeça e pescoço, submetidos a tratamento oncológico no Serviço de Radioterapia do Hospital Regional de Araguaína. Esta patologia é muito freqüente em pacientes submetidos à quimio e radioterapia. Trata-se de projeto relevante, de alto impacto social, podendo produzir conhecimentos úteis em termos de saúde pública e melhoria da qualidade de vida de pacientes oncológicos, atingindo classes sociais menos favorecidas, pois o serviço é disponibilizado pelo SUS.

2.1 - Objetivos e Adequação metodológica (Verificar a exeqüibilidade da proposta, isto é, se existe clareza do objeto, compatibilidade entre os objetivos, a fundamentação teórica e a metodologia ou plano de ação, evidenciando consistência entre objetivos, procedimentos, ações de execuçäo da pesquisa e capacidade do proponente, demonstrada por outros trabalhos similares.)

Projeto é claro e apresenta compatibilidade entre os objetivos a metodologia proposta e fundamentação teórica.

2.2 - Avaliação do Questionário a ser aplicado e do Termo de Consentimento Livre e Esclarecido:

Questionário e termo de consentimento adequados.

2.3 - Revisão Bibliográfica

Adequada.

3 - Qualificação do Pesquisador/Orientador (Indicar os atributos do Pesquisador/Orientador, salientando a titulação e experiência compativel com a função de orientação; qualidade e regularidade da produção científica/tecnológica/artistica, compativel com o projeto de pesquisa/Trabalho de Conclusão de Curso)

Orientadora experiente.

4 - Parecer conclusivo, recomendações elou sugestões:

Projeto altamente viável e de grande impacto social. 
APÊNDICE A - Parecer consubstanciado

5 - Pendências: (Enumerar sucintamente as pendências a serem sanadas pelo Coordenador do Projeto de Pesquisa/Trabalho de Conclusão de Curso

Não se aplica

6 - Parecer Consubstanciado

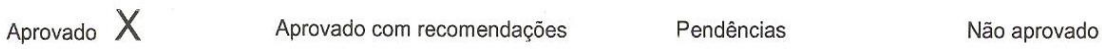

Assinatura do Coordenador do CEP: P/S Data da reunião: $\quad 04 / 03 / 2009$

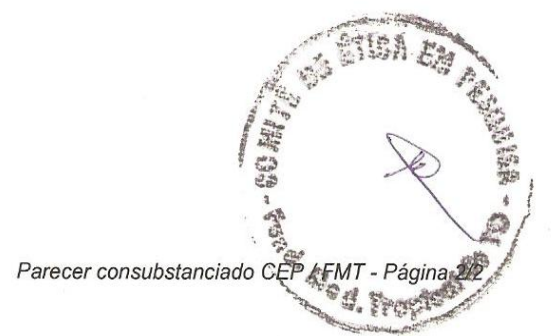


APÊNDICE B - Ficha de Avaliação / Grupo 1( ) 2( ) 3( )

1.1 Identificação:

Nome:

Gênero: Data de nascimento:

Cor: Escolaridade:

End. Contato:

Zona: Telefone:

Naturalidade: Procedência:

1.2 Protocolo Utilizado:

( ) I - Medicamentos e orientações a serem empregados a partir do início do tratamento radio quimioterápico;

( )II - Medicamentos e orientações a serem empregados a partir do início do tratamento radioquimioterápico, e laserterapia a ser empregada a partir das manifestações clínicas de mucosite radioquimio induzidas;

( )III - Medicamentos, orientações e laserterapia a ser empregada a partir do início do tratamento radioquimioterapico.

1.3. Diagnóstico histopatológico:

1.4. Estadiamento:

1.5. Localização da lesão:

1.6. Hábitos nocivos:

1.7. Doenças concomitantes:

1.8. Medicamentos de uso continuo extra-tratamento oncológico:

1.9.Esquema de tratamento

Radioterapia:

Quimioterapia: Esquema I ( ) esquema II （ ）

Araguaína, de de 20

Examinador

Anelise R. Peixoto 
APÊNDICE C - Ficha de Avaliação / Grupo 1( ) 2 ( ) 3( )

Nome:

Data:

Sentia a boca seca antes? ( )sim ( )não

Tem aftas freqüientemente? ( )sim ( )não

Tem herpes bucal/labial? ()sim ()não

Sente ardência ()sim ()não

Há sangramento gengival? ()sim ( )não

Observações extra-orais:

Exame intra-oral:

Uso de prótese: ( ) PT sup/inf ( )PPR sup/inf ( ) PF sup/inf

Tempo de

uso:

Odontograma:
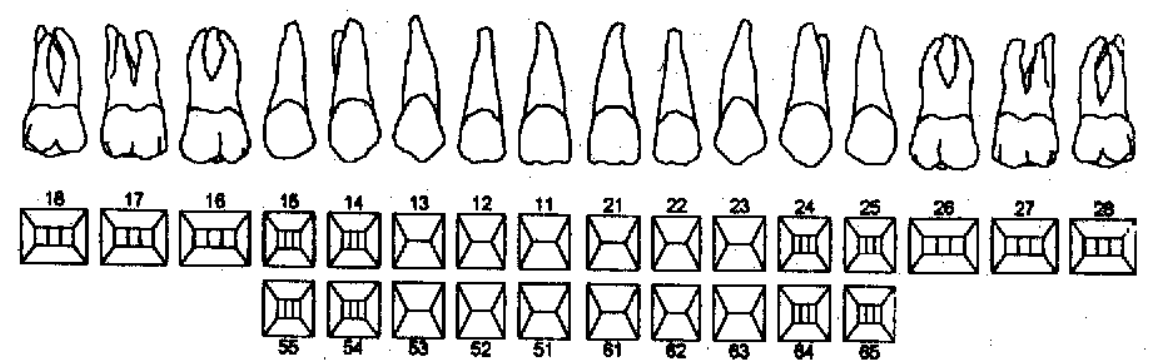

西)
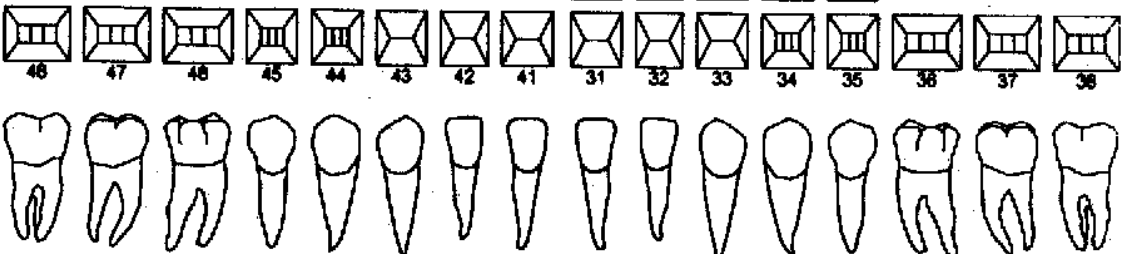

Legenda:

(X) Dente Ausente

(RR) Raiz Residual

(M) Mobilidade Classificada em GI, II ou III

(•) Cárie ou Restauração fraturada

(*) Restaurações

Presença de biofilme?

Cálculo?

( ) $\operatorname{sim}$

( ) não

Exudato?

( ) $\operatorname{sim}$

( ) não

Sangramento gengival:

( ) $\operatorname{sim}$

( ) não

Condição de Higiene Bucal:

( ) à sondagem

( ) espontâneo

( ) ausente

Presença de abcesso?

( ) boa

( ) regular

( ) insatisfatória

Lesões estomatológicas:

Exames Complementares:

( ) Radiografia Panorâmica

( ) Radiografia Periapical . Elementos dentários:

( ) Citológico ( ) Biópsia 
APÊNDICE D - Protocolo adotado pelo Serviço de Prevenção e Diagnóstico de Câncer Bucal / Cons: 12 Ambulatório de Especialidades Médicas - Hospital de Regional de Araguaína.

Medidas úteis na prevenção, tratamento de lesões e manutenção da saúde bucal de pacientes em tratamento oncológico para tumores em cabeça e pescoço.

\section{A partir do início da radioterapia e/ou quimioterapia}

- Não fume e não consuma bebidas alcoólicas durante todo o tratamento;

- Dê preferência para alimentos líquidos, e/ou pastosos, frios ou a temperatura ambiente. Evite alimentos muito doces, ácidos e temperados;

- Pacientes usuários de prótese devem evitar o seu uso durante o tratamento;

- Escove os dentes após cada refeição e antes de dormir;

- Utilize escova de dente macia e creme dental com flúor. Pacientes desdentados utilizar gaze umedecida em soro fisiológico $0,9 \%$ ao invés de escova;

- Fazer bochecho com uma colher de sopa de hidróxido de alumínio, 2 a 4 vezes ao dia por cerca de 1 minuto. Cuspir e não enxaguar a boca;

- Uma hora após o uso do hidróxido de alumínio fazer bochecho com nistatina solução, uma colher de sopa, 4 vezes vão dia, bochechar por 1 minuto e depois se preferir engolir. Cuspir e não enxaguar a boca nos próximos 20 minutos;

- Fazer bochecho com uma colher de sopa de gluconato de clorexidina a $0,12 \%$ sem álcool durante 1 minuto, 2 vezes ao dia;

- No caso de lábios ressecados fazer uso de protetor labial;

- Leve sempre consigo uma garrafa com água, e umedeça a boca sempre que ela estiver seca;

- No caso de machucados em boca fazer bochechos com uma colher de sopa de decadron elixir, 3 a 4 vezes ao dia, não engolir;

- No caso de machucados ou qualquer alteração em boca procure o cirurgião-dentista o mais rápido possível;

- Retorne ao consultório para avaliação sempre que estiver retornando para as consultas médicas de acompanhamento;

Obs: Os medicamentos citados acima serão prescritos ao longo do tratamento à medida que seu uso se faça necessário. A utilização dos mesmos será acompanhada pelo profissional responsável pelo seguimento dos pacientes. Sendo o uso suspenso caso se constate qualquer intercorrência resultante do emprego dos mesmos. $\mathrm{O}$ uso de antifúngicos sistêmicos (cetoconazol 200mg e fluconazol 150mg), analgésicos, sucralfato e de antibióticos será feita de acordo com a necessidade e em comum acordo com o médico responsável, e a dose utilizada depende de sua indicação, se para prevenção ou para tratamento. 
APÊNDICE E - Ficha de Avaliação / Grupo 1( ) 2 ( ) 3( )

Nome:

Gênero:

Cor:

Data de nascimento:

End. Contato:

Zona: Escolaridade:

Naturalidade: Telefone:

Esquema de QT: Esquema I ( )

Procedência:

Esquema II ( )

\begin{tabular}{|c|c|c|c|c|c|c|c|c|c|}
\hline Data & $\begin{array}{l}\mathrm{N}^{\circ} \text { de } \\
\text { sessões } \\
\text { de RT }\end{array}$ & $\begin{array}{l}\text { RT- Dose } \\
\text { fracionada }\end{array}$ & $\begin{array}{l}\mathrm{RT}- \\
\text { Dose } \\
\text { total }\end{array}$ & $\begin{array}{l}\text { Grau de } \\
\text { mucosite }\end{array}$ & Sintomatologia & $\begin{array}{l}\text { Esc. de } \\
\text { BW antes } \\
\text { da } \\
\text { laserterapia }\end{array}$ & \begin{tabular}{ll}
\multicolumn{2}{l}{ Laserterapia } \\
$\mathrm{n}^{\mathrm{o}}$ & $\mathrm{de}$ \\
sessões
\end{tabular} & $\begin{array}{lr}\text { Esc. } & \text { de } \\
\text { BW } & \text { após } \\
\text { da } & \\
\text { laserterapia }\end{array}$ & Peso \\
\hline & & & & & & & & & \\
\hline & & & & & & & & & \\
\hline & & & & & & & & & \\
\hline & & & & & & & & & \\
\hline & & & & & & & & & \\
\hline & & & & & & & & & \\
\hline & & & & & & & & & \\
\hline & & & & & & & & & \\
\hline & & & & & & & & & \\
\hline & & & & & & & & & \\
\hline & & & & & & & & & \\
\hline & & & & & & & & & \\
\hline & & & & & & & & & \\
\hline & & & & & & & & & \\
\hline & & & & & & & & & \\
\hline & & & & & & & & & \\
\hline & & & & & & & & & \\
\hline & & & & & & & & & \\
\hline & & & & & & & & & \\
\hline & & & & & & & & & \\
\hline & & & & & & & & & \\
\hline & & & & & & & & & \\
\hline & & & & & & & & & \\
\hline & & & & & & & & & \\
\hline & & & & & & & & & \\
\hline & & & & & & & & & \\
\hline & & & & & & & & & \\
\hline & & & & & & & & & \\
\hline & & & & & & & & & \\
\hline & & & & & & & & & \\
\hline & & & & & & & & & \\
\hline & & & & & & & & & \\
\hline & & & & & & & & & \\
\hline & & & & & & & & & \\
\hline
\end{tabular}




\section{REFERÊNCIAS BIBLIOGRÁFICAS}

ALBUQUERQUE, I.L.S; CAMARGO, T.C. Prevenção e tratamento da mucosite oral induzida por radioterapia: revisão de literatura. Rev. Bras. Cancerol., v. 53, n. 2, p. 195209, 2007.

ALMEIDA, E.O.C; UMEOKA, W.G; VIEIRA, R.C.; MORAES, I.F. Estudo audiométrico de alta frequência em pacientes tratados com cisplatina. Rev. Bras. Otorrinlaring., v. 74, n. 3, p. 382-390, 2008.

ALMEIDA, F.C.S; CAZAL, C; DURAZZO, A.R; et al. Radioterapia em cabeça e pescoço: efeitos colaterais agudos e crônicos bucais. Rev. Bras. Patol. Oral, v. 3, n. 2, p. 62-69, 2004.

ANDREWS, N; GRIFFITHS, C. Dental complications of head and neck radiotherapy: Part 1. Australian Dental Journal, v. 46, n. 2, p. 88-94, 2001.

ANTUNES, L.M.G; BIANCHI, M.L.P. Antioxidantes da dieta como inibidores da nefrotoxicidade induzida pelo antitumoral cisplatina. Rev Nut. Campinas, v.17, n.1, p.8996, 2004.

BALDISSEROTTO, J; ARAÚJO, S.S.C; PADILHA, D.M.P. Câncer bucal: importância de promover a saúde bucal durante e pós o tratamento oncológico - relato de caso clínico. Revista Técnico Cientifica do Grupo Hospitalar Conceição, v.17, n.1, p. 49-53, 2004.

BARASCH, A; ELAD, S; ALTMAN, A; DAMATO, K; EPSTEIN, J. Antimicrobials, mucosal coating agents, anesthetics, analgesics, and nutritional supplements for alimentary tract mucositis. Support Care Cancer, v. 14, p. 528-532, 2006.

BARASCH, A; COKE, J.M. Cancer therapeutics: an update on its effects on oral health. Periodontology 2000, v. 44, p. 44-54, 2007.

BENSADOUN, R.J; FRANQUIN, J.C; CIAIS, G; DARCOURT, V; SCHUBERT, M.M; et al. Low-energy $\mathrm{He} / \mathrm{Ne}$ laser in the prevention of radiation-induced mucositis. A multicenter phase III randomized study in patients with head and neck cancer. Support Care Cancer, v.7, p. 244-252, 1999.

BENSADOUN, R.J; MAGNÉ, N; MARCY, P.Y; DEMARD, F. Chemotherapy-and radiotherapy-induced mucositis in head and neck cancer patients: new trends in pathophysiology, prevention and treatment. Eur. Arch. Otorhinolaryngol., n. 258, p. 481487, 2001. 
BIRON, P; SEBBAN, C; GOURMET, R; CHVETZOFF, G; PHILIP, I; BLAY, J.Y. Research controversies in management of oral mucositis. Support Care Cancer, v.8, p. 68-71, 2000.

BONAN, P.R.F; LOPES, M.A; ALVES, F.A; et al. Aspectos clínicos, biológicos, histopatológicos e tratamentos propostos para a mucosite oral induzida por radioterapia: revisão da literatura. Rev. Bras. Cancerol., v. 51, n. 3, p. 235-242, 2005.

BLUNK, V.; BUENO, L.M.; NICOLETTI, A.G.B. et al. Quimioterapia em tumores de cabeça e pescoço. Arq. Med ABC, n. 1 e 2, p. 2-6, 1997.

BRASIL, Ministério da Saúde. Carcinoma epidermóide da cabeça e pescoço. Rev. Bras. Cancerol., v. 47, n. 4, p. 361-376; 2001.

BRASIL, MINISTÉRIO da SAÚDE. Instituto Nacional do Câncer. A epidemiologia do câncer. Rio de Janeiro; 2002.

BRASIL, MINISTÉRIO da SAÚDE. Instituto Nacional de Câncer. Câncer no Brasil: dados dos registros de base populacional. Rio de Janeiro (Brasil): Instituto Nacional de Câncer, 2003.

BRASIL, MINISTÉRIO da SAÚDE. Instituto Nacional de Câncer. Estimativa 2010: Incidência de Câncer no Brasil. Instituto Nacional de Câncer. Rio de Janeiro: INCA, 2009.

BRASIL, MINISTÉRIO da SAÚDE. Instituto Nacional do Câncer. Câncer de boca: manual de detecção de lesões suspeitas [site na internet]. 2009 [citado 2009 abr 2]. [cerca de 2p.]. Disponível em: http://www.inca.gov.br/prevencao/boca/lesoessuspeitas (b)

BRASIL, MINISTÉRIO da SAÚDE. Instituto Nacional de Câncer. Estimativa 2008: Incidência de Câncer no Brasil. Instituto Nacional de Câncer. Rio de Janeiro: INCA, 2007.

BRASIL, MINISTÉRIO da SAÚDE. Instituto Nacional do Câncer. Quimioterapia [site na internet]. 2010 [citado 2010 jul 12]. [cerca de 7p.]. Disponível em: http://www.inca.gov.br/conteudo_view.asp?id=101

BRENER, S; JEUNON, F.A; BARBOSA, A.A; GRANDINETTI, H.A.M. Carcinoma de células escamosas bucal: uma revisão de literatura entre o perfil do paciente, estadiamento clínico e tratamento proposto. Rev. Bras. Cancerol., v. 53, n. 1, p. 63-69, 2007.

CACELLI, E.M.N; RAPAPORT,A. Para-efeitos das radiações nas neoplasias de boca e orofaringe. Rev. Bras. Cir. Cabeça e Pescoço, v. 37, n. 4, p. 198-201, 2008.

CAMPOS, L; SIMÕES, A; SÁ, P.H.R.N; EDUARDO, C.P. Improvement in quality of live of na oncological patient by laser phototherapy: a case report. Photomedicine and Laser Surgery, p. 1- 4, 2008. 
CARL, W; HAVENS, J. The cancer patient with severe mucositis. Current Review of Pain, v. 4, p. 197-202, 2000.

CHOONG, N; VOKES, E. Expanding role of the medical oncologist in the management of head and neck cancer. A Cancer Journal for Clinicians, v. 58. p. 32-53, 2008.

CISNEROS, J.LV. Láser y Fuentes de luz pulsada intense em dermatologia y dermocosmética. Madrid: Aula Médica Ediciones, 2000.

COWEN, D; TARDIEU, C; SCHUBERT, M; PETERSON D, RESBEUT, M; FAUCHER, $\mathrm{C}$; et al. Low energy Helium- Neon in the prevention of oral mucositis in patients undergoing bone marrow transplant: results of a double blind randomized trial. Int. J. Radiat. Oncol. Biol. Phys., v.38, n.4: 697-703, 1997.

COLOMBO, J; RAHAL, P. Alterações genéticas em câncer de cabeça e pescoço. Rev. Bras. Cancerol., v. 55, n. 2, p. 165-174, 2009.

COSTA, E.G; MIGLIORATTI, C.A. Câncer bucal: avaliação do tempo decorrente entre a detecção da lesão e o início do tratamento. Rev. Bras. Cancerol., v. 47, n. 3, p. 283-289, 2001.

COSTA, R.C.L.; COSTA, E. L.; COSTA, J.F.; et al. Manifestações bucais em pacientes infanto-juvenis submetidos a tratamento antineoplásico: Revisão de literatura. Newslab edição 84, p. 130-142, 2007.

DEDIVITIS, R.A.; FRANÇA, C.M; MAFRA, A.C.B;GUIMARÃES, F.T.; GUIMARÃES, A.V. Características clínico-epidemiológicas no carcinoma espinocelular de boca e orofaringe. Rev. Bras. Otorrinolaringol.,v. 70, n. 1, p. 35-40, 2004.

DIB, L.L; GONÇALVES, R.C.C; KOWALSKI, L.P. et al. Abordagem multidisciplinar das complicações orais da radioterapia. Revista da APCD, v. 54, n. 5, p. 391-396, 2000.

DIB, L.L; CURI, M.M. Complicações orais na oncologia: atuação odontológica na oncologia. In: KOWALSKI, L.P; ANELLI, A; SALVAJOLI, J.V; LOPES, L.F. Manual de condutas diagnósticas e terapêuticas em oncologia. Âmbito Editores, 2002. Parte III, p.199-205.

DOBROSSY L. Epidemiology of head and neck cancer: magnitude of the problem. Cancer and Metastasis Rev., v. 24, p. 9-17, 2005.

DODD, M.J; MIASKOWSKI, C; DIBBLE, S.L; et al. Factors influencing oral mucositis in patients receiving chemotherapy. Cancer Practice, v. 8, p. 291-297, 2000 .

DONALDSON, S.S. Nutricional consequences of radiotherapy. Cancer Res., v.37, p. 2407-2413, 1977. 
DREIZE, S. Oral complications of cancer therapies. Description and incidence of oral complications. NCI Monog., v.9, p. 11-15, 1990.

FABRÍCIO, V.C.; AMADO, F.; DEL GIGLIO, A. Low-cost outpatient chemotherapy regimen of cisplatin, 5-fluorouracil and leucovorin for advanced head and neck and esophageal carcinomas. São Paulo Med. J., v. 126, n.1, p. 63-66, 2008.

FERREIRA, K.A.S.L.; CAPONERO, R; TEIXEIRA, M.J. Dor induzida por quimioterapia antineoplásica: mecanismos, prevenção e tratamento. Prática Hospitalar, Ano X. n.57, 2008.

FONTES, A.P.S; ALMEIDA, S.G. Compostos de platina em quimioterapia do câncer. Química Nova, v. 20, n.4, p. 398-406, 1997.

FRANÇA, C.M; NÚNEZ, S.C; PRATES, R.A; NOBORIKAWA, E; FARIA, M.R; et al. Low-intensity red laser on the prevention and treatment of induced-oral mucositis in hamsters. Journal of Photochemistry and Photobiology B: Biology, v. 94, p. 25-31, 2009.

GALDAMES, I.C.S; SEPULVEDA, M.C.L; LÓPEZ, M.G.C; et al. Efecto de La aplicación de laser de baja potencia sobre la mucosa oral lesionada. Int. J. Morphol., v. 25,n. 3, p. 523-528, 2007.

GALVÃO, V; CASTRO, C.H.B.C; CONSOLARO,A. Mucosite severa em paciente com leucemia: uma abordagem terapêutica. Rev. Cir. Traumatol. Buco-Maxilo-Fac., v.6, n.2, p. 35-40, 2006.

GENOT-KLASTERSKY, J; AWADA, F; PAESMANS, M; et al. The use of low-energy laser (LEL) for the prevention of chemotherapy and/or radiotherapy - induced oral mucositis in cancer patients: results from two prospective studies. Support Care Câncer, v.16, p. 1381-1387, 2008.

GUIMARÃES, J.R. J. Tratamento das manifestações estomatológicas antes, no decorrer e depois de quimio e radioterapia. In: MARCUCCI, G. Fundamentos de odontologia. Rio de Janeiro: Guanabara Koogan, 2005. p. 205-212.

HERCHENHORN, D.; DIAS, F.L. Review: Advances in radiochemotherapy in the treatment of head and neck cancer. Rev. Hosp. Clín. Fac. Med. S. Paulo, v. 59, n.1, p. 3946, 2004.

HESPANHOL, F. L.; TINOCO, E.M.B.; TEIXEIRA, H.G.C. et al. Manifestações bucais em pacientes submetidos à quimioterapia. Revista Ciência e Saúde, 2007. Disponível em: http://www.abrasco.org.br/cienciaesaudecoletiva/artigos/artigo_int.php?id_artigo=1688

HONORATO, J; CAMISASCA, D. R; SILVA, L. E. et al. Análise de sobrevida global em pacientes diagnosticados com carcinoma de células escamosas de boca no INCA no ano de 1999. Rev. Bras. Epidemiol., v. 12, n.1, p. 69-81, 2009. 
JHAM, B.C; FREIRE, A.R.S. Complicações bucais da radioteraia em cabeça e pescoço. Rev. Bras. Otorrinolaringol., v. 72. n. 5, p.704-708, 2006.

JOHNSON, J.T. Prevention of radiation-induced mucositis. Head and Neck Cancers, v. 3, p. 56-58, 2001.

JOYSTON-BECHAL, S. Management of oral complications following radiotherapy. Dental Update, v.19, n. 6, p.232-238, 1992.

KARU, T. Molecular mechanism of the therapeutic effect of low-intensity laser radiation. Lasers Life Sci., v.2, p. 53-74, 1988.

KARU, T; PYATIBRAR, L; KALENDO, G. Photobiological modulation of cell attachment via cytochrome oxidace. Photochem Photobiol Sci., v. 3, p. 211-216, 2004.

KELNER, N; CASTRO, J.F.L. Laser de baixa intensidade no tratamento da mucosite oral induzida pela radioterapia: relato de casos clínicos. Rev. Bras. Cancerol., v. 53, n.1, p. 2933, 2007.

KHOURI, V.Y; LIMA, A.B.P; RODRIGUES, M.C; et al. Use of therapeutic laser for prevention and treatment of mucositis. Braz Dent J., v. 20, n. 3, p. 215-220, 2009.

KOSTLER, W.J; HEJNA, M; WENZEL, C; ZIELINSKI, C.C. Oral mucositis complicating chemotherapy and/or radiotherapy: options for prevention and treatment. CA A Cancer Journal for Clinicians, v. 51, n. 5, p. 290-315, 2001.

KOWASLKI, L.P; CARVALHO, A.P; PELLIZZON, A.C.A. Carcinoma de boca. In: KOWALSKI, L.P; ANELLI, A; SALVAJOLI, J.V et al. Manual de condutas diagnósticas e terapêuticas em oncologia. 2. ed. São Paulo:Âmbito; 2002. Parte 7, p. 411-416.

KUMMAR, S; NORONHA, V; CHU, E. Antimetabolites. In:. Cancer: Principles e pratice of oncology. JR DEVITA, V.T; HELLLMAN, S; ROSENBERG, S.A. 7ed. Lippincott Williams e Wilkins. v 1, 2000, p.362-365.

LABBATE, R; LEHN, C.N; DENARDIN,O.V.P. Efeito da clorexidina na mucosite induzida por radioterapia em câncer de cabeça e pescoço. Rev Bras Otorrinolaringol., v.69, n.3, p. 349-354, 2003.

LEES, J. Incidence of weight loss in head and neck câncer patients on commending radiotherapy treatment at a regional oncology centre. Eur J Cancer Care, v. 8, p. 133136, 1999.

LOPES, C. O; MAS, J.R; ZÂNGARO, R. A. Prevenção da xerostomia e da mucosite oral induzidas por radioterapia com uso do laser de baixa potência. Radiol Bras., v. 39, n. 2, p.131-136, 2006. 
MACHADO, S. M; SAWADA. N.O. Avaliação da qualidade de vida de pacientes oncológicos em tratamento quimioterápico adjuvante. Texto e Contexto Enferm., v. 17, n. 4, p. 750-757, 2008.

MEALEY, B.L; SEMBA, S.E; HALLMON, W.W. The head and neck radiotherapy patient: Part 2 - Management of oral complications. Compend Contin Educ Dent., v. XV, n. 4, p. 442-458, 1994.

MGGUIRE, D.B; CORREA, M.E.P; JOHNSON, J; WIENANDTS, P. The role of basic oral care and good clinical practice principles in the management of oral mucositis. Support Care Cancer, v. 14, p. 541-547, 2006.

MIGLIORATI, C. A; MIGLIORATI, E. K. J. Preparo odontológico. In: PARISE JR, O. Câncer de boca: aspectos básicos e terapêuticos. São Paulo. Savier, 2000. p.185-192.

MIGLIORATI, C; MASSUMOTO, C; EDUARDO, F.P; MULLER, K.P; CARRIERI, T; HAYPEK, P; et al. Low-energy laser therapy in oral mucositis. J Oral Laser Appl., v.1, p. 97-101, 2001.

NES, A.G; POSSO, M.B.S. Patients with moderate chemotherapy-induced mucositis: pain therapy using low intensity lasers. Int Nurs Rev., v. 52, n. 1, p. 68-72, 2005.

NEVILLE, B.W; DAY, T.A. Oral cancer and precancerous lesions. A Cancer Journal for Clinicians, v. 52, p. 195-215, 2002.

NGUYEN, A.M.H. Dental management of patient who receive chemo- and radiation therapy. General Dentistry, p.305-311, 1992.

OLIVEIRA, L.R; RIBEIRO-SILVA, A; ZUCOLOTO, S. Perfil da incidência e da sobrevida de pacientes com carcinoma epidermóide oral em uma população brasileira. J Bras. Patol. Méd. Lab., v. 42, n.5, p. 385-392, 2006.

OSTENE, R.L.V; BRITO, R.G.M; NOGUEIRA, R.L.M; et al. Saúde bucal em pacientes portadores de neoplasias malignas: Estudo clínico-epidemiológico e análise de necessidades odontológicas de 421 pacientes. Rev. Bras. Cancerol., v., 54, n 3, p. 221226, 2008.

PAOLI, S; FONSECA, A.S; PAOLI F; et al. A review of scientific papers about head and neck cancers. Braz. Arch. Biol. Technol., v.51, n. special, p. 63-69, 2008.

PETERSON, D.E. New strategies for management of oral mucositis in cancer patients. J. Support Oncol., v. 4,n. 2, p. 9-13, 2006.

RAMPINI, M.P; FERREIRA, E.M.S; FERREIRA, C.G; et al. Utilização da terapia com laser de baixa potência para a prevenção de mucosite oral: revisão de literatura. Rev. Bras. Cancerol., v. 55, n. 1, p. 59-68, 2009. 
RAPOPORT, A; KOWALSKI, L.P; HELTER, N.T; BRANDÃO, L.G; WALDER, F. Rastreamento, diagnóstico e tratamento do câncer de boca. Projeto de diretrizes: associação médica brasileira e conselho federal de medicina. p. 1-12, 2001.

RIBEIRO, M.S; ZEZELL, D.M. Laser de baixa intensidade. In.: GUTKNECHT, N; EDUARDO, C.P.A. Odontologia e o laser: atuação do laser na especialidade odontológica. São Paulo: Quitessence Editora, 2004.

RUBIRA, C.M.F; DEVIDES, N.J; ÚBEDA, L.T; et al. Evalution of some oral postradiotherapy sequelae in patients treated for head and neck tumors. Braz. Oral. Res., v. 21, n.3, p. 272-277, 2007.

SANDOVAL, R. L.; KOGA, D. H.; BULOTO, L.S.; SUZUKI, R.; DIB, L. L. Management of chemo and radiotherapy induced oral mucositis with low-energy laser: initial results of A. C. Camargo Hospital. J. Appl. Oral Sci., v. 11, n. 4, p. 1678-1775, 2003.

SANTO-FILHO, S.D; PRESTA, G.A; PAOLI, S; et al. Radiotherapy, câncer and some anatomical structures related with the pelvic floor: na evalution of the scientific literature. Braz. Arch. Biol. Technol., v. 51, p. 45-50, 2008.

SAWADA, N.O; DIAS, A.M; ZAGO, M.M.F. O efeito da radioterapia sobre a qualidade de vida dos pacientes com câncer de cabeça e pescoço. Revista Brasileira de Oncologia, v. 52, n. 4, p. 323-329, 2006.

SCHUBERT, M.M; EDUARDO, F.P; GUTHRIE, K.A; FRANQUIN, J.C; BENSADOUN, R.J. MIGLIORATI, A.; et al. A phase III randomized double-blind placebo-controled clinical trial to determine the efficacy of low level laser therapy for prevention of oral mucositis in patients undergoing hematopoietic cell transplantation. Support Care Cancer, v. 15, n.10, p.1145-1154, 2007.

SCULLY, C; EPSTEIN, J; SONIS, S. Oral mucositis: a challenging complication of radiotherapy, chemotherapy, and radiochemotherapy: part 1, pathogenis and prophylaxis of mucositis. Head \& Neck, p.1057-1070, 2003.

SCULLY, C; EPSTEIN, J; SONIS, S. Oral mucositis: a challenging complication of radiotherapy, chemotherapy, and radiochemotherapy. Part 2: diagnosis and management of mucositis. Head \& Neck, p. 77-84, 2004.

SCULLY, C; SONIS, S; DIZ, P.D. Oral mucositis. Oral Diseases, v. 12, p. 229-241, 2006.

SEIWERT, T.Y; SALAMA, J.K; VOKES, E.E. The chemoradiation paradigm in head and neck cancer. Oncology, v.4, n.3, p.156-171, 2007.

SEMBA, S.E; MEARLY, B.L; HALLMON, W.W. The head and neckradiotherapy patienty: Part 1 - Oral manifestations of therapy. Compedium of Continuing Education Dental, v. 15, n. 2, p. 250-260, 1994. 
SILVA FILHO, G. Neoplasias não-espinocelulares da cavidade oral. In: PARISE JÚNIOR, O. Câncer de boca: aspectos básicos e terapêuticos. São Paulo: Savier, 2000. Cap 12, p. 87-95.

SILVESTRE DONAT F.J., PUENTE SANDOVAL A. Efectos adversos del tratamiento del câncer oral. Av Odontoestomatol., v.24, n.1, p. 111-121, 2008.

SIMÕES, A; CAMPOS, L; FREITAS, P.M; EDUARDO, C.P; NICOLAU, J. Laser as therapy for oral complications induced by chemotherapy and radiotherapy. Jornal Brasileiro de Laser, v.2, n. 10, 2009.

SIMÕES, A; EDUARDO, F.P; LUIZ, A.C; CAMPOS, L; SÁ, P.H.R.N; CRISTÓFARO, $\mathrm{M}$; et al. Laser phototherapy as topical prophylaxis against head and neck cancer radiotherapy-induced oral mucositis: comparasion between low and high/low power lasers. Lasers in Surgery and Medicine, v. 41, p.264-270, 2009.

SONIS, S.T. Mucositis as a biological process: a new hypothesis for the development of chemotherapy-induced stomatoxicity. Oral Oncology, v. 34, p. 39-43, 1998.

SONIS ST; ELTING LS; KEEFE D; PETERSON, DE; SCHUBERT, M; HAUER-JESEN, et al. Mucositis Study Section of the Multinational Association for Supportive Care in Cancer; International Society for Oral Oncology. Perspectives on Cancer therapy-induced mucosal injury: pathogenesis, measurement, epidemiology, and consequences for patients. Cancer, v. 100, p. 1995-2005, 2004. Supplement 9.

SONIS, S. The pathobiology of mucositis. Nature Reviews, v. 4, p. 277-284, 2004.

SONIS, ST; COSTELLO, K.A. A database for mucositis induced by câncer chemotherapy. Eur. J. Cancer B. Oral Oncol., v. 31B, n. 4, p. 258-260, 1995.

SPECENIER, P. M; VERMORKEN, J.B. Current concepts for the management of head and neck cancer: Chemotherapy. Oral Oncol., v.34, p.271-278, 2008

TURHAL, N.S; ERDAL, S; KARACAY, S. Efficacy of treatment to relieve mucositisinduced discomfort. Support Care Cancer, v. 8, p. 55-58, 2000.

UNIÃO INTERNACIONAL CONTRA o CÂNCER (UICC). Manual de Oncologia Clínica. 6. ed. São Paulo: Springer-Verlag: 1999. p. 11-19.

VAN BOKHORST-DE VAN DER SCHUEREN, M.A.E; VON BLOMBERG-VAN DER FLIER, B.M.E; RIEZEBOS, R.K; et al. Differencer in immune status berween wellnourished and malnourished head and neck cancer patients. Clinical Nutrition, v. 17, p. 107-111, 1998.

VIEIRA, A.C.F; LOPES, F.F. Mucosite oral: efeito adverso da radioterapia antineoplásica. Cl. Med. Biol., v. 5, n. 3, p. 268-274, 2006. 
VOLPATO, L.E.R.; SILVA, T.C; OLIVEIRA, T. M; et al. Mucosite bucal radio e quimioinduzida. Rev. Bras. Otorrinolaringol., v. 73, n. 4, p. 562-568, 2007.

WORLD HEALTH ORGANIZATION. Polices and managerial guidelines for national cancer control programs. Rev. Panam Salud Publica, v. 12, n. 15, p. 366-370, 2002.

YOGI, V; SINGH, O.P. Induction followed with concurrent chemo radiotherapy in advanced head \& neck cancer. J. Cancer Res. Ther., v.1, p. 198-203, 2005. 